Uma abordagem heurística para o corte de itens irregulares em múltiplos recipientes

\author{
Leandro Resende Mundim
}



SERVIÇO DE PÓS-GRADUAÇÃO DO ICMC-USP

Data de Depósito:

Assinatura:

\title{
Uma abordagem heurística para o corte de itens irregulares em múltiplos recipientes
}

\author{
Leandro Resende Mundim
}

Orientadora: Profa. Dra. Marina Andretta

Dissertação apresentada ao Instituto de Ciências Matemáticas e de Computação - ICMC-USP, como parte dos requisitos para obtenção do título de Mestre em Ciências - Ciências de Computação e Matemática Computacional. VERSÃO REVISADA. 
Ficha catalográfica elaborada pela Biblioteca Prof. Achille Bassi e Seção Técnica de Informática, ICMC/USP, com os dados fornecidos pelo(a) autor(a)

\begin{tabular}{|c|c|}
\hline \multirow[t]{3}{*}{ M965a } & $\begin{array}{l}\text { Mundim, Leandro Resende } \\
\quad \text { Uma abordagem heurística para o corte de itens } \\
\text { irregulares em múltiplos recipientes / Leandro } \\
\text { Resende Mundim; orientadora Marina Andretta. -- São } \\
\text { Carlos, } 2015 \text {. } \\
\quad 107 \text { p. }\end{array}$ \\
\hline & $\begin{array}{l}\text { Dissertação (Mestrado - Programa de Pós-Graduação } \\
\text { em Ciências de Computação e Matemática } \\
\text { Computacional) -- Instituto de Ciências Matemáticas } \\
\text { e de Computação, Universidade de São Paulo, } 2015 .\end{array}$ \\
\hline & $\begin{array}{l}\text { 1. Problemas de corte de itens irregulares. } 2 . \\
\text { Problemas de empacotamento em recipientes } \\
\text { irregulares. 3. Heurísticas. I. Andretta, Marina, } \\
\text { orient. II. Título. }\end{array}$ \\
\hline
\end{tabular}


À minha família e meus amigos. 



\section{Agradecimentos}

Agradeço a Deus por ter me dado saúde e tranquilidade para a conclusão deste trabalho. Quero agradecer a Bandeira da minha família: São João Batista, Santo Antônio e São Pedro, que sempre nos cuidam, protegem e nos guardam de todo mal.

Para não esquecer de vocês, que sempre me ajudaram, os agradecimentos estão divididos em três partes.

\section{Minas Gerais}

Minas é a minha terra natal e onde moram as pessoas que mais amo. Meus pais, minha irmã, meus avós e toda minha família. Minha família de tios, primos, padrinhos e muitos amigos. Tudo que faço na minha vida é para honrar essas pessoas e o meu estado.

\section{Goiás}

Em Goiás descobri o quanto é difícil morar longe da minha família. Foi nesse maravilhoso estado que construí uma segunda família: primeira turma de matemática industrial, rep. Capim Canela, turma do bloco J, amigos do futebol, da educa e do dcc. Gostaria de agradecer os professores da UFG que sempre me ajudaram e despertaram a minha vocação. Meus agradecimentos principalmente para meus orientadores Vaston, Stoppa e Thiago.

\section{São Paulo}

No estado de São Paulo fui muito bem acolhido na rep. K2, onde aprendi: a filosofia da SEICHO-NO-IE, a comer de hashi e a agradecer por tudo. Muito obrigado a todos os moradores e amigos da K2.

Gostaria de agradecer aos meus amigos da Goiás, do ICMC e do DCC/UFSCar, que me apresentaram São Carlos, além de me apresentarem o Broa, a Federal e o futebol de sexta.

Na Universidade de São Paulo fui recebido pelos alunos e professores do Laboratório de Otimização. Neste laboratório fiz muitos amigos. Com eles, os lotianos, varei muitas noites estudando, aprendi a jogar tênis, aprendi a tomar café sem açúcar e formamos uma grande família. Não poderia me esquecer das duas cozinhas dessa família: a primeira é a lanchonete do ICMC, local do café da tarde, regida pela carismática Aurinha. A segunda é o Quase Bom, o querido QB, local de alegrias, confraternizações e artigos. Além disso, os amigos Airton, Pati e Minhoca deixam essa cozinha sempre muito mais feliz e acolhedora.

Muito obrigado aos integrantes do Nesting Club. Foi um grande prazer aprender tanto com vocês e trabalhar com dois especialistas no assunto: José Fernando e Maria Antônia. A liderança da Fran foi fundamental para o desempenho e o sucesso do Club.

Eu gostaria de agradecer muito minha orientadora, Marina, principal responsável pela qualidade deste trabalho e por tudo que eu aprendi durante os últimos anos. Obrigado por me deixar livre para trabalhar e sempre ter tempo para uma reunião de emergência.

Muito obrigado a todos vocês que me ajudaram de alguma forma, em especial à CAPES.

Mundim, 29/01/2015. 



\section{RESUMO}

Problemas de corte e empacotamento de itens irregulares são problemas que visam determinar um leiaute ótimo de objetos pequenos dentro de objetos maiores, a fim de atender a uma demanda. Estes problemas têm grande importância prática, já que surgem em vários tipos de indústria (como a têxtil, a de móveis e a de calçados). O problema estudado neste trabalho é o problema de corte de itens irregulares em recipientes. Os recipientes são delimitados e o objetivo é encontrar um leiaute dos objetos menores, sem sobreposição, dentro dos objetos maiores utilizando a menor quantidade de recipientes. Propomos um novo método de resolução para o problema. Nosso método é um algoritmo que gerencia um conjunto de heurísticas, de baixo nível, específicas para a resolução do problema com recipientes retangulares e irregulares. Recipientes irregulares são polígonos convexos e não convexos, que podem ser furados. As heurísticas desenvolvidas utilizam uma malha de pontos sobre a técnica de no-fit polygon para evitar a sobreposição dos itens e encontrar posições viáveis no recipiente retangular ou irregular. Os experimentos computacionais foram feitos para um grande conjunto de instâncias, de recipientes retangulares e irregulares. Os resultados demonstram a competitividade do método, que obtêm resultados bons e algumas soluções ótimas, em um tempo computacional aceitável.

Palavras-chave: Problema de corte de itens irregulares, problemas de empacotamento em recipientes irregulares, heurísticas, no-fit polygon. 



\section{ABSTRACT}

Cutting and packing of irregular items are problems that aim to determine the optimum layout of small objects within larger objects (that we call bins), in order to meet a demand. These problems have great practical importance, since they emerge in various types of industry (such as textile, furniture and shoemaking). The problem studied in this work is the irregular bin packing problem. The bins are enclosed and the goal is to find a layout of items, without overlap, within the bins by using the minimum quantity of them. We propose a new method of resolution to this problem. Our method is an algorithm that manages a set of low-level heuristics, specific to solve the problem with rectangular bins and irregular bins. Irregular bins are convex and non-convex polygons, which may contain holes. The developed heuristics uses a mesh of points and the technique of no-fit polygon to avoid the overlapping of items and find feasible positions in rectangular or irregular bins. The computational experiments were performed for a large set of instances, using both rectangular and irregular bins. The results demonstrate the competitiveness of the method, which can get good results and some optimal solutions within an acceptable computational time.

Keywords: Nesting problems, irregular bin packing problem, heuristics, no-fit polygon. 



\section{SUMÁRIO}

1 Introdução 1

2 O problema estudado e sua geometria 5

2.1 Representação dos objetos . . . . . . . . . . . . . 6

2.1.1 Representação dos itens . . . . . . . . . . . . . . . . . 6

2.1.2 Representação dos recipientes . . . . . . . . . . . . 8

2.2 Geometria dos itens . . . . . . . . . . . . . . . . . . 10

$2.2 .1 \quad$ No-fit polygon . . . . . . . . . . . . . . . . . 11

2.3 Geometria dos recipientes . . . . . . . . . . . . . . . . 15

3 Métodos de resolução para o corte de itens irregulares 19

3.1 Corte de itens irregulares em faixa $\ldots \ldots \ldots$. . . . . . . . . . 20

3.2 Corte de itens irregulares em recipientes fechados . . . . . . . . . . . 23

3.2.1 Recipientes retangulares . . . . . . . . . . . . . . . 24

3.2.2 Recipientes irregulares . . . . . . . . . . . . . 26

4 Método de resolução proposto 29

4.1 Etapas de pré-processamento . . . . . . . . . . . . . . . . 29 
4.2 Heurísticas . . . . . . . . . . . . . . . . . . . 30

4.2.1 Variações das heurísticas . . . . . . . . . . . . . . . . . 31

4.2.2 Análise de complexidade das heurísticas . . . . . . . . . . . 33

4.3 Método de resolução . . . . . . . . . . . . . . . . . . . . . . . . 34

5 Implementação $\quad 39$

5.1 Estruturas de dados auxiliares . . . . . . . . . . . . . . . . . 40

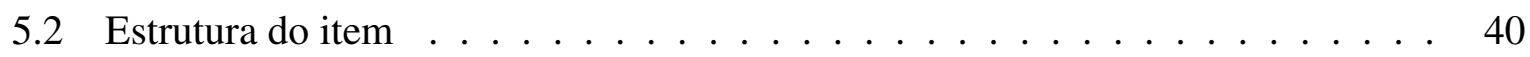

5.3 Estrutura do recipiente $\ldots \ldots \ldots \ldots \ldots \ldots \ldots$

5.4 Entrada e saída de dados . . . . . . . . . . . . . . . . . . 42

5.4.1 Entrada de dados . . . . . . . . . . . . . . . 42

5.4 .2 Saída de dados . . . . . . . . . . . . . . . . 47

6 Resultados numéricos 49

6.1 Corte de itens irregulares em recipientes retangulares $\ldots \ldots$. . . . . . . . 49

6.1 .1 Instâncias . . . . . . . . . . . . . . . 50

6.1.2 Resultados numéricos . . . . . . . . . . . . . . . . 50

6.2 Corte de itens irregulares em recipientes irregulares $\ldots \ldots . \ldots$. . . . . . 54

6.2 .1 Instâncias . . . . . . . . . . . . . . . . . 54

6.2.2 Resultados numéricos . . . . . . . . . . . . . . . 55

6.3 Corte de itens irregulares em um único recipiente $\ldots \ldots \ldots 6$

6.3 .1 Mochila ilimitada . . . . . . . . . . . . . . . 56

6.3.2 Mochila $0-1 \ldots \ldots \ldots \ldots \ldots$

7 Conclusões e trabalhos futuros

$\begin{array}{ll}\text { Referências Bibliográficas } & 65\end{array}$

A Soluções ótimas Terashima 2 
B Soluções Tay

C Soluções mochila ilimitada

D Soluções mochila 0-1 



\section{CAPÍTULO 1}

\section{INTRODUÇÃO}

Cortar objetos grandes, como placas de madeira, tecidos, papel e couro, em produtos menores, ou empacotar itens pequenos dentro de espaços delimitados possuem uma estrutura idêntica. Em ambos os casos, temos um ou mais objetos grandes, denominados recipientes, e um conjunto de objetos menores, chamados de itens. Em geral, o objetivo é minimizar o desperdício encontrando um leiaute de todos os itens sem sobreposição no interior dos recipientes, o que é interessante do ponto de vista econômico e sustentável. Estes problemas são conhecidos em Wascher et al. (2007) como problemas de corte e empacotamento (cutting and packing problems).

A maior dificuldade destes problemas é evitar a sobreposição de itens e encontrar posições viáveis no recipiente. Para itens retangulares podemos discretizar uma malha de pontos e verificar de maneira simples a não-sobreposição entre itens e a viabilidade de empacotamentos. Os problemas de corte e empacotamento com itens irregulares (nesting problems) apresentam uma componente geométrica mais complexa, dado que lidam com itens não regulares.

Um caso particular destes problemas, que será abordado no presente trabalho, é o problema de corte de itens irregulares em recipientes (irregular bin packing problem). Os recipientes são conhecidos a priori e neles devemos arranjar os itens, tentando utilizar o menor número de recipientes possível. Neste trabalho, os recipientes são retangulares e irregulares. Os recipientes irregulares são representados por polígonos convexos e não convexos, que podem ser furados. Recipientes retangulares podem ser encontrados no corte de materiais como placas de metal, madeira ou vidro. Recipientes convexos e não convexos também podem ser encontrados nas 
indústrias de metal-mecânica, moveleira ou no corte do vidro, entretanto tais recipientes aparecem com mais frequência no corte de peças de couro, que podem ser aproximadas por uma representação poligonal. Apesar da representação poligonal conseguir uma boa aproximação da peça de couro, em geral, as peças possuem furos ou regiões de baixa qualidade que não podem ser utilizadas. Neste trabalho, chamamos estas regiões de defeitos e nelas não cortamos itens.

Diversas técnicas de resolução para problemas de corte e empacotamento com itens irregulares vêm sendo desenvolvidas, baseadas, predominantemente, em meta-heurísticas. Recentemente foram desenvolvidos algoritmos exatos, que garantem uma solução ótima do problema. No entanto, nestes algoritmos, o tempo de execução cresce drasticamente com o aumento da quantidade de itens. Com raríssimas exceções, todos os trabalhos usam uma representação poligonal para as formas irregulares.

Neste trabalho propomos um novo método para a resolução do problema de corte de itens irregulares em recipientes com o objetivo de minimizar o número de recipientes utilizados. Nosso método de resolução é um algoritmo heurístico que gerencia um conjunto de heurísticas de baixo nível, específicas para a resolução do problema com recipientes retangulares e irregulares (os irregulares são representados por recipientes retangulares com defeitos). As heurísticas de baixo nível foram desenvolvidas para resolver o problema em um baixo tempo computacional.

Os maiores gargalos com relação ao tempo computacional na resolução do problema em questão são o cálculo de posições viáveis no recipiente, também conhecido como inner-fit polygon, e posições viáveis no leiaute com itens já empacotados. Apresentamos uma maneira robusta de evitar a sobreposição dos itens a partir de uma malha de pontos usando um procedimento na etapa de pré-processamento. Tal procedimento decompõe os itens em polígonos convexos e utiliza a técnica de ordenação de arestas para obter o no-fit polygon que define a malha de pontos. Além disso, para o cálculo do inner-fit polygon propomos um procedimento simples para gerar a malha de qualquer recipiente retangular ou irregular. Este procedimento é baseado no no-fit polygon e utiliza uma lista de itens empacotados (defeitos) dentro de um retângulo. Esta lista de defeitos, no interior de um retângulo, permite criar recipientes convexos e não convexos, que também podem conter furados.

No Capítulo 2, apresentamos o problema estudado neste trabalho e descrevemos os principais conceitos geométricos sobre problemas de corte e empacotamento com itens irregulares. Apresentamos, também, nossa representação geométrica. Estes conceitos são importantes para familiarizar o leitor com os termos e estratégias utilizadas no restante da dissertação. No Capítulo 3, descrevemos uma revisão dos métodos de resolução existentes para o corte de itens 
irregulares. No Capítulo 4, apresentamos as heurísticas desenvolvidas e o método de resolução proposto. No Capítulo 5, descrevemos a estrutura de dados desenvolvida. O objetivo é mostrar o que esta por trás da implementação das heurísticas. Os experimentos computacionais são apresentados no Capítulo 6. Por fim, o Capítulo 7 apresenta as conclusões do trabalho e propostas para trabalhos futuros. 


\section{CAPÍTULO 2}

\section{O PROBLEMA ESTUDADO E SUA GEOMETRIA}

O problema estudado neste trabalho consiste na versão bidimensional do problema de corte de itens irregulares em recipientes (irregular bin packing problem). O objetivo deste problema é, dados uma lista de $m$ recipientes retangulares (possivelmente com defeitos) e uma lista de $n$ itens irregulares, determinar como empacotar todos os $n$ itens utilizando o menor número de recipientes possível, respeitando as configurações do recipiente e a não sobreposição dos itens. Este problema ocorre no corte de peças de roupa, tecido, papel, metal, madeira, assim como nos ramos da indústria que necessitam encaixar múltiplos itens em regiões limitadas. Alguns trabalhos nesta linha, aplicados ao corte de couro, podem ser encontrados em: Alves et al. (2012a), Alves et al. (2012b) e Baldacci et al. (2014).

Podemos exemplificar o interesse no problema do corte de couro no Brasil por meio da indústria de calçados, que, minimizando o número de peças de couro utilizadas na fabricação de seus produtos, reduz os custos de produção. Com essa melhoria, a indústria pode diminuir os custos com a matéria-prima e economizar com o elevado custo no descarte do couro. No Brasil, o resíduo do couro é considerado um produto tóxico e não pode simplesmente ser descartado na natureza sem o tratamento adequado, gerando, assim, um custo adicional para a indústria. A classificação dos resíduos da indústria coureira calçadista pode ser vista em ABNT (2004).

Outros exemplos são as indústrias de manufatura e produção que enfrentam o problema de cortar chapas de aço e bobinas de alumínio em itens itens irregulares. Em geral, estes problemas 
também são encontrados, às vezes na versão bidimensional, durante o empacotamento de itens em paletes, contêineres, salas e caminhões. Neste caso, a minimização do número de recipientes provoca a redução do número de viagens ou espaços utilizados para estoque, facilitando o processo de logística. Do ponto de vista teórico os problemas de corte e empacotamento são análogos, para facilitar a leitura a partir de agora usaremos apenas o termo corte para este problemas.

Apesar dos problemas envolvendo corte de itens irregulares serem enunciados de maneira simples, do ponto de vista computacional são bastante complexos, principalmente pelas restrições de não sobreposição entre os itens, que crescem de forma combinatória com a quantidade de itens. Devido a esta complexidade, várias estratégias heurísticas vêm sendo desenvolvidas. Estas estratégias não analisam todas as combinações possíveis, mas conseguem, em alguns casos, boas soluções e, eventualmente, a solução ótima para o problema.

As próximas seções apresentam considerações importantes sobre os conceitos geométricos envolvidos na área de corte de itens e recipientes irregulares. Estes conceitos serão utilizados no restante da dissertação e facilitam a leitura da revisão dos métodos de solução apresentado no Capítulo 3. A Seção 2.1 apresenta as representações detalhadas dos objetos utilizados neste trabalho e as representações mais utilizadas da literatura. Na Seção 2.2, são apresentadas as principais estratégias utilizadas para evitar a sobreposição de itens irregulares e a estratégia utilizada por nossas heurísticas. Em seguida, a Seção 2.3 apresenta a estratégia utilizada neste trabalho para verificar se um item pode ser empacotado dentro de um recipiente.

\subsection{Representação dos objetos}

Esta seção discute como os itens e os recipientes podem ser representados.

\subsubsection{Representação dos itens}

Existem diversas maneiras de se representar um item, principalmente por uma malha ou por uma representação poligonal. As abordagens com malhas são mais flexíveis e amplamente utilizadas em métodos heurísticos. Em geral, estas abordagens dividem o recipiente em áreas discretas, reduzindo a complexidade geométrica a uma matriz.

Uma das primeiras abordagens de malhas foi proposta no trabalho de Segenreich e Braga (1986). Este trabalho apresenta uma forma eficiente para evitar a sobreposição. Cada posição na matriz recebe um valor. O número um na malha representa as fronteiras do item, o valor 
três representa o interior do item e o valor zero é usado quando não existe coisa alguma naquela posição. Assim, quando somamos duas malhas e obtemos o valor dois, pelo trabalho de Segenreich e Braga (1986), significa que os itens estão a uma distância aceitável, definida pela espessura da malha. Quando o valor é maior que três, temos sobreposição dos itens, como podemos observar na Figura 2.1.
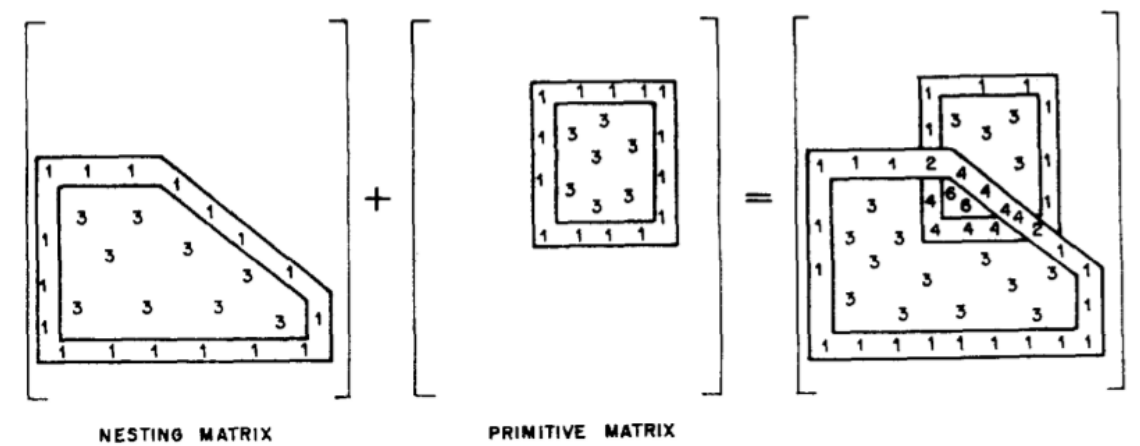

Figura 2.1: Representação dos itens extraída de Segenreich e Braga (1986).

Oliveira e Ferreira (1993) propuseram uma maneira simples de codificar a matriz, definindo valor um para as posições ocupadas pelo item e zero para as demais. Para avaliar a sobreposição de itens, assim como no trabalho de Segenreich e Braga (1986), basta somar duas matrizes e verificar os algarismos de cada elemento. O valor pode ser zero (posição vazia), um (um item ocupa aquela posição) ou maior que um (existe a sobreposição de itens). A Figura 2.2 ilustra esta representação.
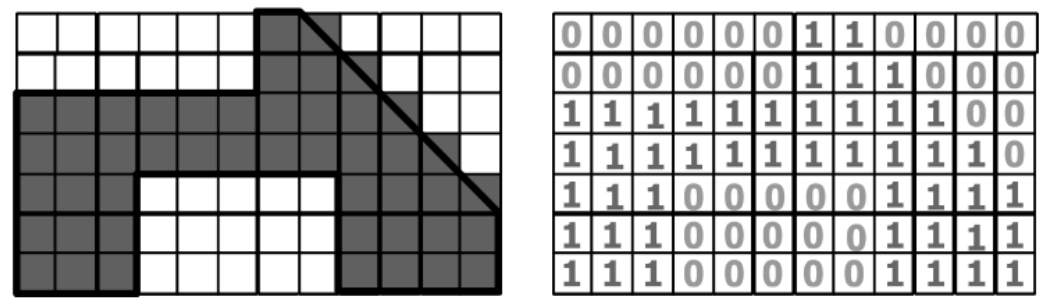

Figura 2.2: Representação extraída de Bennell e Oliveira (2008).

Com a utilização de malhas, podemos representar o leiaute por uma matriz e verificar a não sobreposição de forma rápida. Porém, a abordagem discreta pode não ser uma aproximação eficaz do item, dado que o item pode ser bem pequeno ou muito grande quando comparado à malha. A qualidade da aproximação depende da discretização da malha, ou seja, quanto menor for a discretização, mais próxima será a aproximação de um item real e maior o seu custo computacional.

A abordagem mais utilizada no corte de itens irregulares é a representação poligonal dos itens. Os itens são aproximados por polígonos convexos ou não convexos. Para exemplificar, a 
Figura 2.3 apresenta os itens da instância Shapes 0, que pode ser encontrada em Oliveira et al. (2000).
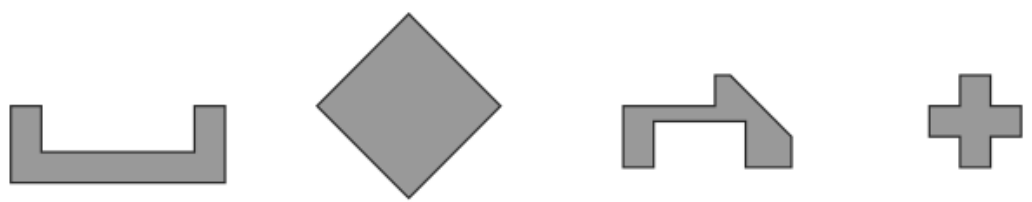

Figura 2.3: Itens da instância Shapes 0.

No presente trabalho, os itens são representados por um conjunto de polígonos convexos, formados por uma lista de vértices ordenados no sentido horário. A principal vantagem desta abordagem é que, com um conjunto de polígonos convexos, podemos representar qualquer polígono em duas dimensões, tais como polígonos não convexos, polígonos com buracos e separados. A Figura 2.4 apresenta como a nossa abordagem considera os itens da instância Shapes 0. Veja um exemplo de uma representação de um polígono com buraco na Figura 2.5.
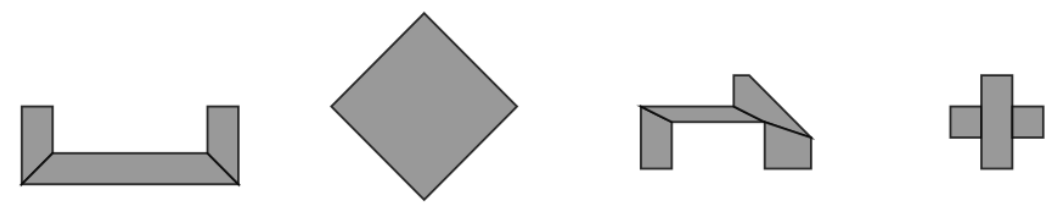

Figura 2.4: Itens da instância Shapes 0 representados por polígonos convexos.

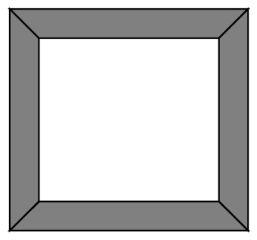

Figura 2.5: Item com buraco representado por polígonos convexos.

Para decompor os polígonos em polígonos convexos utilizamos a biblioteca geométrica Computational Geometry Algorithms Library (CGAL), disponível no endereço eletrônico http: //www.cgal.org/, que visa facilitar o acesso a algoritmos eficientes e confiáveis implementados na linguaguem $\mathrm{C}++$. Neste trabalho, utilizamos a implementação do algoritmo de programação dinâmica de Greene. Para mais detalhes, veja http://doc.cgal.org/latest/ Partition $\backslash$ 2/index.html.

\subsubsection{Representação dos recipientes}

Assim como os itens, os recipientes podem ser representados por malhas e por polígonos. A grande maioria dos trabalhos representa os recipientes por polígonos convexos e não convexos. 
Em recipientes retangulares são definidos uma altura $H$ e largura $W$. Recipientes irregulares são definidos por polígonos convexos e não convexos, que podem ser furados. A Figura 2.6 apresenta um recipiente representado por um polígono não convexo. A Figura 2.7 apresenta um recipiente furado e um recipiente não convexos. Como dito no trabalho de Martins e Tsuzuki (2010), cada um destes recipientes pode ser representados por um recipiente retangular, que o envolve, e uma lista de itens já alocados nas posições dos furos e das posições externas ao recipiente original. Assim, o recipiente do lado esquerdo da Figura 2.7 pode ser representado por um retângulo e um polígono (em preto) e o recipiente do lado direito pode ser representado por um retângulo e dois polígonos (em preto)

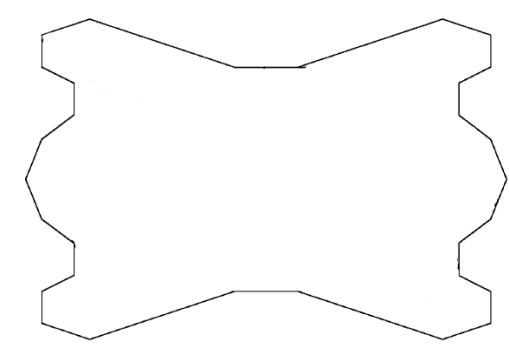

Figura 2.6: Recipiente extraído de Tay e Lee (2002).
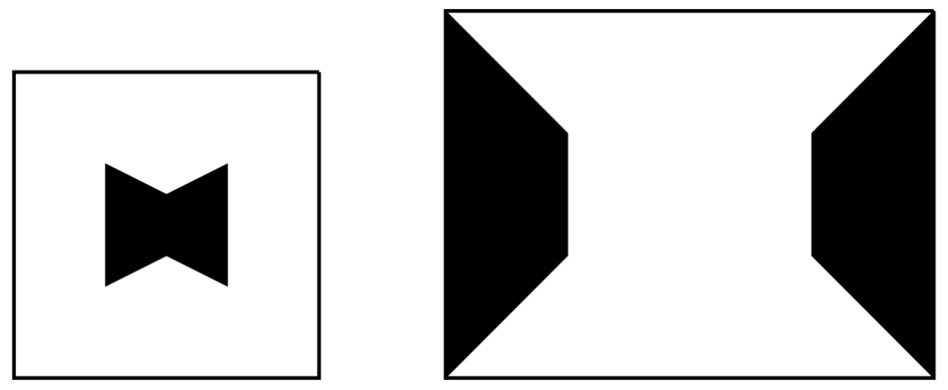

Figura 2.7: Recipientes extraído de Martins e Tsuzuki (2010).

Os recipientes também podem possuir regiões com diferentes qualidades, como pode ser visto no trabalho de Alves et al. (2012a), Alves et al. (2012b) e Baldacci et al. (2014). A Figura 2.8 apresenta uma representação de um couro com diferentes regiões de qualidade, onde as cores mais escuras representam as regiões de melhor qualidade.

Neste trabalho, os recipientes serão representados por um retângulo e uma lista de polígonos convexos, denominados defeitos, alocados em regiões proíbidas ou defeituosas. Apresentamos, na Figura 2.9, um exemplo baseado no recipiente de Tay e Lee (2002) da Figura 2.6. Os itens podem ser alocados na região clara. Vale salientar que os defeitos não necessariamente devem estar encostados na borda do recipiente, eles podem estar em qualquer local dentro do recipiente. Caso o recipiente seja um retângulo, a lista de defeitos é vazia. 


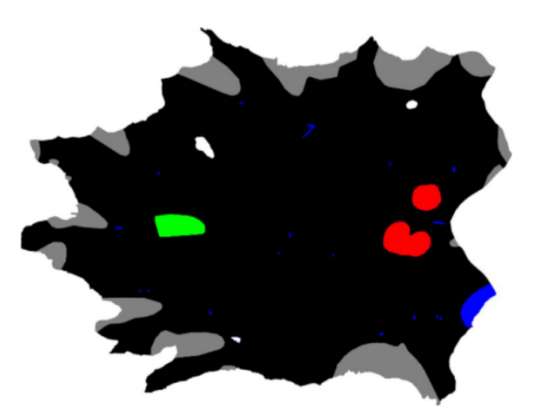

Figura 2.8: Couro com diferentes regiões de qualidade extraídos de Alves et al. (2012a).

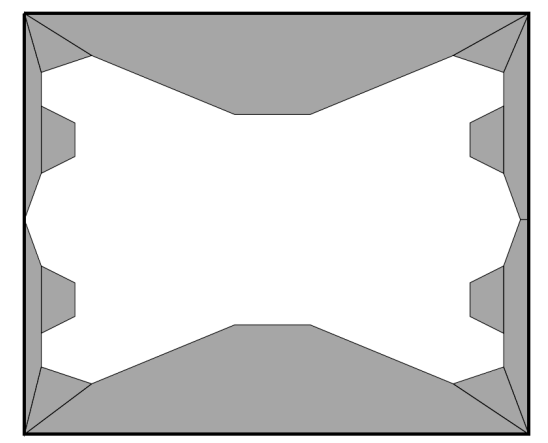

Figura 2.9: Exemplo de representação do recipiente extraído de Tay e Lee (2002).

\subsection{Geometria dos itens}

A grande dificuldade em problemas de corte de itens irregulares é lidar com a geometria dos itens, principalmente para tratar as questões de como evitar a sobreposição de itens e de encontrar posições em que os itens estejam inteiramente contidos nos recipientes. As abordagens mais utilizadas para evitar a sobreposição foram elegantemente condensadas em Bennell e Oliveira (2008), apresentando o método raster, trigonometria direta, phi function e o no-fit polygon.

O método raster utiliza as ideias propostas por Segenreich e Braga (1986) e Oliveira e Ferreira (1993), apresentadas na Seção 2.1.1. A ideia é discretizar os itens em uma malha, para verificar, através de matrizes, a existência ou não de sobreposição. A dificuldade desta abordagem é que a qualidade da representação depende da espessura da malha e da homogeneidade dos itens. Quando existem itens muito pequenos e itens grandes, a discretização ou gera uma representação ruim para os itens pequenos ou é computacionalmente caro.

A trigonometria direta utiliza as arestas de pares de itens para verificar se há sobreposição entre eles. Para que esta verificação seja eficiente, podem ser feitos quatro testes. O primeiro verifica a sobreposição dos menores retângulos que envolvem os itens (retângulos envolventes): se os retângulos não estiverem se sobrepondo, os itens estão separados. O segundo teste verifica 
se existe sobreposição entre os retângulos envolventes de todos os pares de arestas dos itens: caso não exista a sobreposição entre as envoltórias das arestas, os itens não se sobrepõe. O terceiro teste verifica se existe interseção entre as arestas dos itens: se existir, os itens estão sobrepostos. O quarto teste verifica se cada vértice de cada item está contido no outro item: podemos garantir que os itens estão separados se o quarto teste informar que nenhum vértice de um item está no interior do outro.

A phi function é utilizada para descrever a relação entre dois itens. É uma expressão matemática que informa a posição relativa entre um par de itens. O valor da função é zero se os itens estão encostados; maior do que zero, quando os itens estão separados; e menor do que zero, quando existe sobreposição. A principal desvantagem no uso das phi function é que, trabalhando com itens irregulares, as funções precisão ser manualmente feitas para cada caso, pois não existe um método robusto para automatizar a construção das expressões. Para mais detalhes sobre phi functions, veja Stoyan et al. (2001) e Stoyan et al. (2004).

A ideia do no-fit polygon é reduzir a complexidade do cálculo de sobreposição durante o empacotamento dos itens. Trocamos a verificação de sobreposição entre dois itens, por verificar a posição de um ponto em relação a um polígono. Este polígono é construído fixando um dos itens, enquanto o outro orbita ao seu redor, de maneira que os itens sempre se encostem e nunca se sobreponham. A principal desvantagem é que, para utilizar o no-fit polygon, é preciso calculá-lo para cada par de polígonos a respeito dos quais queremos verificar a sobreposição. A vantagem é que isso precisa ser feito apenas uma vez, em uma fase de pré-processamento. A abordagem deste trabalho utiliza o no-fit polygon para definir uma malha de pontos onde os itens podem ser colocados sem sobreposição. Logo, na Seção 2.2.1 apresentamos com mais detalhes o cálculo do no-fit polygon e como definimos a malha de pontos.

\subsubsection{No-fit polygon}

Esta seção tem como objetivo apresentar o cálculo do no-fit polygon para verificar a não sobreposição de itens e explicar como definimos a malha de pontos utilizada neste trabalho. Na Seção 2.1.1 definimos o item irregular como um conjunto de polígonos convexos, no qual cada polígono é representado por um conjunto de pontos ordenados no sentido horário. Cada par de pontos consecutivos representa um vetor no plano.

O no-fit polygon de cada par de polígonos depende da posição e da rotação do item fixo e de um ponto, denominado ponto de referência, do item orbital. Cada par de polígonos convexos dos itens, um polígono do item orbital e o outro do item fixo, definem um no-fit polygon parcial e, após o cálculo de todos os no-fit polygons parciais, temos o no-fit polygon resultante. O no-fit 
polygon de um par de itens é formado pela união de todos os no-fit polygons dos pares $P_{i}$ e $P_{j}$ de polígonos convexos dos itens, sendo $P_{i}$ um polígono do item orbital e $P_{j}$ um polígono do item fixo. Vale destacar que o no-fit polygon entre dois itens depende da rotação do item no plano $(x ; y)$ do item fixo e do item orbital.

Para o cálculo de cada no-fit polygon parcial, utilizamos a abordagem definida por CuinghameGreen (1989) para construir o no-fit polygon entre dois polígonos convexos. Nesta abordagem, o no-fit polygon sempre é calculado através de um par de polígonos, um denominado $A$, fixo no plano e com orientação anti-horária, e o outro chamado de $B$, com orientação horária e com um ponto de referência dado pelo vértice de maior coordenada no eixo das ordenadas (eixo y) em caso de empate, o ponto de referência é dado pelo vértice dentre estes que tem maior coordenada no eixo das abscissas (eixo $x$ ).

A região do no-fit polygon é construída transladando todas as arestas de $A$ e $B$ para o vértice de $A$ com a menor coordenada no eixo $y$ (em caso de empate, dentre estes, o de menor coordenada no eixo $x$ ). Em seguida, basta concatenar todas as arestas dos polígonos no sentido anti-horário. A Figura 2.10 serve para ilustrar a obtenção do no-fit polygon parcial dos polígonos A e B, inspirada no trabalho de Cuinghame-Green (1989).
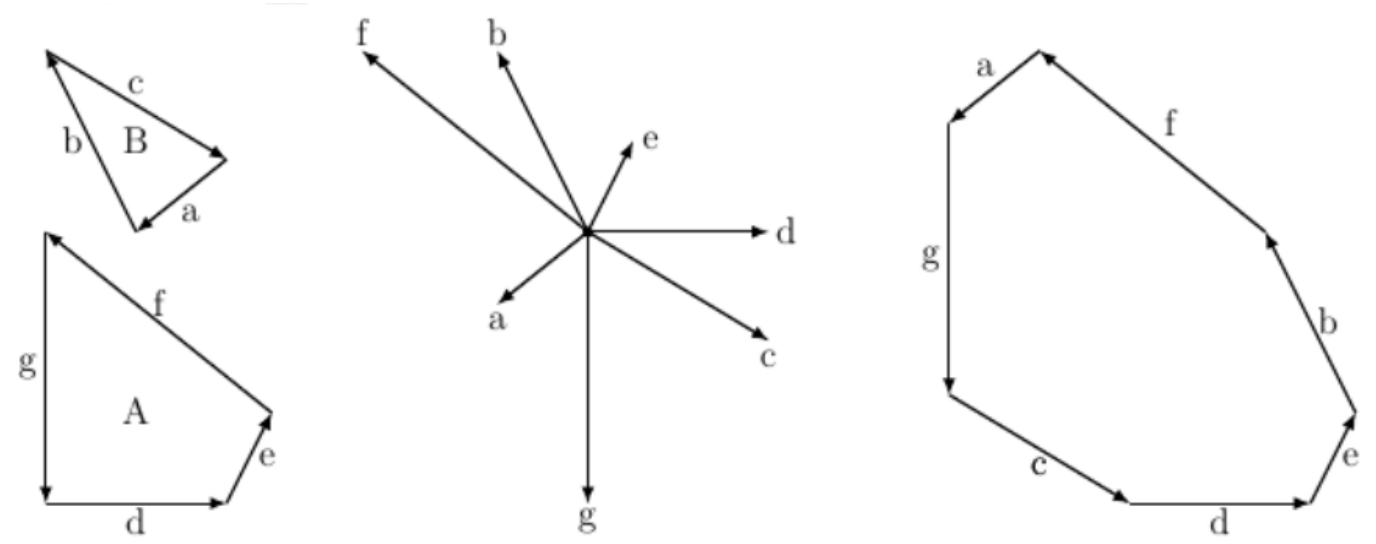

Figura 2.10: no-fit polygon parcial entre os polígonos A (fixo) e B (orbital).

Definido como calculamos os no-fit polygons parciais, o no-fit polygon resultante é formado por todos no-fit polygon parciais em suas respectivas posições. Para que o no-fit polygon resultante esteja correto, devemos tomar o cuidado de calcular os no-fit polygon parciais com os polígonos convexos em suas respectivas posições no item fixo original. A partir do no-fit polygon resultante, podemos determinar a relação entre um par de itens e verificar se existe sobreposição, utilizando apenas um o ponto de referência do item orbital (neste trabalho, o ponto de referência é o primeiro vértice do item fornecido pelo usuário). Se o ponto de referência do item orbital estiver no interior de pelo menos um no-fit polygon parcial, os itens estão se sobrepondo; se os itens não se sobrepõem e o ponto de referência estiver na borda de pelo menos um 
no-fit polygon parcial, os itens estão se tocando; e se o ponto de referência estiver de fora de todos os no-fit polygons parciais, os itens estão separados.

Para verificar se o ponto de referência está fora, no interior ou sobre os no-fit polygons parciais, utilizamos a propriedade do no-fit polygon parcial ser sempre um polígono convexo. Assim, para verificar se um ponto está no seu interior, utilizamos a função D, descrita no trabalho de Bennell e Oliveira (2008). Esta função é utilizada para encontrar a distância entre o ponto de referência e os segmentos de reta que ligam cada par de vértices consecutivos dos no-fit polygons parciais. Se a distância do ponto de referência a um dos segmentos de reta for zero, o ponto está contido em um segmento de reta do no-fit polygon parcial; se a distância for maior do que zero para todos os pares, o ponto está no interior do no-fit polygon parcial; e se a distância for negativa para algum par de vértices, o ponto de referência está fora da região do no-fit polygon parcial.

É fácil perceber que nosso método é muito dependente da quantidade de polígonos convexos que formam os itens, já que a quantidade de no-fit polygons parciais é igual à quantidade de polígonos convexos do item fixo multiplicada pela quantidade de polígonos convexos do item orbital. Por exemplo, dois itens com quatro polígonos convexos cada um formam um no-fit polygon resultante com dezesseis partes. Assim, para evitar a sobreposição, precisamos verificar se o ponto de referência está no interior de algum dos dezesseis no-fit polygons parciais. Fazer todas estas verificações é um processo muito caro e nada interessante quando temos como objetivo desenvolver heurísticas rápidas. A união de polígonos convexos poderia ser uma saída, mas ela não é uma tarefa fácil e pode retornar polígonos não convexos, o que requer mais testes para verificar se um ponto está no seu interior.

Por estes motivos escolhemos uma abordagem alternativa, que se mostrou muito eficiente. Optamos por utilizar uma malha que representa o no-fit polygon resultante. Em outras palavras, representamos o no-fit polygon por uma matriz, com os valores zero e um. O valor zero representa posições externas ou encostadas nas bordas do no-fit polygon resultante (região onde os itens não se sobrepõem). $\mathrm{O}$ valor um representa a região estritamente interna do no-fit polygon resultante. A ideia é obter, em uma etapa de pré-processamento, a matriz equivalente ao no-fit polygon para uma dada discretização. Transformar o no-fit polygon em uma matriz de posições factíveis é muito interessante, pois evitamos que durante o método de resolução tenhamos que verificar todos os no-fit polygons parciais para encontrar posições factíveis.

Para criar a matriz com o no-fit polygon resultante é necessário definir uma discretização, com uma única espessura para as células das matrizes de no-fit polygon e do recipiente. Definida a discretização, podemos calcular a dimensão da matriz que representa o no-fit polygon. $\mathrm{O}$ 
número de colunas da matriz é dado pelo teto da diferença da maior e menor coordenada do eixo x, no no-fit polygon resultante, dividido pela discretização definida ou seja, a espessura das células das matrizes (que representam o no-fit polygon e o recipiente). De forma similar, o número de linhas é dado pelo teto da diferença das coordenadas extremas do eixo y do no-fit polygon resultante, dividido pela discretização. A matriz do no-fit polygon é limitada por essas dimensões porque qualquer ponto que esteja de fora da envoltória retangular do no-fit polygon é uma posição factível, ou seja, os pontos externos à matriz estão estritamente fora do no-fit polygon resultante.

A busca de uma heurística rápida nos trouxe a uma malha de pontos, mas, à primeira vista, estamos muito dependentes da malha. Realmente, esta dependência existe, mas com o poder computacional de hoje os computadores conseguem trabalhar com uma malha de pontos extremamente grande e, por trabalharmos com uma malha para representar apenas os no-fit polygons, e não os itens, conseguimos diversos encaixes não ortogonais à discretização. Estes encaixes permitem soluções muito boas, obtendo diversos encaixes perfeitos, com ocupação de $100 \%$ do recipiente, como será apresentado nos resultados computacionais. Estes encaixes seriam impossíveis se estivéssemos utilizando o método raster.

Para ilustrar os conceitos descritos nesta seção, a Figura 2.11 ilustra o no-fit polygon entre dois itens da instância Shapes 0. Em seguida, a Figura 2.12 apresenta a matriz que representa o no-fit polygon. Para facilitar a visualização, apresentamos somente as posições onde existe sobreposição (valor um). O restante da matriz recebe valor zero e não foi apresentado na Figura 2.12. O tamanho da discretização utilizada foi de uma unidade utilizando as dimensões originais da instância Shapes 0 .

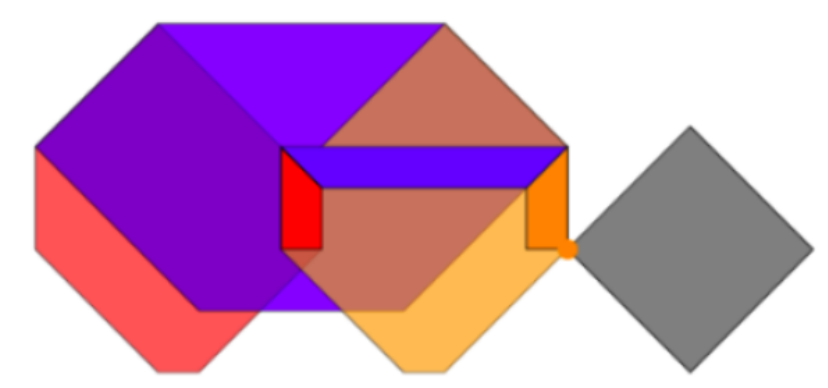

Figura 2.11: No-fit polygon completo da trave (item fixo) com o losango (item orbital). 


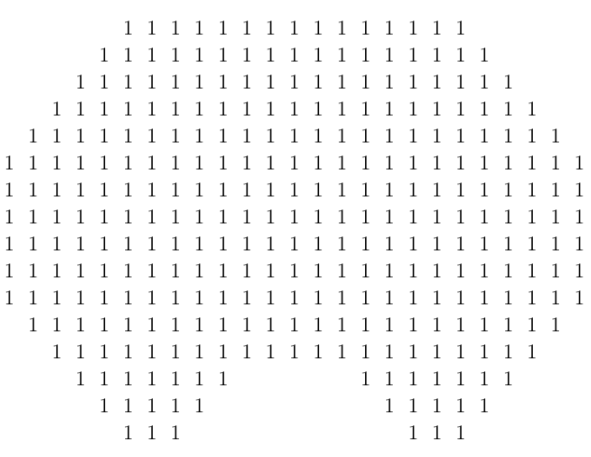

Figura 2.12: Malha de pontos proibidos do no-fit polygon da trave (item fixo) com o losango (item orbital).

\subsection{Geometria dos recipientes}

Para definir a região onde o item pode ser empacotado em um recipiente, a técnica mais utilizada é o inner-fit polygon. Esta técnica é parecida com o no-fit polygon: cada item possui um ponto de referência e, a partir deste ponto, é definida uma região onde o item pode ser empacotado. Nesta seção, apresentamos como o inner-fit polygon é usualmente utilizado e descrevemos a nossa abordagem.

Para o cálculo da região em que o item pode ser empacotado dentro do recipiente retangular, algumas ideias simples são utilizadas. Supondo que todo item pode ser alocado em um recipiente, as dimensões do menor retângulo que contém o conjunto de polígonos de um item (retângulo envolvente) são menores ou iguais às dimensões do recipiente. Posicionamos o item inteiramente no retângulo do recipiente, no canto inferior esquerdo. Ao deslizar o item no interior do recipiente, sempre encostando nas bordas do recipiente, a região definida pelo ponto de referência do item é a região onde o ponto de referência do item pode ser alocado, de modo que o item esteja inteiramente contido no recipiente. A Figura 2.13 ilustra este processo.

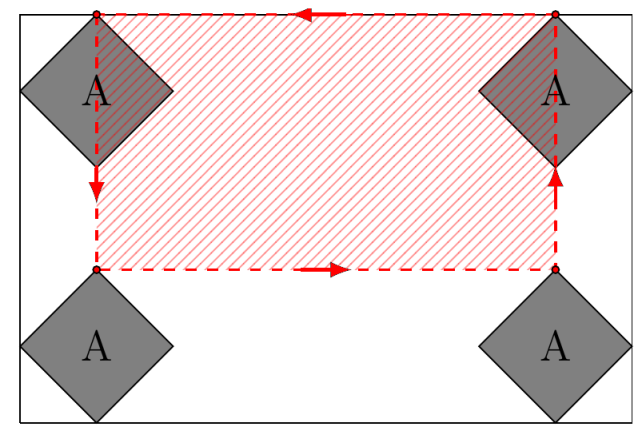

Figura 2.13: Inner-fit retângulo entre um item $A$ e um recipiente retangular.

Note que o retângulo encontrado, chamado de inner-fit retângulo, tem a largura igual à largura do recipiente menos a largura do item, e sua altura é dada pela altura do recipiente menos 
a altura do item. A localização do inner-fit retângulo no recipiente é definida pelo ponto de referência do item, ou seja, o canto inferior esquerdo do inner-fit retângulo é dado pela posição do ponto de referência do item quando colocado no canto inferior esquerdo do recipiente. Com este inner-fit retângulo, sempre que formos alocar um item em um recipiente retangular, se o ponto de referência do item está fora do inner-fit retângulo, temos que o item está fora do recipiente; se o ponto de referência do item está no interior do inner-fit retângulo, o item está no interior do recipiente; e se o ponto de referência do item está sobre as arestas do inner-fit retângulo, o item está alocado dentro do recipiente, encostado na borda.

O cálculo do inner-fit polygon entre um item e um recipiente irregular, assim como no recipiente retangular, pode ser feito através de translações do item pelas arestas do recipiente. A grande dificuldade computacional é encontrar uma posição inicial viável, ou seja, uma posição em que o item está completamente dentro do recipiente. A Figura 2.14 apresenta o inner-fit polygon de um recipiente irregular.

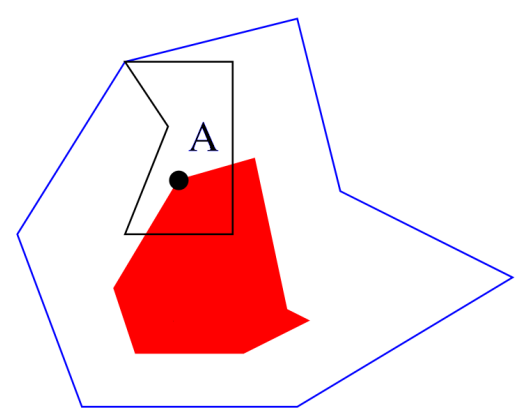

Figura 2.14: Inner-fit polygon (região em vermelho) entre um item $A$ e um recipiente irregular. Figura extraída de Fischetti e Luzzi (2009).

Para tornar este procedimento eficiente, adotamos uma estratégia mencionada nos trabalhos Hu-yao e Yuan-jun (2006) e Martins e Tsuzuki (2010). Nestes trabalhos os autores mencionam que podemos representar recipientes irregulares ou furados como recipientes retangulares com polígonos alocados nas regiões defeituosas. Seguindo esta ideia, decidimos formalizar e descrever melhor um procedimento para o cálculo do inner-fit polygon, até onde sabemos algo inédito na área. $\mathrm{O}$ cálculo do inner-fit polygon entre um item $A$ e um recipiente irregular pode ser dividido em quatro etapas. Na primeira, calcula-se o inner-fit retângulo entre o item $A$ e o retângulo que envolve todo recipiente. Na segunda etapa, alocam-se polígonos convexos (que chamamos de defeitos) sobre as regiões proibidas do recipiente. Na terceira etapa, calculamos todos os no-fit polygons entre os defeitos (itens fixos) e o item A (item orbital). Desta forma, o inner-fit polygon completo é dado pela diferença da matriz do inner-fit retângulo e das matrizes dos no-fit polygons dos defeitos, posicionados na região do defeito.

Por fim, na quarta etapa, cada inner-fit polygon deste trabalho, assim como os no-fit poly- 
gons, é dado por uma matriz. Primeiramente, criamos uma matriz do tamanho do recipiente e encontramos a posição do inner-fit retângulo (veja a Figura 2.13) nesta matriz. Todos os pontos do inner-fit retângulo recebem o valor um e as demais posições recebem o valor zero. Quando subtraímos os no-fit polygons dos defeitos da matriz, ficamos com o valor um nas posições factíveis e, para todos os outros pontos, valores menores do que um. Agora, para encontrar uma posição para que um item esteja inteiramente contido no recipiente, basta procurar uma posição da matriz que tenha o valor um e nela alocar o ponto de referência do item.

Este procedimento, embora simples, torna o cálculo do inner-fit polygon muito robusto e rápido. Robusto porque é capaz representar de forma exata qualquer recipiente irregular e com furos onde as arestas, do recipiente e dos furos, são segmentos de reta. Rápido porque lidamos apenas com operações de translação de arestas. 


\section{CAPÍtULO 3}

\section{MÉTODOS DE RESOLUÇÃO PARA O CORTE DE ITENS IRREGULARES}

O corte de itens irregulares pode ser visto sob diversas perspectivas. O objetivo pode ser minimizar o custo de cortar os objetos, minimizar o caminho do corte, minimizar os custos de produção, minimizar o tempo do corte, minimizar o desperdício de material, maximizar a utilização dos recipientes e outros. Neste trabalho, estudamos o problema de corte de itens irregulares em recipientes (também conhecido por irregular bin packing problem). Neste problema, desejamos arranjar um conjunto de itens, sem sobreposição, dentro de um ou mais recipientes. O objetivo é minimizar a quantidade de recipientes utilizados para alocar todos os itens. Em nosso trabalho, cada item é representado por um conjunto de polígonos convexos e os recipientes são retangulares, podendo conter polígonos alocados no seu interior (representando os defeitos). Para mais detalhes sobre a representação e dos recipientes, veja o Capítulo 2.

Neste capítulo, fazemos uma revisão dos principais métodos de resolução para problemas de corte de itens irregulares. Primeiramente, na Seção 3.1, apresentamos uma revisão sobre métodos utilizados para a resolução do problema de corte de itens irregulares em faixa, um dos problemas mais estudados na área. Na Seção 3.2, focamos em problemas com recipientes fechados. Esta seção está divida em métodos que tratam de problemas com recipientes retangulares (Seção 3.2.1) e com recipientes irregulares (Seção 3.2.2). 


\subsection{Corte de itens irregulares em faixa}

Antes de entrar em mais detalhes sobre o problema estudado no presente trabalho, precisamos apresentar um importante problema de corte irregular. Pela definição de Wascher et al. (2007), este problema é um problema de dimensão aberta, também conhecido como corte de itens irregulares em faixa (irregular strip packing problem). Este problema é tão comum na área de corte irregular que às vezes se confunde com o termo nesting problem. Este é um problema bidimensional, no qual uma dimensão é definida e a outra é ilimitada ou aberta. O objetivo do problema é cortar um conjunto de itens dentro do recipiente, de largura fixa utilizando o menor comprimento de faixa possível. Existem diversas aplicações deste problema, como no corte de rolos de tecido, onde o comprimento do rolo pode ser considerado infinito e desejamos minimizar o tamanho da faixa utilizada para cortar uma demanda de peças de roupa.

Grande parte dos trabalhos que lidam com este problema se baseiam, predominantemente, em heurísticas com busca local e/ou meta-heurísticas, nos quais, a partir de uma solução inicial, são feitas algumas modificações que objetivam melhorar a solução inicial. Baker et al. (1980) introduziu uma das heurísticas construtivas mais utilizadas na área de corte, denominada bottom-left. A ideia desta heurística é bem simples. Escolhe-se uma sequência para alocar os itens no ponto do recipiente mais abaixo e à esquerda possível. Para chegar nesta posição, na heurística bottom-left clássica, o item é alocado no canto superior direito do recipiente e, então, deslocado verticalmente para baixo até encostar em outro item ou no recipiente. Em seguida, o item é deslocado para a esquerda até encostar em outro item ou no recipiente. Este procedimento é repetido até que o item não possa se movimentar. A heurística bottom-left se tornou uma estratégia bastante interessante por ser de fácil compreensão, além de produzir leiautes bons em um baixo tempo computacional.

Na década de 90, Jakobs (1996) apresentou um algoritmo genético para o corte de itens irregulares em faixa. Neste trabalho, cada indivíduo foi representado por um vetor de itens. A ordem dos itens era armazenada no cromossomo e esta ordem era utilizada para alocar as envoltórias retangulares dos itens, utilizando a heurística bottom-left clássica. Em seguida, Jakobs (1996) utilizou um algoritmo de compactação, que considera apenas a compactação em linha na qual os itens são deslocados para baixo.

Li e Milenkovic (1995) apresentou um interessante algoritmo de compactação e outro de separação para polígonos convexos e não convexos, que estão muito bem explicados no trabalho de Milenkovic e Daniels (1996). Neste trabalho os autroes apresentam um conjunto de movimentos para trabalhar com soluções factíveis, algo bem mais elaborado que a compactação em 
linha de Jakobs (1996). Milenkovic e Daniels (1996) apresentou um algoritmo de compactação que melhorou a qualidade da soluções da literatura, mas não se preocupavam em preencher buracos.

Neste cenário, Dowsland et al. (1998) levantaram uma questão interessante. A heurística bottom-left proposta por Baker et al. (1980) é eficiente para retângulos, mas quando estamos trabalhando com itens irregulares, utilizar uma heurística bottom-left que não preencha os buracos deixa algumas regiões com uma densidade muito baixa. Com isso, Dowsland et al. (1998) propuseram seis variações da heurística bottom-left, das quais três preenchem os buracos que surgem durante o corte e as outras três não preenchem esses buracos. Os resultados computacionais de Dowsland et al. (1998) chamam a atenção. Nestes resultados, existe uma grande vantagem das heurísticas que preenchem os buracos e, desde então, os trabalhos com itens irregulares começam a se preocupar com esse fato. Assim, os novos algoritmos com a estratégia bottom-left começam a utilizar muitas variações da versão clássica da heurística e dizem apenas que utilizam a política do bottom-left. Para evitar a sobreposição, Dowsland et al. (1998) utiliza trigonometria direta, específica para polígonos convexos e noções elementares de concavidade de polígonos não convexos. Por fim, ainda utilizou o no-fit polygon para evitar a sobreposição de polígonos não convexos.

No início dos anos 2000, conforme a capacidade dos computadores começou a crescer, os resultados na área de corte irregular começaram a melhorar muito. Principalmente nos primeiros anos, surgiram vários artigos que impulsionaram o desenvolvimento de novos algoritmos. Oliveira et al. (2000) é um destes artigos, com 20 citações em revistas de excelência até o presente momento, segundo dados da Springer. Neste trabalho, os autores apresentam diversos critérios para trabalhar com itens irregulares. Os autores criaram um algoritmo construtivo denominado: Técnicas de Optimização para o Posicionamento de Formas Irregulares (TOPOS) e apresentaram diferentes critérios de ordenação para os itens. Estes critérios ordenam os itens em ordem decrescente de acordo com: comprimento, área, irregularidade (diferença entre a área da envoltória convexa e a área do item), retangularidade (diferença entre a área da envoltória retangular e a área do item), área total do item (área do item multiplicada por sua demanda ou a quantidade de cópias a ser inserida) e de forma aleatória. Para alocar os itens, Oliveira et al. (2000) apresentaram critérios como minimizar a envoltória retangular, minimizar o comprimento do leiaute e maximizar a sobreposição entre os retângulos envolventes do item a ser inserido e do leiaute atual. Outros critérios são: minimizar a distância euclidiana do centro do retângulo envolvente do item a ser inserido e da solução parcial. Outras heurísticas baseadas neste trabalho foram propostas por Bennell e Song (2010). 
No ano de 2002, foram publicados dois algoritmos com políticas de bottom-left. Dowsland et al. (2002) apresentou um algoritmo poderoso que resolve instâncias grandes em um tempo computacional baixo. Neste trabalho, os autores utilizam o no-fit polygon para evitar sobreposições e os pontos considerados para alocar o item são extraídos das arestas do no-fit polygon dos itens já alocados com relação ao item que será alocado. Os pontos são atualizados a cada inserção, para evitar que o algoritmo fique com um número muito grande de possibilidades. O trabalho de Gomes e Oliveira (2002) apresentou uma estratégia muito interessante e uma maneira diferenciada de formar a lista de pontos factíveis para a política do bottom-left. Inicialmente, são considerados apenas os pontos do inner-fit retângulo (veja Seção 2.3). Em seguida, são atualizadas listas com todos os vértices do no-fit polygon que podem ser utilizados. São considerados também os pontos viáveis de interseção entre duas arestas dos no-fit polygons dos itens alocados no recipiente e pontos de interseção entre os no-fit polygons e o inner-fitrectangle. Neste artigo, os autores propõem uma heurística que ordena os itens pelos critérios do TOPOS e, a partir da lista de pontos, usa a heurística bottom-left. A partir da solução obtida, é feita uma busca na qual trocam-se dois itens da sequência inicial e aplica-se a heurística bottom-left novamente. Os experimentos computacionais deste trabalho mostram a competitividade do algoritmo proposto. Das cinco instâncias utilizadas, o algoritmo de Gomes e Oliveira (2002) melhorou quatro, permanecendo como os melhores resultados da literatura até meados do ano de 2006, quando surgiram dois trabalhos interessantes: Burke et al. (2006) e Gomes e Oliveira (2006).

Burke et al. (2006) apresentaram uma estratégia bottom-left-fill, que pode ser considerada uma inovação, pois os autores apresentam uma estratégia bottom-left que consegue alocar itens em buracos, utilizando ideias clássica da literatura presente em Dowsland et al. (1998), e consideram outras configurações de itens e não só polígonos convexos e não convexos. Neste trabalho, são considerados polígonos simples, sem auto interseção, formados por um ou mais polígonos convexos e não convexos que podem ser ligados por segmentos de retas ou semicírculos. Essa representação permite representar polígonos com buracos. Este trabalho foi melhorado em Burke et al. (2010).

Gomes e Oliveira (2006) apresentaram uma estratégia híbrida que melhorou vários resultados da literatura. Neste trabalho, os autores apresentam um modelo de compactação muito poderoso. O algoritmo proposto é uma meta heurística de recozimento simulado (simulated annealing) que utiliza basicamente o modelo de compactação e algoritmos de separação para ditar a ordem com que os itens são alocados por uma heurística bottom-left discreta.

Egeblad et al. (2007) propuseram uma técnica de resolução para problemas bidimensionais 
e tridimensionais através de uma heurística de busca local guiada (guided local search). Apesar de bastante intuitivo, o método proposto por Egeblad et al. (2007) é de difícil implementação, pois utiliza diversas ferramentas para efetuar a busca. Basicamente, o método consiste em: dada uma solução inicial, que pode conter sobreposição, minimizar a sobreposição fazendo buscas horizontais e verticais no interior do recipiente.

Elkeran (2013) é o trabalho, até o presente momento, que apresentou os melhores resultados na área de corte de itens irregulares em faixa. Este trabalho melhorou o resultado de doze instâncias clássicas e, dos quinze experimentos computacionais feitos, obteve resultados melhores ou iguais para todos. O algoritmo proposto é uma meta-heurística recente, denominada cuckoo search, de Yang e Deb (2010), combinada com uma busca local direcionada para escapar de mínimos locais. Neste trabalho, os autores combinaram várias estratégias de corte de itens irregulares, como, por exemplo, compactação e separação. Este é um trabalho bastante completo, mas gostaríamos de destacar uma das estratégias propostas pelo autor. Ele utilizou a combinação de pares de itens para obter leiautes mais compactos, isso facilita muito na busca de soluções de boa qualidade.

Fugindo das abordagens heurísticas, Carravilla et al. (2003) apresentaram um modelo de programação por restrições para itens convexos e não convexos, que parte das ideias apresentadas em Ribeiro et al. (1999), no qual é apresentado um modelo de programação por restrições para corte de itens convexos. Este modelo representa o problema de corte de itens irregulares em faixa, cuja solução é ótima para uma malha de pontos. Fischetti e Luzzi (2009) apresentaram um modelo de programação inteira para o problema. Este modelo teve como base o trabalho de Daniels et al. (1994). Recentemente, Alvarez-Valdes et al. (2013) reformularam o modelo de Fischetti e Luzzi (2009) e propuseram um algoritmo branch-and-bound. Neste trabalho, os autores ainda estendem o modelo de compactação de Gomes e Oliveira (2006) para itens convexos. Por fim, Toledo et al. (2013) apresentaram um modelo inteiro misto e resolve as maiores instâncias da literatura para algoritmo exatos, entretanto a solução é ótima para uma malha de pontos, assim como em Ribeiro et al. (1999) e Carravilla et al. (2003).

\subsection{Corte de itens irregulares em recipientes fechados}

No presente trabalho, consideramos o problema de corte de itens irregulares em recipientes fechados. Neste problema, as dimensões dos recipientes são conhecidas e o objetivo é alocar todos os itens utilizando o menor número de recipientes possível. Segundo a classificação de Wascher et al. (2007) este é um problema de corte de itens em recipientes. Também encontrado 
na literatura como problema de empacotamento em recipientes ou bin packing problem.

Diversos algoritmos heurísticos e exatos foram desenvolvidos para o problema de corte de retângulos em recipientes. No problema de corte de retângulos é fácil evitar a sobreposição entre os itens, o que facilitou a formulação de modelos matemáticos e de estratégias muito eficientes. Um trabalho completo sobre o corte de recipientes com itens e recipientes formados por retângulos pode ser encontrado na tese de Lodi (1999). Neste trabalho, o autor apresenta algoritmos exatos e heurísticos para algumas variações do bin packing problem, além de estudar outros problemas de corte. Lodi et al. (2002) apresentaram um levantamento sobre a versão bidimensional do bin packing problem. Neste trabalho, os autores apresentam uma elegante revisão dos algoritmos exatos, heurísticas e meta-heurísticas para o corte de retângulos. Métodos exatos e heurísticos para o bin packing problem podem ser encontrados em: Chung et al. (1982), Martello e Vigo (1998), Lodi et al. (1999) e Gonçalves e Resende (2013). Poucos trabalhos lidam com itens irregulares (polígonos convexos e não convexos) com recipientes fechados. Segundo os dados de Wascher et al. (2007), no período de 1995 até 2004 foram produzidos 64 trabalhos de corte bidimensional de itens irregulares, dos quais apenas dois resolveram o bin packing problem e sete resolveram o problema da mochila, o que representam, juntos, menos de $15 \%$ dos trabalhos publicados com itens irregulares. Wascher et al. (2007) definiram o problema da mochila como um recipiente limitado, onde um conjunto fortemente heterogêneo de itens devem ser alocados a fim de maximizar algum objetivo como, por exemplo, utilização do recipiente ou o valor dos itens alocados.

Dentre os problemas de corte de itens irregulares em recipientes fechados, temos o problema com recipientes retangulares e recipientes irregulares. Recipientes irregulares com representação poligonal podem ser definidos como polígonos convexos e não convexos que podem conter furos e regiões de qualidade diferente. As Seções 3.2.1 e 3.2.2 apresentam a revisão destes trabalhos, para recipientes retangulares e irregulares, respectivamente.

\subsubsection{Recipientes retangulares}

Nesta seção, apresentamos os trabalhos que lidam com recipientes retangulares e itens irregulares que possuem rotação livre ou rotações definidas. O número de trabalhos nessa área aumentou consideravelmente nos últimos anos. Incluindo trabalhos completos de mestrado (Pasha (2003) e Valle (2010)) e de doutorado (Martins (2007)).

Halavati et al. (2007) lidam com o problema de corte de itens irregulares em recipientes retangulares, apresentando uma forma de unir os itens por meio dos vértices e gerar populações. Este trabalho é melhorado em Halavati et al. (2008), onde os autores apresentam uma 
nova abordagem evolutiva para problemas de corte e comparam a abordagem proposta com um algoritmo genético tradicional. Neste trabalho, os genes representam a relação entre dois itens e os cromossomos são formados pela combinação de alguns genes, que podem resultar em uma solução parcial ou completa. A função de aptidão é a razão entre a solução do cromossomo e a área da envoltória retangular dos itens. Esta abordagem se diferencia bastante das abordagens do corte de itens irregulares em faixa, pois não utiliza a heurística bottom-left e apresenta uma heurística construtiva a partir dos genes, que faz com que os itens sejam alocados nos recipientes de dentro para fora, buscando minimizar a envoltória retangular. A maior desvantagem desta abordagem é o tempo de execução do algoritmo, em geral muito elevado. Para a resolução de algumas instâncias, foram necessárias mais de quatro horas.

Terashima-Marín et al. (2010) é um dos trabalhos mais interessantes que lidam com bin packing problem. Este trabalho apresenta uma hiper-heurística geral baseada em um algoritmo genético que resolve o problema de corte de itens retangulares e irregulares em recipientes retangulares. A hiper-heurística desenvolvida gerencia diversas heurísticas de baixo nível e recebe o valor do leiaute dos itens alocados como parâmetro. As heurísticas de baixo nível utilizadas para a alocação dos retângulos foram: a heurística bottom-left de Jakobs (1996) e a heurística improved-bottom-left de Liu e Teng (1999). Para os itens irregulares, foram utilizadas quatro heurísticas: a heurística bottom-left e outras três heurísticas construtivas, uma que utiliza os pontos de Hifi e M'Hallah (2003), uma que modifica a utilização destes pontos para minimizar a área retangular dos itens alocados e a última que utiliza a ideia de alocar o item nos quatro cantos do recipiente, adaptando a ideia de Uday et al. (2001). Foram utilizados dez diferentes critérios para ordenar os itens. A hiper-heurística proposta produziu excelentes resultados para um grande conjunto de instâncias. O trabalho López-Camacho et al. (2010) propõe uma estratégia mais geral para hiper-heurísticas e utilizou a hiper-heurística de Terashima-Marín et al. (2010) para validar seu método.

López-Camacho et al. (2013) propõe a adaptação de um algoritmo desenvolvido originalmente para resolver um bin packing problem unidimensional, denominado DJD, proposto por Ross et al. (2002). Este trabalho utiliza as quatro heurísticas desenvolvidas para o corte de itens irregulares do trabalho de Terashima-Marín et al. (2010) e sete dos dez critérios do mesmo trabalho. As contribuições deste trabalho foram a adaptação do algoritmo DJD, que considerava apenas o comprimento dos itens (característica do problema original, versão unidimensional) e agora considera as configurações dos itens.

Dalalah et al. (2014) resolve o problema,onde o número de recipientes é restrito a um e o objetivo é maximizar a utilização do recipiente, conhecido por problema da mochila. Nesta 
perspectiva, encontramos três trabalho relevantes que resolvem o problema da mochila: Martins e Tsuzuki (2010), Valle et al. (2012) e Dalalah et al. (2014). Martins e Tsuzuki (2010) apresenta um algoritmo de recozimento simulado, onde os itens têm rotação livre. Valle et al. (2012) propõe um algoritmo híbrido para o problema da mochila irrestrita e uma heurística baseada em GRASP para o problema da mochila 0-1, onde temos um conjunto de itens e os podemos alocalos ou não. Dalalah et al. (2014), recentemente, apresenta uma heurística baseada na união de polígonos para lidar com o problema da mochila 0-1 e ilimitada, sempre visando minimizar o desperdício. Os trabalhos de Martins e Tsuzuki (2010) e Dalalah et al. (2014) apresentam também experimentos com mochilas irregulares.

\subsubsection{Recipientes irregulares}

Nesta seção, apresentamos uma revisão dos métodos para resolução de problemas de corte de recipientes irregulares. Um dos trabalhos mais completos sobre esta classe de problemas pode ser encontrado em Heistermann e Lengauer (1995). Até onde sabemos, este é o primeiro trabalho que lida com recipientes irregulares, estudando instâncias reais para o problema do corte de peças de couro. Neste trabalho, os autores apresentaram um software completo para lidar com o problema do corte de peças de couro. Este software estava sendo utilizado no ambiente industrial desde junho de 1992.

O algoritmo proposto por Heistermann e Lengauer (1995) é formado basicamente por quatro etapas: (i) procurar a região mais promissora para cortar; (ii) selecionar um conjunto dos itens (com rotações definidas), promissores, que podem ser alocados; (iii) os itens são alocados provisoriamente e o item do conjunto selecionado com a melhor alocação é mantido no leiaute; (iv) se todos os itens selecionados não podem ser cortados algumas medidas especiais são tomadas para o algoritmo não entrar em um laço infinito, explorando sempre regiões infactíveis. Estas etapas são repetidas enquanto existem itens a serem cortados e existir região livre no recipiente. Os experimentos computacionais mostram que o algoritmo proposto é eficiente, com um baixo tempo computacional.

Durante alguns anos, o trabalho de Heistermann e Lengauer (1995) era a única referência na área de corte de recipientes irregulares. No início dos anos 2000, surgem novos trabalhos que lidam com recipientes irregulares (Tay e Lee (2002), Crispin et al. (2005), Yuping et al. (2005) e Hu-yao e Yuan-jun (2006)).

Tay e Lee (2002) apresentaram um algoritmo genético que consegue empacotar os itens em recipientes convexos e não convexos. Yuping et al. (2005) e Crispin et al. (2005) dão ênfase à indústria do couro. Yuping et al. (2005) apresentaram uma abordagem interessante para o 
problema de corte de couro com zonas de qualidade. Para encontrar posições viáveis, os autores utilizam rotação e deslocamentos com uso de funções de penalização. Crispin et al. (2005) apresentaram um algoritmo genético, e a verificação de sobreposição dos itens utiliza o no-fit polygon. No trabalho de Hu-yao e Yuan-jun (2006) é proposta uma técnica de alocação baseada no centro de gravidade do no-fit polygon, onde o item pode rotacionar livremente encontrando uma posição livre na parte inferior do recipiente. Os buracos são representados por polígonos alocados nos recipientes. Até onde sabemos, esta foi a primeira vez que uma estratégia assim foi utilizada. Com esta estratégia, é bastante simples empacotar itens em recipientes furados ou com regiões proibidas. No presente trabalho, generalizamos esta ideia. Para mais detalhes, veja a Seção 2.3.

Alves et al. (2012a) apresentaram um novo algoritmo para o problema de corte de couro da indústria automobilística. Neste trabalho, foram propostas diversas heurísticas construtivas para o problema do corte de couro. As heurísticas combinam as estratégias de seleção dos itens a serem inseridos e escolha das regiões mais interessantes do recipiente. Os autores utilizam o no-fit polygon para evitar a sobreposição dos itens. Foi feita uma grande quantidade de experimentos computacionais, com dados reais da indústria, que validam as heurísticas propostas. Alves et al. (2012b) utilizaram a mesma representação de Alves et al. (2012a) e apresentaram uma nova estrutura de vizinhança.

Baldacci et al. (2014) é o trabalho mais recente de corte de recipientes irregulares. Neste trabalho, os autores chamam a atenção para as vantagens e desvantagens de se utilizar a representação poligonal e o raster point. A representação poligonal é mais próxima da realidade e o no-fit polygon é uma técnica eficiente para evitar a sobreposição dos itens. O método raster é simples, pois o item é representado por uma matriz e, para evitar a sobreposição, basta verificar se cada posição do recipiente possui apenas um item. Os autores formulam um modelo para o problema da mochila, onde a mochila é representada por uma única peça de couro e propõem uma relaxação lagrangiana para o modelo proposto. Para desenvolver uma heurística iterativa com a relaxação lagrangiana, são gerados padrões de corte, por meio de heurísticas para o problema da mochila que combinam três procedimentos de alocação. A heurística desenvolvida foi testada na resolução de instâncias reais e também comparada com o problema de corte de itens irregulares em faixa, considerando apenas um recipiente.

Os trabalhos de Martins e Tsuzuki (2010) e Dalalah et al. (2014) apresentaram algoritmos que podem ser utilizados no problema da mochila irregular. Martins e Tsuzuki (2010) apresentaram um exemplo para um recipiente furado, enquanto Dalalah et al. (2014) resolveram quatro instâncias com recipientes irregulares. 


\section{CAPÍtULO 4}

\section{MÉTODO DE RESOLUÇÃO PROPOSTO}

Este capítulo apresenta o método desenvolvido para resolver a versão bidimensional do problema de corte de itens irregulares em recipientes. Neste trabalho, propomos um novo método que pode ser adaptado para diversos problemas de corte e empacotamento. Nosso método é um algoritmo que gerencia um conjunto de heurísticas de baixo nível, específicas para o corte de itens irregulares. As heurísticas de baixo nível desenvolvidas foram inspiradas nas heurísticas com política bottom left, visto que alocam um item por vez seguindo um caminho dos pontos do recipiente.

Este trabalho possui duas contribuições relevantes: (i) apresentamos uma estrutura de codificação de heurísticas de baixo custo computacional e eficientes, que podem ser facilmente modificadas; (ii) um novo algoritmo, genérico, que gerencia heurísticas de baixo nível e pode ser utilizado para resolver vários tipos de problemas de corte e empacotamento. Para facilitar a descrição do método de resolução, dividimos o capítulo em três seções. Primeiramente, na Seção 4.1, apresentamos um resumo das etapas de pré-processamento. Estas etapas são fundamentais para codificação das heurísticas. Na Seção 4.2, descrevemos as heurísticas desenvolvidas. $\mathrm{Na}$ Seção 4.3, apresentamos o algoritmo que gerencia as heurísticas.

\subsection{Etapas de pré-processamento}

Os algoritmos desenvolvidos neste trabalho recebem uma lista de itens e de recipientes. A lista de itens contém todas as informações dos $n$ tipos de itens, com a demanda de cada 
tipo, suas possíveis $r$ rotações e um conjunto de polígonos convexos que compõe cada tipo de item. A lista dos $m$ recipientes contém, para cada recipiente, uma altura, uma largura e uma lista de defeitos, que pode ser vazia. Os defeitos são polígonos convexos alocados no interior do recipiente. Com as informações das listas de itens e dos recipientes, calculamos o no-fit polygon entre todos os pares de itens, em todas as rotações possíveis, e entre os defeitos e os itens, em suas possíveis rotações. Para o cálculo do no-fit polygon utilizamos a abordagem de Cuinghame-Green (1989), específica para polígonos convexos e que usa apenas translações de arestas (veja Seção 2.2.1).

Com essas informações, calculamos a malha de pontos factíveis para os itens, em todas as rotações possíveis, no interior do recipiente. Isto é importante para que, ao inserir um item no recipiente, ele esteja completamente dentro do recipiente e não esteja se sobrepondo com nenhum defeito. Para verificar se os pontos são factíveis, ao preencher as malhas de pontos, utilizamos a função D, descrita no trabalho de Bennell e Oliveira (2008). Em seguida, calculamos, da mesma forma, a malha dos no-fit polygon. Para mais detalhes sobre o no-fit polygon e as malhas de pontos, veja as Seções 2.2 e 2.3.

\subsection{Heurísticas}

As heurísticas propostas são algoritmos construtivos, baseados predominantemente na ordenação dos itens. A partir de uma ordem dos itens, para cada um dos $m$ recipientes, tentamos inserir todos os itens, um de cada vez. Para isso, as heurísticas recebem vários parâmetros. Entre eles, temos uma lista com $n$ tipos de itens cada um com uma demanda, as possíveis rotações e os polígonos convexos que constituem o item. O somatório da demanda dos $n$ tipos de itens fornece a quantidade total de itens (numItens). O vetor order, de tamanho numItens, contém a ordem em que os itens serão inseridos. Temos também a lista com as informações dos $m$ recipientes (altura, largura e lista de defeitos). Por fim, os dois últimos parâmetros são: as malhas de pontos $\left(M_{j, i, k}\right)$ e as malhas dos no-fit polygons $\left(N F P i_{f}, r_{f}, i_{o}, r_{o}\right)$. A malha de pontos com as posições factíveis é uma matriz binária que representa o recipiente $j$ para o tipo do item $i$ com rotação $k$. As malhas com o no-fit polygon são matrizes binárias que representam o no-fit polygon do item fixo $i_{f}$ na rotação $r_{f}$ contra o item orbital $i_{o}$ na rotação $r_{o}$. As malhas dos no-fit polygons são utilizadas para atualizar as malhas de pontos ao inserir um item no recipiente. Para mais detalhes sobre os parâmetros utilizados e como obtemos as malhas de pontos e o no-fit polygon, veja as Seções 2.2 e 2.3.

O Algoritmo 1 apresenta o algoritmo geral das heurísticas de baixo nível desenvolvidas 
neste trabalho. As heurísticas serão apresentadas em mais detalhes na Seção 4.2.1.

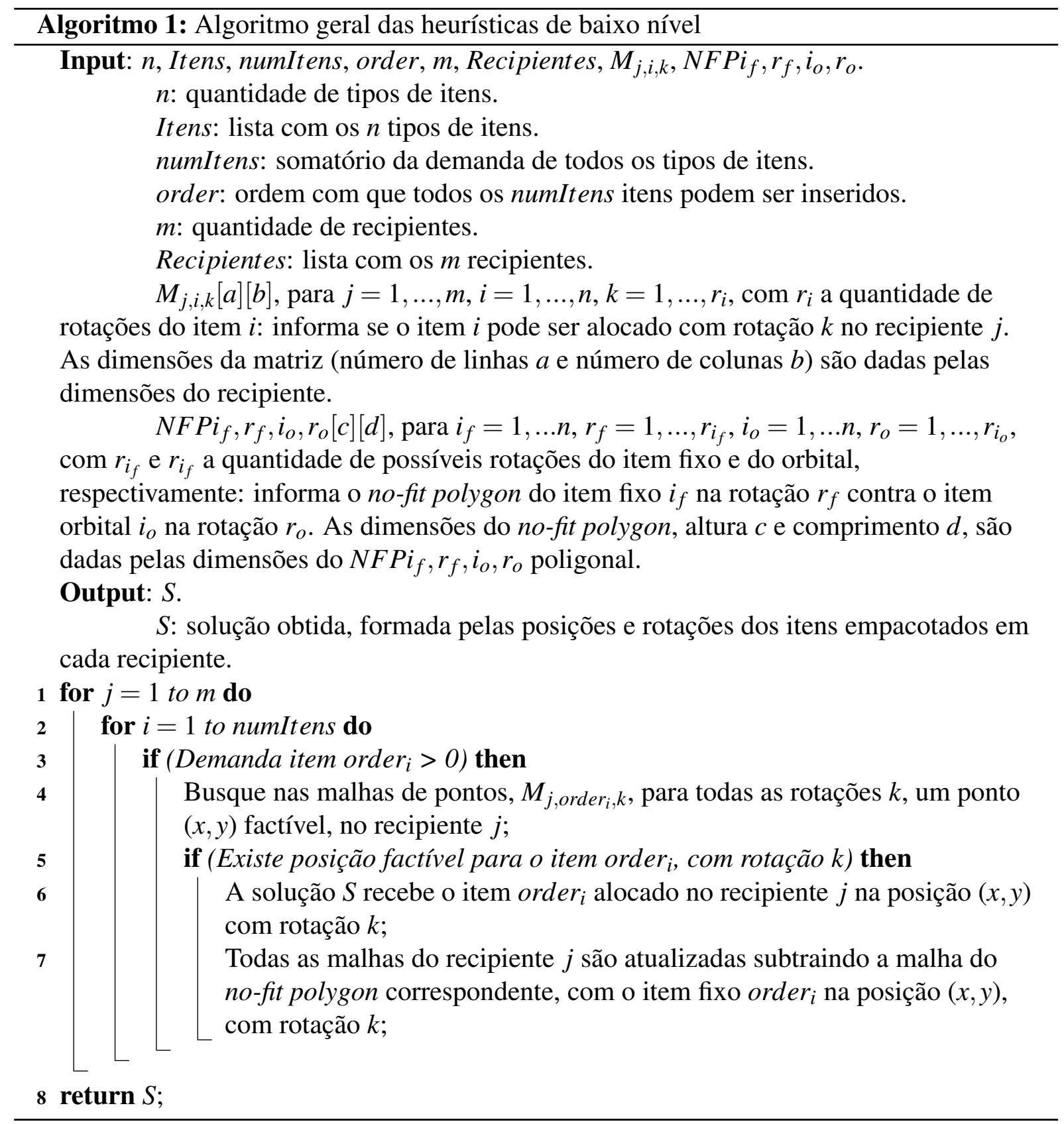

\subsubsection{Variações das heurísticas}

Nesta seção apresentamos quatro versões das heurísticas, que se diferenciam apenas na busca por uma posição factível na linha 4 do Algoritmo 1, ou seja, o caminho pelo qual as heurísticas buscam um ponto para inserir um item. Para facilitar a compreensão, apresentamos uma descrição de cada caminho e, em seguida, desenhamos uma malha quadrada de dimensão cinco, onde as posições estão numeradas na ordem com que são verificadas por cada caminho. 
1. Bottom left: A verificação começa do ponto inferior esquerdo (origem da malha, ponto $(0,0)$ ), avançando uma unidade no eixo y até alcançar o ponto superior (altura da malha), recomeçando a verificação na parte inferior (altura zero), uma unidade à direta. Este processo é repetido até que se encontre uma posição para alocação do item ou até ser atingido o ponto superior direito (o ponto de maior coordenada no eixo $x$ e no eixo $y$ ).

\begin{tabular}{|c|c|c|c|c|}
\hline 5 & 10 & 15 & 20 & 25 \\
\hline 4 & 9 & 14 & 19 & 24 \\
\hline 3 & 8 & 13 & 18 & 23 \\
\hline 2 & 7 & 12 & 17 & 22 \\
\hline 1 & 6 & 11 & 16 & 21 \\
\hline
\end{tabular}

2. Rand-Corner: Fazemos um sorteio, com iguais probabilidades, e um canto é escolhido para dar início à busca. Se o canto inferior esquerdo for escolhido, o caminho é idêntico ao bottom left. Se o canto superior esquerdo for sorteado, a matriz é percorrida de cima para baixo, da esquerda para a direita.

\begin{tabular}{|c|c|c|c|c|}
\hline 1 & 6 & 11 & 16 & 21 \\
\hline 2 & 7 & 12 & 17 & 22 \\
\hline 3 & 8 & 13 & 18 & 23 \\
\hline 3 & 9 & 14 & 19 & 24 \\
\hline 4 & 10 & 15 & 20 & 25 \\
\hline
\end{tabular}

Se o canto superior direito for sorteado, a matriz é percorrida de cima para baixo, da direita para a esquerda.

\begin{tabular}{|c|c|c|c|c|}
\hline 21 & 16 & 11 & 6 & 1 \\
\hline 22 & 17 & 12 & 7 & 2 \\
\hline 23 & 18 & 13 & 8 & 3 \\
\hline 24 & 19 & 14 & 9 & 4 \\
\hline 25 & 20 & 15 & 10 & 5 \\
\hline
\end{tabular}

Se o canto inferior direito for sorteado, a matriz é percorrida de baixo pra cima, da direita para a esquerda.

\begin{tabular}{|c|c|c|c|c|}
\hline 25 & 20 & 15 & 10 & 5 \\
\hline 24 & 19 & 14 & 9 & 4 \\
\hline 23 & 18 & 13 & 8 & 3 \\
\hline 22 & 17 & 12 & 7 & 2 \\
\hline 21 & 16 & 11 & 6 & 1 \\
\hline
\end{tabular}


3. Bottom Zigzag: Começamos a verificação do ponto inferior esquerdo (origem da malha, ponto $(0,0))$, avançando uma unidade no eixo $x$ até alcançar o ponto inferior direito. Recomeçamos a verificação uma posição acima no eixo $y$, recuando uma unidade no eixo $x$ até chegar em $x$ igual a zero. Esse processo é repetido, avançando uma unidade no eixo $y$, até que se encontre uma posição para alocação do item ou até percorrer toda a matriz.

\begin{tabular}{|c|c|c|c|c|}
\hline 21 & 22 & 23 & 24 & 25 \\
\hline 20 & 19 & 18 & 17 & 16 \\
\hline 11 & 12 & 13 & 14 & 15 \\
\hline 10 & 9 & 8 & 7 & 6 \\
\hline 1 & 2 & 3 & 4 & 5 \\
\hline
\end{tabular}

4. Spiral: Neste caminho os pontos são percorridos formando um caminho em torno do ponto central da matriz. Este caminho parte do ponto inferior esquerdo, avançando uma unidade no eixo $x$ até alcançar o ponto inferior direito. Em seguida, o caminho sobe uma unidade no eixo $y$, até alcançar o ponto superior direito. Do ponto superior direito, recuamos uma unidade do eixo $x$ até chegar no ponto superior esquerdo. A partir do ponto superior esquerdo reduzimos uma unidade do eixo $y$ até alcançar o ponto $(0,1)$, uma unidade do eixo y acima do, ponto inferior esquerdo. Este caminho é repetido até alcançar o ponto central da matriz.

\begin{tabular}{|c|c|c|c|c|}
\hline 13 & 12 & 11 & 10 & 9 \\
\hline 14 & 23 & 22 & 21 & 8 \\
\hline 15 & 24 & 25 & 20 & 7 \\
\hline 16 & 17 & 18 & 19 & 6 \\
\hline 1 & 2 & 3 & 4 & 5 \\
\hline
\end{tabular}

\subsubsection{Análise de complexidade das heurísticas}

Algumas considerações sobre o Algoritmo 1 são importantes. O algoritmo encontra uma solução factível? Quanto tempo computacional o algoritmo consome ao resolver uma instância do problema?

Uma solução é dita factível se todos os itens podem ser empacotados nos recipientes, formando um leiaute com todos os itens empacotados. Se tivermos numItens recipientes, o Algoritmo 1 encontrará uma solução factível. No entanto, isto não é uma condição necessária, mas, com uma quantidade menor de recipientes, não podemos afirmar a priori se o Algoritmo 1 será capaz de encontrar uma solução factível. 
A segunda pergunta, referente ao tempo computacional, é uma pergunta fundamental da análise de algoritmos. Faremos a análise assintótica do pior caso. Esta análise faz uma estimativa de quantas operações elementares, no máximo, são necessárias para executar o algoritmo. Faremos a análise das heurísticas sobre o Algoritmo 1, dado que a única diferença entre as heurística deste trabalho acontece na linha 4. Podemos fazer isso, pois a busca da posição factível, feita na linha 4 do algoritmo é praticamente a mesma em todas as heurísticas. O número de operações na linha 4 é, no máximo, o número de elementos da matriz que representa o recipiente.

O laço principal (linhas 1-7) é executado $m$ vezes, enquanto o laço secundário, linhas 2-7, é executado para todos os itens (numItens). Na linha 3 temos um laço condicional (linhas 3-7), para verificar se a quantidade de cópias do item é maior do que zero. $\mathrm{Na}$ linha 4, as heurísticas buscam, na malha de pontos de um recipiente $j$, uma posição $(x, y)$ e alguma rotação para inserir o item no recipiente. A quantidade de pontos do recipiente $j$ é igual à largura (width $[j]$ ) e altura (height $[j]$ ) dividido pelo tamanho da discretização. Vamos denominar a quantidade de pontos por $p$. Assim a complexidade da linha 4 é limitada por $\mathscr{O}(r \cdot p)$ operações.

O laço condicional das linhas 5-7 é satisfeito numItens vezes. Na linha 7 a malha de pontos é atualizada e o número de operações é limitado por $\mathscr{O}(n \cdot r \cdot p)$. Na linha 8 o Algoritmo 1 é finalizado, retornando a solução encontrada. Podemos concluir, depois da análise de cada linha, que a complexidade assintótica do Algoritmo 1 é dada por $\mathscr{O}(m \cdot$ numItens $\cdot n \cdot r \cdot p)$ operações. A parte mais cara do Algoritmo 1 é a atualização de todas as malhas (linha 7).

\subsection{Método de resolução}

Nesta seção apresentamos o método de resolução para o problema de corte de itens irregulares em recipientes. Esse método, apresentado no Algoritmo 2, gerencia as heurísticas apresentas na Seção 4.2, modificando a ordem de inserção dos itens e armazenando a melhor solução obtida. O Algoritmo 2 recebe a quantidade de heurísticas $(h)$ e o conjunto das heurísticas $(H)$, além dos parâmetros $\sigma$ e $\varepsilon$, a quantidade $(n)$ e lista de itens e a quantidade $(m)$ e lista recipientes. Por fim, o Algoritmo 2 recebe as malhas de pontos $\left(M_{j, i, k}\right)$ e as malhas dos no-fit polygons $\left(N F i_{f}, r_{f}, i_{o}, r_{o}\right)$

O Algoritmo 2 descreve o método de resolução deste trabalho. Primeiramente, o algoritmo calcula o somatório da demanda de todos os tipos de itens (numItens), ordena de forma crescente a lista de itens por suas áreas e inicializa a lista tabu, responsável por armazenar as ordenações de itens que já foram utilizadas pelas heurísticas. Como nossas heurísticas são construtivas e dependem basicamente da ordenação dos itens, a lista tabu impede que uma sequência 


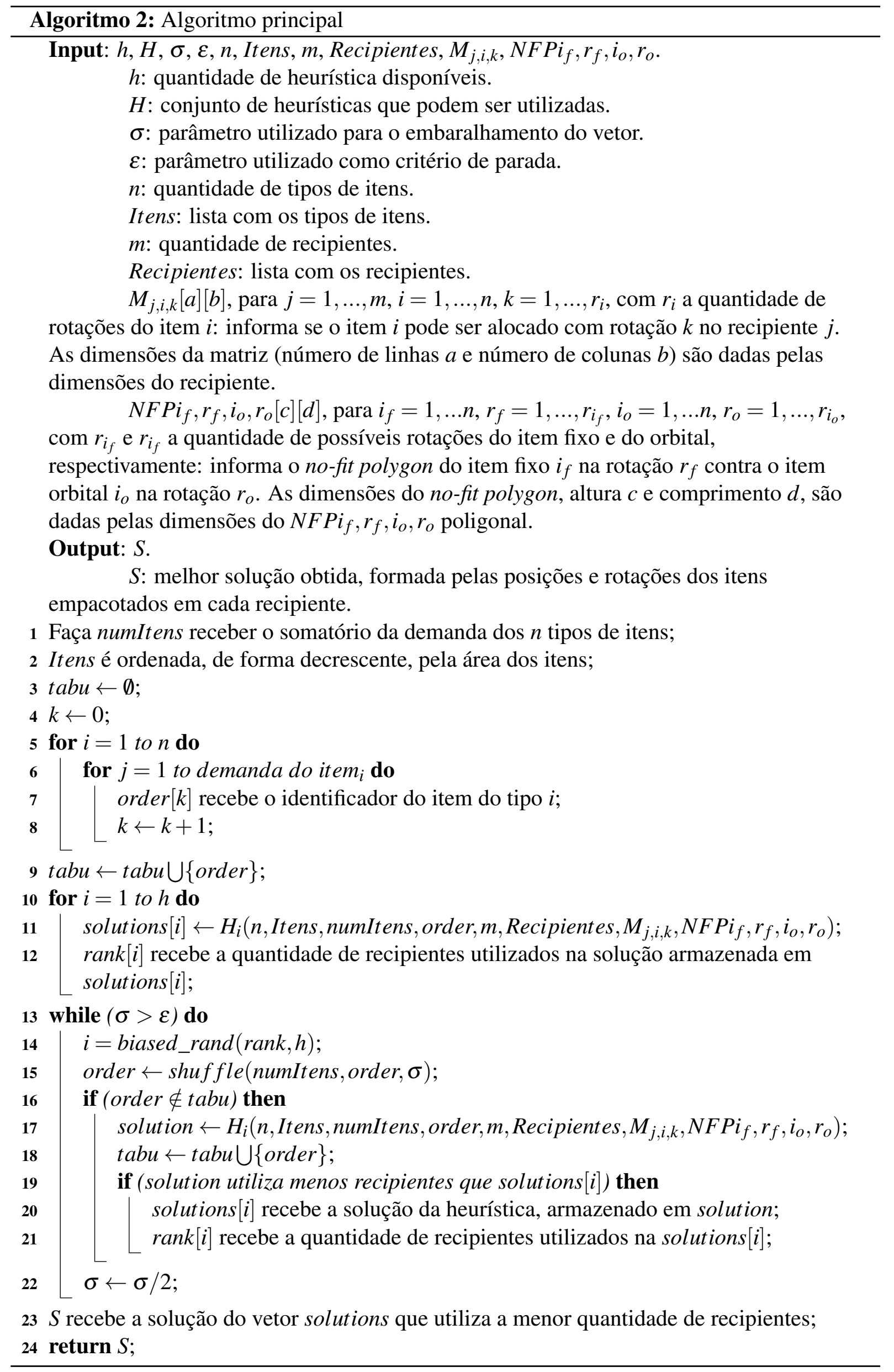


já avaliada seja repetida. O vetor order, de tamanho numItens, armazena a sequência em que os itens são alocados no recipiente, cada posição do vetor recebe um identificador para cada tipo de item. A função shuffle embaralha o vetor order (esta função será discutida adiante). $\mathrm{O}$ vetor de soluções, solutions, armazena as melhores soluções de cada heurística até o momento, enquanto a quantidade de recipientes desta solução é armazenada na posição correspondente do vetor rank.

As informações dos vetores solutions e rank são preenchidas executando uma vez cada uma das heurística. Estas informações são relevantes para selecionar a próxima heurística, por meio da função biased_rand, que favorece as heurísticas que obtiveram melhores resultados. A cada iteração do Algoritmo 2 uma heurística $i$ é escolhida pela função biased_rand e o vetor order é novamente embaralhado. Caso o vetor order não tenha sido avaliado, a $i$-ésima heurística é executada e a lista tabu recebe o vetor order. Se a solução encontrada for melhor que a solução armazenada em solutions $[i]$, a posição $i$ dos vetores solutions e rank são atualizadas. Isso acontece enquanto o valor de $\sigma$ for menor que o parâmetro $\varepsilon$. O Algoritmo 2 retorna a melhor solução obtida, formada pelas posições e rotações dos itens empacotados em cada recipiente.

Devemos, após a descrição do Algoritmo 2, chamar a atenção para a forma como o vetor order é embaralhado, função shuffle, e na forma como uma heurística é escolhida, função biased_rand.

A função shuffle, apresentada no Algoritmo 3, recebe um vetor seq_priv e devolve um vetor order, com os elementos de seq_priv embaralhados. A forma com que o vetor é embaralhado privilegia uma sequência pré-definida (seq_priv) e depende do valor do parâmetro $\sigma$ que, quanto mais próximo de zero, faz com que a sequência em order esteja mais próxima da sequência de seq_priv.

O Algoritmo 3 ilustra a função shuffle. A função rand_normal sorteia um número inteiro entre 1 e numItens seguindo uma distribuição normal com média $i$ e desvio padrão $\sigma$. O vetor order inicializa com todas as posições recebendo -1. O Algoritmo 3, então, percorre o vetor seq_priv e, para cada elemento, sorteia uma nova posição para este elemento no vetor order, seguindo uma distribuição normal. Quando a nova posição já é ocupada por outro elemento, procura-se a posição mais próxima a ela para inserir o elemento.

A sequência privilegiada (seq_priv) é a mesma para todas as heurísticas e foi escolhida a partir da revisão bibliográfica e de experimentos computacionais. Esta sequência é definida ordenando os itens, em ordem decrescente, pela área. Este é um dos critérios de ordenação proposto em Oliveira et al. (2000). 


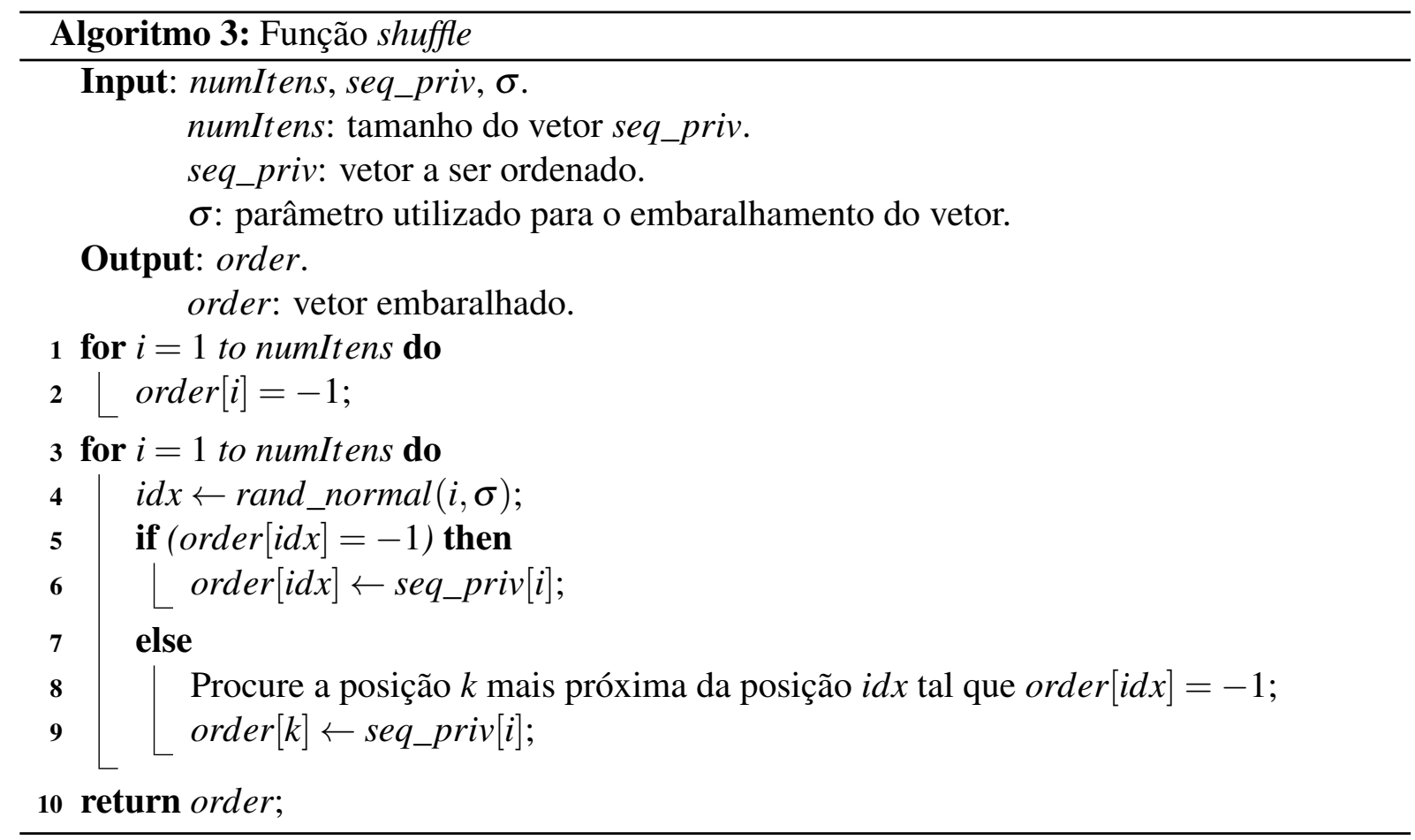

A função biased_rand retorna uma heurística escolhida. Essa função recebe o vetor rank, de tamanho $h$, que armazena, para cada posição $i$, a quantidade de recipientes utilizados pela melhor solução da heurística $i$ (lembrando que o objetivo do problema estudado é minimizar a quantidade de recipientes). Assim, utilizamos as informações do vetor rank para privilegiar as heurísticas com melhores resultados. O Algoritmo 4 descreve esta função. Criamos um vetor best cujos elementos são os índices de rank percorrido em ordem crescente, ou seja, os melhores resultados nas primeiras posições. Em seguida, definimos $i=1$ e escolhemos a heurística best $[i]$ com probabilidade de $50 \%$. Se esta heurística não for escolhida, repetimos o processo com $i \leftarrow i+1$, até que uma heurística seja escolhida (se $i=h$ e nenhuma heurística tiver sido escolhida, escolhemos a heurística best $[h]$ ). Na linha 3 do Algoritmo 4, a função rand_uniforme gera um número inteiro aleatório com distribuição uniforme. 


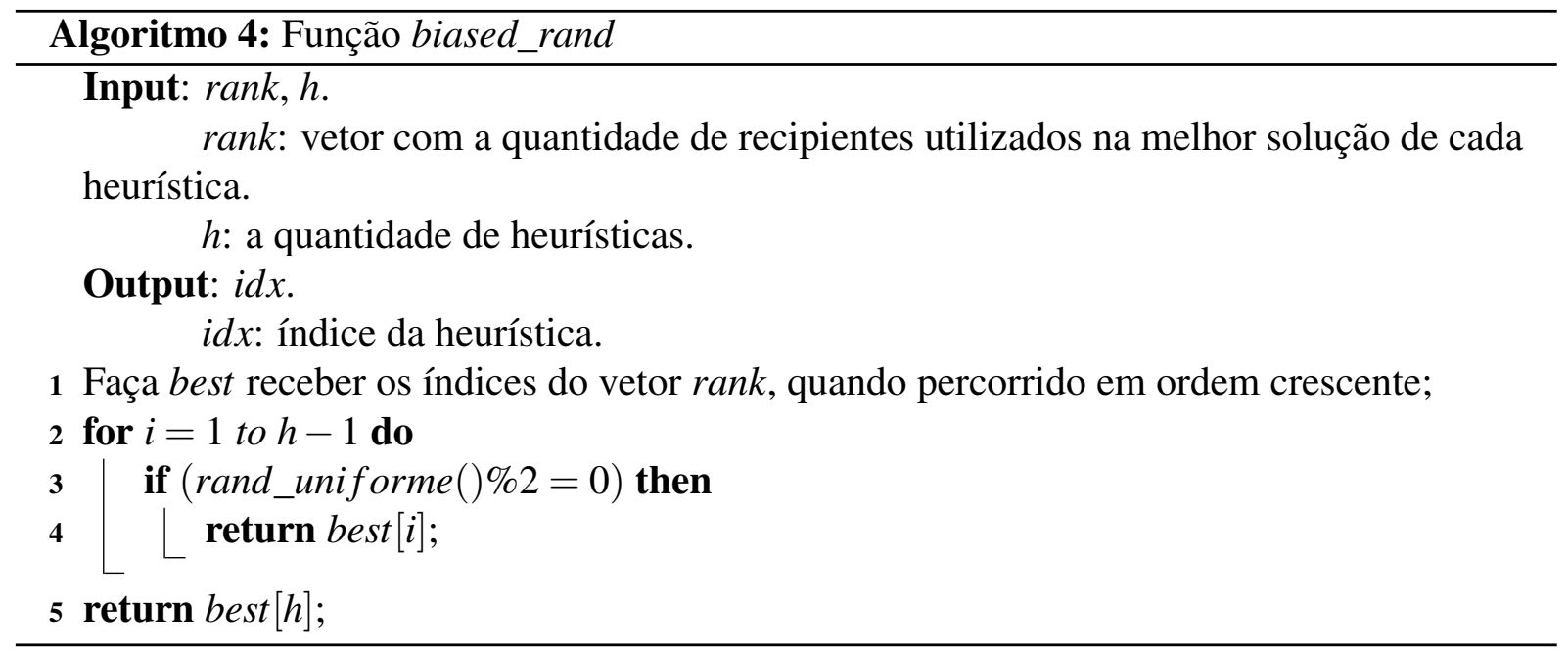




\section{CAPÍtulO 5}

\section{IMPLEMENTAÇÃO}

O objetivo deste capítulo é apresentar a estrutura desenvolvida para armazenar os dados do problema estudado, que pode ser facilmente adaptada para diversos problemas de corte de itens irregulares. Toda a estrutura foi implementada em linguagem $\mathrm{C}$, bem como os algoritmos para criação de no-fit polygons apresentados na Seção 2.2.1 e as heurísticas apresentadas no Capítulo 4.

Para resolver o problema estudado, precisamos definir as características dos itens e dos recipientes. Cada item possui um ponto de referência, uma lista de cópias associadas (demanda), uma lista de rotações permitidas e um conjunto de polígonos convexos. Cada recipiente é formado por uma altura, uma largura, uma malha de posições factíveis e uma lista de defeitos (representados por polígonos convexos). Definidos os itens e os recipientes, a solução é dada por uma lista com as localizações dos itens nos recipientes.

Criamos uma estrutura de dados para armazenar os dados de forma organizada. A estrutura proposta é composta por seis estruturas independentes, que serão apresentadas nas próximas seções. A Seção 5.1 faz algumas considerações sobre algumas estruturas de dados mais simples (_polygon e _point). Na Seção 5.2, apresentamos as estruturas que armazenam os itens e os no-fit polygons (_item e _NFP) e, na Seção 5.3, as que representam os recipientes (_bin e _solution). A Figura 5.1 apresenta a relação destas estruturas. Na Seção 5.4, temos uma visão geral de como é feita a entrada e a saída de dados. 


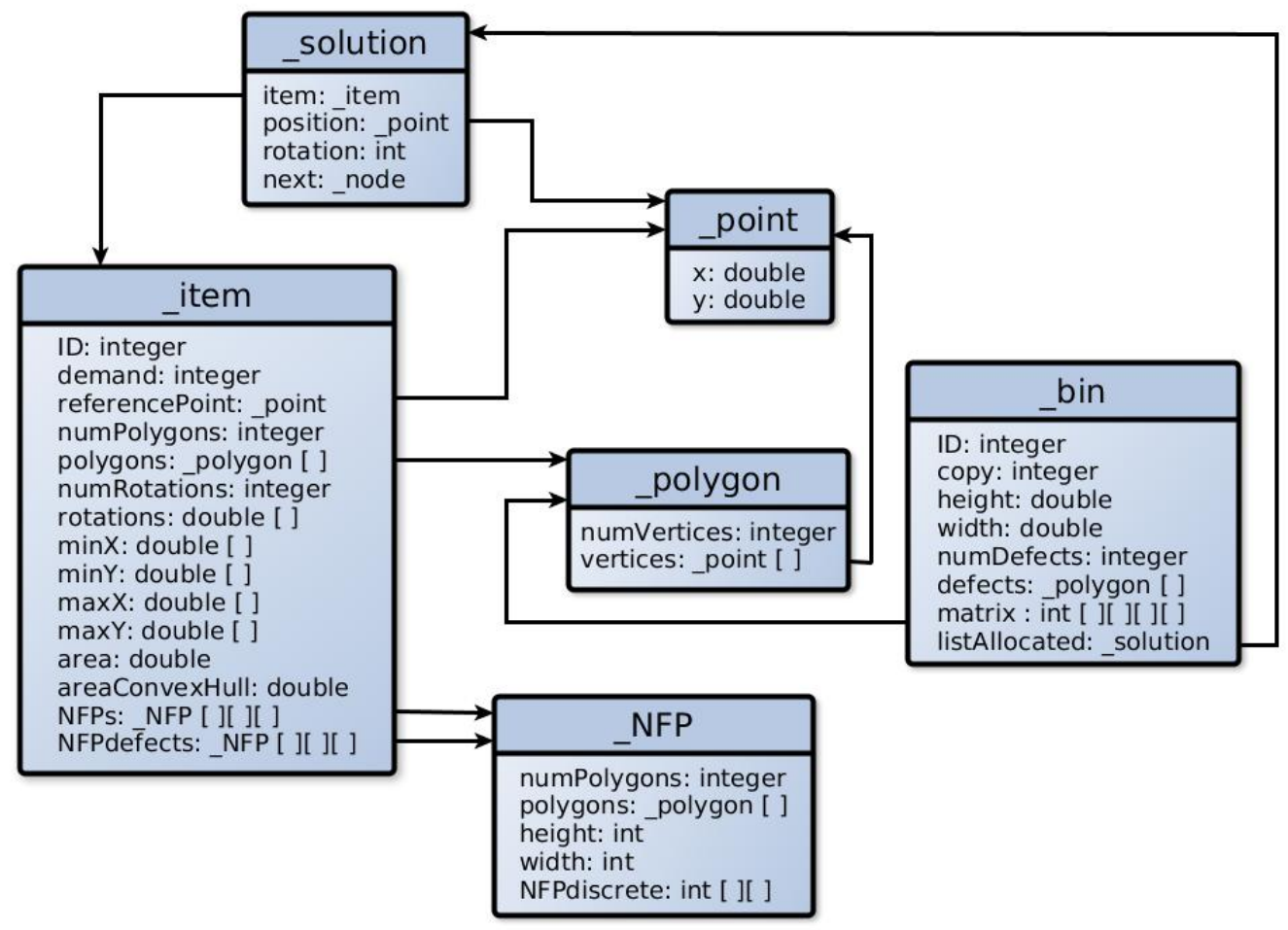

Figura 5.1: Estrutura de dados para armazenamento dos dados do problema, bem como sua solução.

\subsection{Estruturas de dados auxiliares}

Antes de apresentarmos as principais estruturas de dados, que representam os itens e os recipientes, é necessário introduzir algumas estruturas auxiliares. Os vértices, que são dados por coordenadas no plano, são necessários para as estruturas_item,_polygon e _solution. Por isso criamos a estrutura _point, que armazena uma coordenada em $x$ e uma em $y$. A estrutura _polygon armazena os dados de um polígono. A primeira informação é o número de vértices (numVertices) do polígono, seguida pelo vetor dos vértices (vertices) ordenados no sentido horário.

\subsection{Estrutura do item}

Cada item tem seus dados armazenados em uma estrutura _item. Esta estrutura contém o número de identificação (ID) e a quantidade de cópias de um item (demand). Cada item é formado por um número de polígonos convexos (numPolygon). Os polígonos são armazenados no vetor (polygons). O item ainda tem um número de rotações possíveis (numRotations). Estas rotações (em graus) são armazenadas em um vetor (rotations) na ordem fornecida pelo usuário. 
Para a construção do no-fit polygon entre os itens e os defeitos, a alocação do item no recipiente e a verificação de não sobreposição é necessário um ponto de referência. Este ponto de referência é armazenado em referencePoint e sempre é definido pelo primeiro vértice do primeiro polígono do item na leitura de dados.

A partir destas informações, podemos calcular as menores e maiores coordenadas em $x$ e $y$ ( $\min X, \min Y, \max X, \max Y)$ e a área do item (area). Estas informações são necessárias para as heurísticas, apresentadas no Capítulo 4.

Além disso, armazenamos uma lista de todos os no-fit polygon (NFPs) em que o item aparece como item orbital. Esta lista contém o no-fit polygon de todos os itens como itens fixos, ou seja, de todos os itens (incluindo o atual) em todas as rotações, contra o item em questão (orbital). Nesta lista, o item orbital sempre é o item armazenado na estrutura, em todas as suas rotações. Para representar todos estes no-fit polygons utilizamos uma matriz de ponteiros de três dimensões, em que cada dimensão representa as seguintes informações (nesta ordem): rotação do item orbital, qual o item fixo e qual sua rotação.

O no-fit polygon é representado pela estrutura_NFP. Esta estrutura contém o número de polígonos do no-fit polygon (numPolygons). O campo polygons armazena a lista dos polígonos que formam o no-fit polygon. A matriz do no-fit polygon, com dimensões height e width, é armazenada em NFPdiscrete.

Por fim, calculamos ainda uma lista (NFPdefects) de todos os no-fit polygon dos defeitos (itens fixos) contra o item em questão (orbital). Esta lista também é representa usando a estrutura_NFP e contém uma matriz de ponteiros de três dimensões, e cada dimensão representa as seguintes informações: rotação do item em questão, qual o recipiente dos defeitos e qual o número do defeito (item fixo). Os defeitos são numerados pela sua posição na lista de defeitos (defects), na estrutura_bin, recebendo números de 1 até numDefects.

\subsection{Estrutura do recipiente}

Os recipientes são armazenados na estrutura _bin. Cada recipiente recebe um número de identificação (ID), o número de cópias (copy) e suas dimensões - largura (width) e altura (height) - formando os respectivos vértices no plano: (0,0), (width,0), (width, height) e (0, height). Em seguida, o número de defeitos (numDefects), que pode ser zero. Se o número de defeitos for maior que zero, listDefects armazena todos os polígonos que representam os defeitos, com suas posições no recipiente. 
A malha com as posições do recipiente é calculada e armazenada em matrix. As posições factíveis recebem o valor 1 , enquanto as outras posições recebem o valor 0 .

Para armazenar a solução, criamos uma lista com os itens alocados para cada recipiente (listAllocated). Esta lista é representada pela estrutura_solution, que contém o ID de cada item alocado no recipiente (item), sua posição (position) e rotação (rotation). Como esta estrutura é uma lista de itens alocados o campo next aponta para o endereço do próximo item da lista.

\subsection{Entrada e saída de dados}

Definida a estrutura de dados desenvolvida, podemos apresentar como é feita a leitura e a saída dos dados do problema. Esta seção explica como os dados do problema são fornecidos para o programa e, depois de calculada a solução, como esta é fornecida ao usuário.

\subsubsection{Entrada de dados}

Foram definidos, na estrutura de dados, todos os dados necessários para resolver um problema de corte de itens irregulares em recipientes. Estes dados são fornecidos através de arquivos. Um deles armazena os dados gerais do problema e os demais contêm as informações sobre os itens e os recipientes.

Apesar dos no-fit polygons necessários para a resolução do problema poderem ser calculados pelo nosso programa, o usuário tem a possibilidade de fornecer esses dados. A vantagem do usuário fornecer esses dados é que o no-fit polygon calculado por nós é formado por um conjunto de polígonos, mais precisamente, um polígono para cada par de polígonos convexos que fazem parte da representação do item fixo e do item orbital. Se o usuário possuir os dados referentes ao no-fit polygon e o innerfit polygon com uma quantidade menor de polígonos, os cálculos utilizados para verificar a não sobreposição são reduzidos. Cada um dos arquivos será discutido a seguir.

Para exemplificar todos os arquivos de entrada e saída de dados vamos introduzir um caso bastante simples, no qual queremos alocar dois itens utilizando o menor número de recipientes, com dois recipientes disponíveis. Denominamos o exemplo de Toy Problem. Os recipientes foram inspirados em Martins e Tsuzuki (2010) e os itens foram desenvolvidos para facilitar o entendimento. Veja os itens (1 e 2) e os recipientes (A e B) na Figura 5.2. Vale destacar que o item 1 foi dividido em dois polígonos convexos e que o defeito do recipiente B é formado por dois polígonos convexos. 


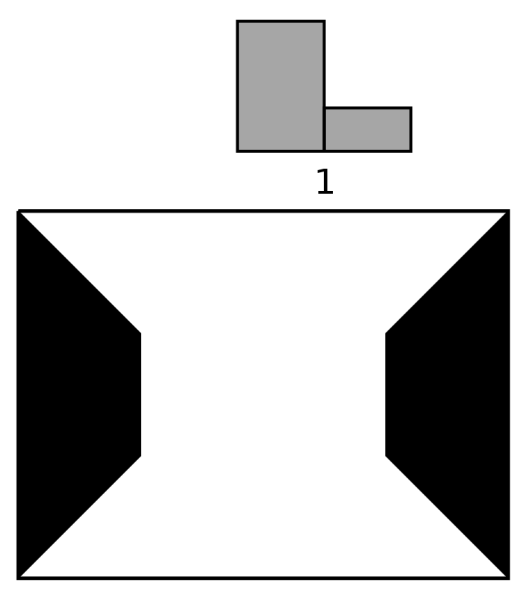

A

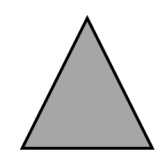

2

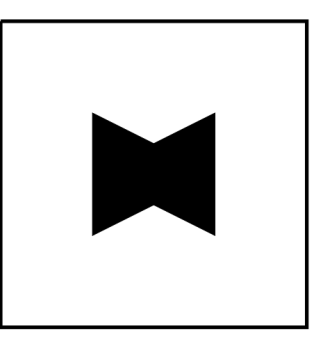

B

Figura 5.2: Representação dos itens (1 e 2) e recipientes (A e B) do Toy Problem.

\section{Dados gerais}

O arquivo general_data.in possui as informações gerais do problema. Ele contém o número de tipos de itens, seguido pelas características de cada tipo. Estas características são o ID, a demanda, o número de rotações permitidas e as rotações (em graus). Além disso, é informado o número de tipos de recipientes, seguido pelo ID e o número de cópias de cada um.

A Figura 5.3 apresenta o arquivo general_data.in para os dados do Toy Problem. As linhas que se iniciam em \# são ignoradas. Como podemos observar, temos dois itens, itens 1 e 2 , com demandas de seis unidades e oito unidades, respectivamente. Além disso, o item 1 possui três rotações possíveis $\left(0^{\circ}, 90^{\circ}\right.$ e $\left.180^{\circ}\right)$ enquanto o item 2 possui duas rotações possíveis $\left(0^{\circ} \mathrm{e}\right.$ $180^{\circ}$ ). Existem dois recipientes, com ID 1 e 2, respectivamente, e uma cópia de cada.

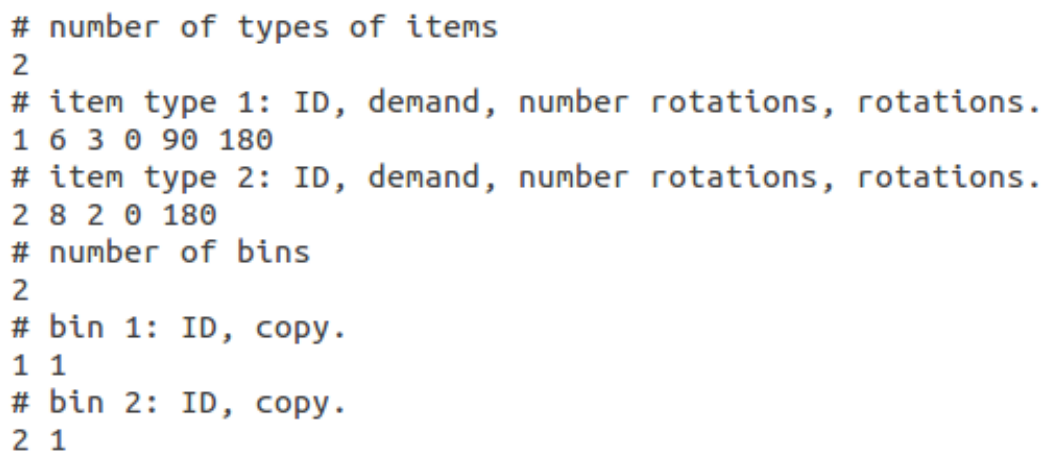

Figura 5.3: Conteúdo do arquivo general_data.in. 


\section{Item}

O nome do arquivo que contém os dados de cada item é definido usando o ID do item, ou seja, o arquivo item_ID $1 D_{1}$.in possui as informações do item com $I D_{1}$. Este arquivo contém o número de polígonos convexos que compõem o item, seguido pelos dados dos polígonos: número de vértices e as coordenadas dos vértices ordenados no sentido horário. A Figura 5.4 ilustra os arquivos com os dados dos itens do Toy Problem.

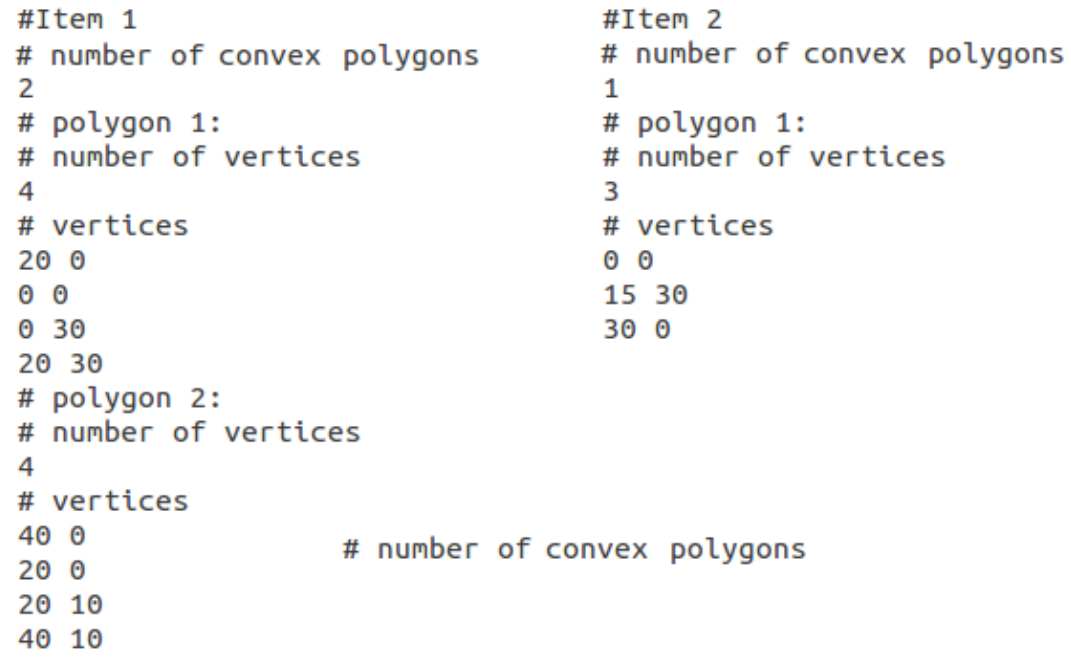

Figura 5.4: Conteúdo dos arquivos item_1.in (lado esquerdo) e item_2.in (lado direito).

Se o usuário necessitar dividir um polígono não convexo em polígonos convexos, implementamos um programa que utiliza o algoritmo de programação dinâmica de Greene. Este algoritmo divide um polígono não convexo no menor número de polígonos convexos possível. Para mais detalhes sobre o algoritmo de Greene veja http://doc.cgal.org/latest/ Partition \_2/index.html.

\section{Recipiente}

O nome dos arquivos que contém os dados dos recipientes são definidos da mesma maneira que o de itens. $\mathrm{O}$ arquivo com os dados do recipiente com o identificador $\mathrm{ID}_{1}$ recebe o nome de bin_ID $D_{1}$ in. Este arquivo possui as dimensões do recipiente - altura (height) e largura (width) - o número de defeitos e a lista dos defeitos. A lista com os defeitos informa a quantidade de vértices e as coordenadas dos vértices no sentido horário, já posicionados no recipiente. Os dados do recipiente A (com ID 1) e do recipiente B (com ID 2) do Toy Problem são apresentados na Figura 5.5.

Todos os defeitos são polígonos convexos. Caso o usuário tenha apenas o contorno do recipientes e defeitos no interior do contorno, adaptamos o algoritmo de Greene para dividir o 

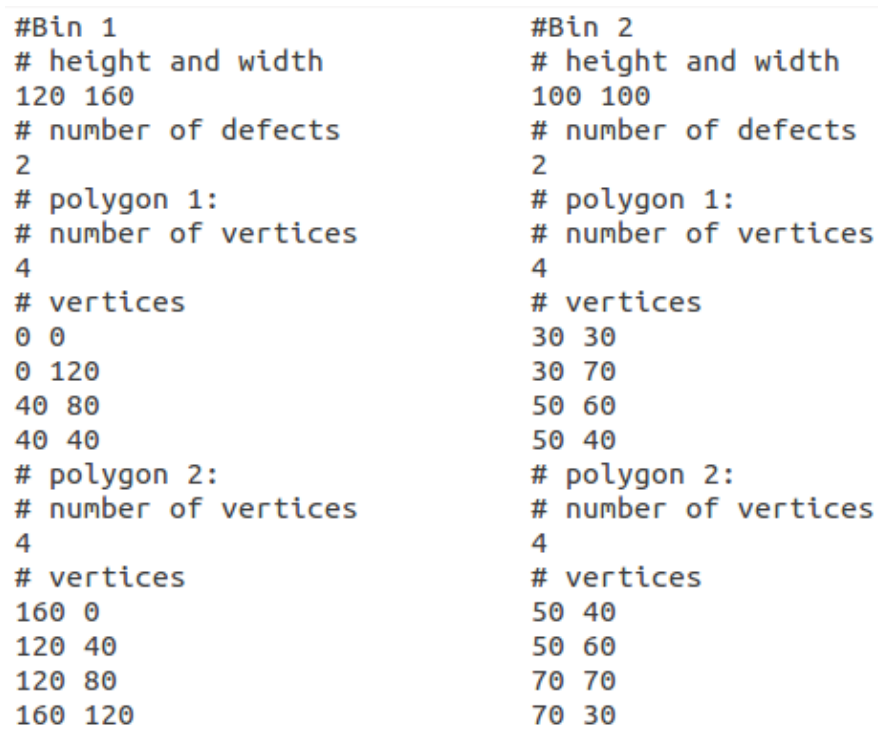

Figura 5.5: Conteúdo dos arquivos bin_l.in (lado esquerdo) e bin_2.in (lado direito).

contorno e as regiões defeituosas em polígonos convexos. A decomposição das regiões defeituosas é idêntica à decomposição dos itens. Já para decompor o contorno, primeiro encontramos o retângulo envolvente do recipiente, formando um polígono com um buraco onde o polígono é o retângulo envolvente e o buraco é o contorno. Em seguida dividimos o polígono com buraco ao meio formando dois polígonos não convexos. Estes dois polígonos são decompostos da mesma maneira que os itens e os defeitos.

\section{no-fit polygon}

Os no-fit polygons necessários para a resolução do problema podem ser fornecidos pelo usuário. Um arquivo com nome $n f p \_I D_{1} \_$rotation ${ }_{1 \_I D_{2} \_r o t a t i o n}$. in possui as informações do no-fit polygon do item fixo $\left(I D_{1}\right)$ com rotation 1 (orientação em graus), contra o item orbital $\left(I D_{2}\right)$ na rotation 2 (rotação em graus). As informações deste arquivo são a quantidade de polígonos convexos do no-fit polygon, seguido por esses polígonos, nesta ordem, com o número de vértices e as coordenadas dos vértices de cada polígono, no sentido horário. A Figura 5.6 apresenta o no-fit polygon do item 1 fixo e o item 2 orbital, ambos com rotação de zero grau, construído pelo nosso programa. Observe que, neste caso, o no-fit polygon é constituído por dois polígonos. O ponto assinalado representa o ponto de referência do polígono orbital.

O usuário poderia fornecer o arquivo para representar o no-fit polygon, como é ilustrado na Figura 5.7. Assim como os itens e os defeitos, os no-fit polygons devem ser compostos por um conjunto de polígonos convexos. Caso o usuário prefira, pode utilizar novamente o programa implementado com a biblioteca CGAL para decompor o no-fit polygon em polígonos convexos. 


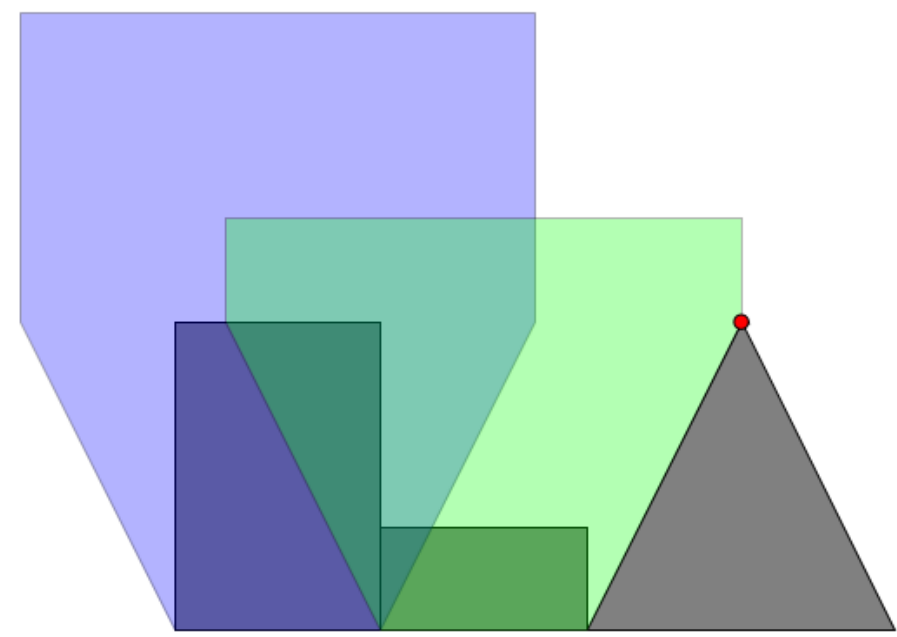

Figura 5.6: no-fit polygon do item 1 (fixo) e o item 2 (orbital) do Toy Problem.

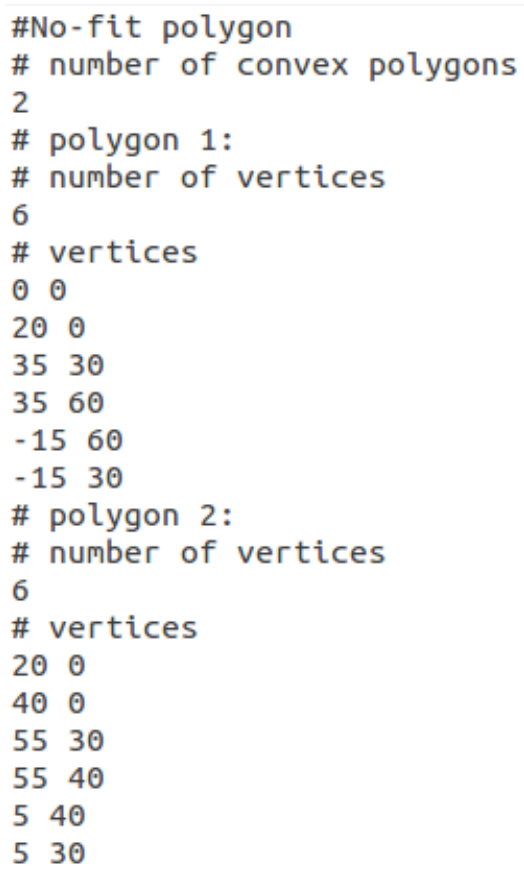

Figura 5.7: Conteúdo do nfp_1_0_2_0.in. 


\section{no-fit polygon dos defeitos}

Se o recipiente possui defeitos, o arquivo NFPdefects_ID $1 \_$defect_ID 2 rotation ${ }_{1}$.in informa a quantidade de polígonos convexos do no-fit polygon do defeito (defect) como item fixo no recipiente $I D_{1}$ contra o item orbital $I D_{2}$ na rotação rotation ${ }_{1}$. O campo defect é o número do defeito. Lembrando que os defeitos são numerados pela sua posição na lista de defeitos (listDefects) recebendo os números de 1 até numberDefects. Os defeitos sempre são os itens fixos, pois eles não podem se movimentar. Cada polígono do no-fit polygon informa o número de vértices e as coordenadas dos vértices no sentido horário.

\subsubsection{Saída de dados}

Após a resolução do problema estudado, encontramos as posições onde cada um dos itens devem ser alocados, as rotações utilizadas e o recipiente em que cada item foi alocado. Estas informações são armazenadas no arquivo solution.out. $\mathrm{O}$ arquivo solution.out apresenta a quantidade de recipientes utilizados para alocar todos os itens, seguida, para cada recipiente utilizado, de uma lista com os itens alocados nele. Esta lista contém o ID do item, o ponto do recipiente onde o ponto de referência do item foi posicionado e a rotação utilizada (nesta ordem). Na Figura 5.8 temos um exemplo do arquivo solution.out para o Toy Problem.

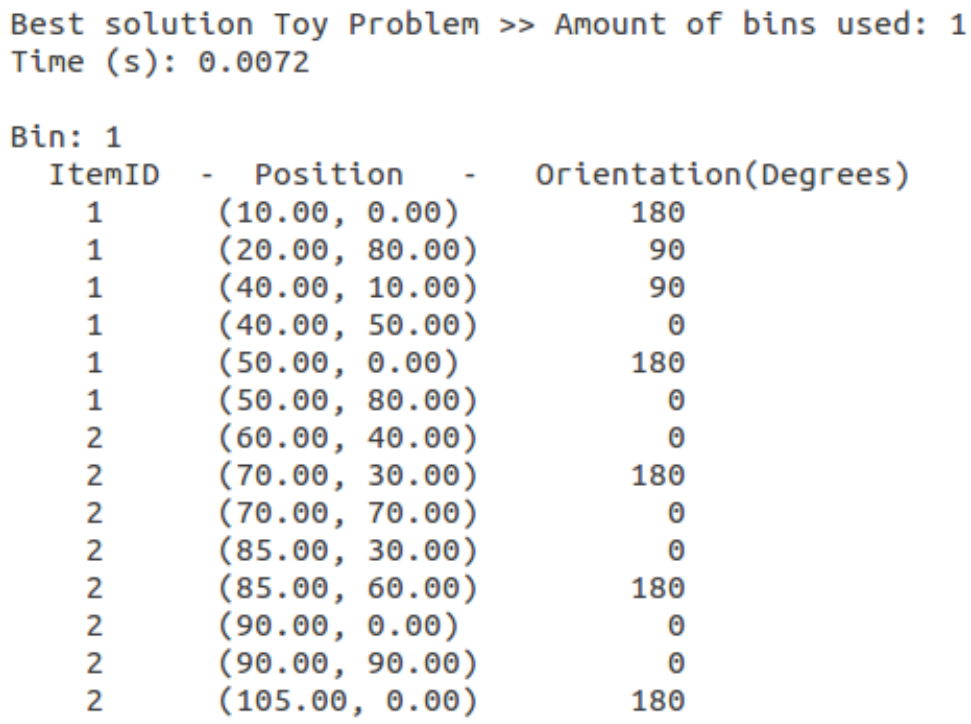

Figura 5.8: Conteúdo do solution.out.

Além disso, é gerado um arquivo solution.tex com o desenho da solução obtida, ou seja, os recipientes utilizados com os itens alocados. Para visualizar o desenho da solução é preciso gerar um arquivo PDF a partir do arquivo solution.tex. A Figura 5.9 apresenta o desenho da solução da instância do Toy Problem. 

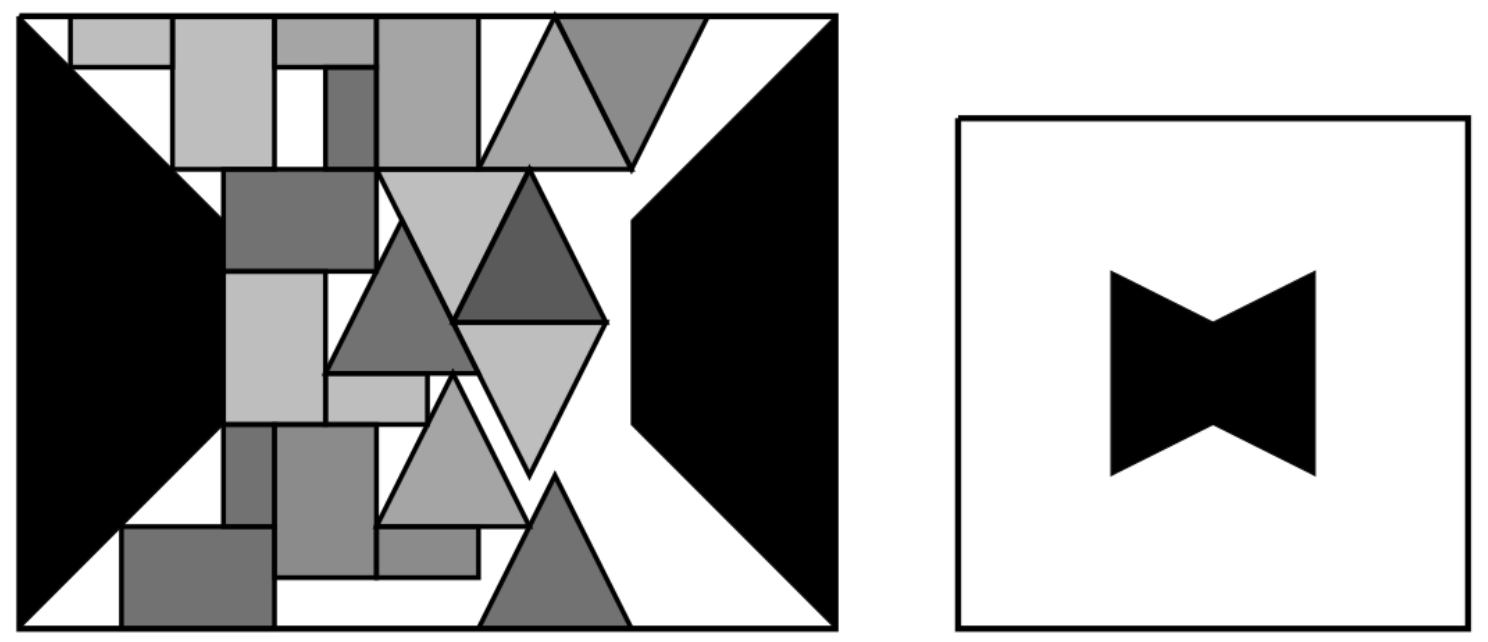

Figura 5.9: Desenho de uma solução obtida para o Toy Problem. 


\section{CAPÍTULO 6}

\section{RESULTADOS NUMÉRICOS}

Neste capítulo apresentamos os experimentos computacionais para o método de resolução apresentado no Capítulo 4, implementado em linguagem $\mathrm{C}$. Todos os experimentos foram feitos em um computador Intel ${ }^{\circledR}$ Xeon ${ }^{\circledR}$ de $2.40 \mathrm{GHz}$ e $32 \mathrm{~GB}$ de memória no sistema operacional Linux Ubuntu 12.04.1. Os experimentos estão divididos em três seções. Na Seção 6.1, apresentamos os experimentos para o corte de itens irregulares em recipientes retangulares. $\mathrm{Na}$ Seção 6.2, apresentamos os experimentos para o corte de itens irregulares em recipientes irregulares. Por fim, na Seção 6.3 apresentamos alguns experimentos extras, para o problema da mochila ilimitada e mochila 0-1 onde temos uma lista de itens para empacotar em um único recipiente (ou mochila).

\subsection{Corte de itens irregulares em recipientes retangulares}

Para resolver o problema de corte de itens irregulares em recipientes retangulares, escolhemos os conjuntos de instâncias ${ }^{1}$ Terashima 1 e Terashima 2. Na Seção 6.1.1 descrevemos as instâncias utilizadas e a Seção 6.1.2 apresenta os resultados numéricos do corte de recipientes retangulares.

\footnotetext{
${ }^{1}$ Disponíveis em http://www.fe.up.pt/esicup/
} 


\subsubsection{Instâncias}

Esta seção pretende fornecer uma visão geral dos conjuntos de instâncias Terashima 1 (proposta em Terashima-Marín et al. (2010)) e Terashima 2 (proposta em López-Camacho (2012)). Estas instâncias são artificiais e foram criadas a partir de um algoritmo aleatório. Em linhas gerais, esse algoritmo recebe uma quantidade de recipientes e uma quantidade de itens. A partir dessas informações, o algoritmo gera cortes aleatórios nos recipientes, que são quadrados de lado mil, para obter os itens da instância. Em geral, uma instância possui encaixe perfeito e a quantidade mínima de recipientes é conhecida. A Figura 6.1 representa uma instância com três recipientes e nove itens.
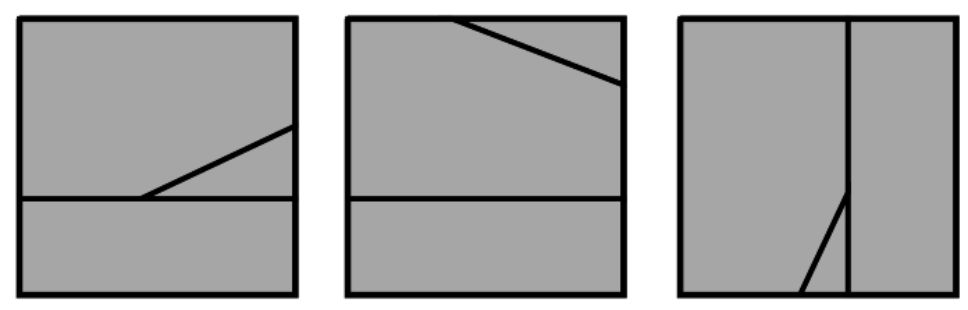

Figura 6.1: Exemplo baseado em uma instância Terashima com três recipientes e nove itens.

Os dois conjuntos, Terashima 1 e Terashima 2, são divididos em classes. Apenas uma classe de instâncias (Conv G) foi criado para ter uma solução desconhecida. O procedimento adotado para essa instância foi semelhante ao descrito acima, com a diferença de que alguns itens gerados são desconsiderados. Para mais detalhes, veja López-Camacho (2012).

Cada classe de instância possui 30 instâncias diferentes geradas de forma aleatória com uma quantidade de itens e de recipientes definida. Esses dados estão apresentados na Tabela 6.1. No total, o conjunto Terashima 1 contém 540 instâncias formadas por itens convexos e o conjunto Terashima 2 contém 480 instâncias formadas por itens convexos e não convexos.

Como as instâncias da classe Conv G retira alguns itens da instância, a quantidade de recipientes utilizadas para criar os itens é um limitante superior. Neste caso, foram usados 15 recipientes (LÓPEZ-CAMACHO et al., 2013).

\subsubsection{Resultados numéricos}

Nesta seção apresentamos os resultados obtidos pelo método de resolução proposto neste trabalho (descrito no Algoritmo 2 do Capítulo 5), que chamamos de Método de Resolução de Corte de Múltiplos Recipientes (MRCMR), para o corte de itens irregulares em recipientes retangulares. Para os experimentos computacionais utilizamos uma discretização 1:1, ou seja, 


\begin{tabular}{|c|c|c|c|c|c|}
\hline \multicolumn{3}{|c|}{ Terashima 1 } & \multicolumn{3}{c|}{ Terashima 2 } \\
\hline Classe & Número de itens & Número de recipientes & Classe & Número de itens & Número de recipientes \\
\hline Conv A & 30 & 3 & NConv A & $35-50$ & 3 \\
\hline Conv B & 30 & 10 & NConv B & $40-52$ & 10 \\
\hline Conv C & 36 & 6 & NConv C & $42-60$ & 6 \\
\hline Conv D & 60 & 3 & NConv F & $35-45$ & 2 \\
\hline Conv E & 60 & 3 & NConv H & $42-60$ & 12 \\
\hline Conv F & 30 & 2 & NConv L & $35-45$ & 3 \\
\hline Conv G & 36 & $\leq 15$ & NConv M & $45-58$ & 5 \\
\hline Conv H & 36 & 12 & NConv O & $33-43$ & 7 \\
\hline Conv I & 60 & 3 & NConv S & $17-20$ & 2 \\
\hline Conv J & 60 & 4 & NConv T & $30-40$ & 10 \\
\hline Conv K & 54 & 6 & NConv U & $20-33$ & 5 \\
\hline Conv L & 30 & 3 & NConv V & $15-18$ & 5 \\
\hline Conv M & 40 & 5 & NConv W & $24-28$ & 3 \\
\hline Conv N & 60 & 2 & NConv X & $25-39$ & 6 \\
\hline Conv O & 28 & 7 & NConv Y & $40-50$ & 12 \\
\hline Conv P & 56 & 8 & NConv Z & 60 & \\
\hline Conv Q & 60 & 15 & & & \\
\hline Conv R & 54 & 9 & & & \\
\hline
\end{tabular}

Tabela 6.1: Dados das instâncias de Terashima 1 e Terashima 2.

utilizamos as mesmas escalas das instâncias originais. Os parâmetros $\sigma$ e $\varepsilon$ receberam os valores 1 e 0.01 , respectivamente. Estes parâmetros foram determinados por testes computacionais.

A Tabela 6.2 apresenta os resultados para o conjunto de instância de Terashima 1. Para facilitar a análise, agrupamos as instâncias por classes. As linhas da Tabela 6.2 representam um resumo dos resultados obtidos por MRCMR na resolução das 30 instâncias de cada classe do conjunto Terashima 1. A coluna ótimo na Tabela 6.2 apresenta a quantidade mínima de recipientes necessária para resolver cada classe de instância. Os resultados reportados são a quantidade mínima, máxima e média de recipientes na solução obtida por MRCMR para cada classe de instância (a média receve o somatório da quantidade de recipiente das 30 instâncias da classe divido por 30) e tempos mínimo, máximo e médio (em segundos) para obter as soluções (médio recebe a soma do tempo das 30 instâncias da classe divido por 30).

Podemos observar que o resultado do MRCMR para o conjunto de instâncias de Terashima 1 está próximo da solução ótima. Em geral, a quantidade mínima de recipientes utilizados está à uma unidade do ótimo, o que acontece em 13 dos 18 conjuntos de instâncias de Terashima 1. A média da quantidade de recipientes utilizados pelo MRCMR está entre uma e três unidades acima do ótimo, em apenas dois casos está próximo de quatro unidades, para as instâncias Conv $\mathrm{P}$ e Conv $\mathrm{Q}$.

Como pode ser observado na Tabela 6.2, o tempo médio gasto pelo MRCMR é inferior a 10 minutos para a maioria dos casos. Mas, para as instâncias com o maior número de recipientes 


\begin{tabular}{|r|r|r|r|r|r|r|r|}
\hline \multirow{2}{*}{ Classe } & \multirow{2}{*}{ Ótimo } & \multicolumn{9}{|c|}{ Quantidade de recipientes na solução encontrada } & \multicolumn{3}{|c|}{ Tempo gasto na solução encontrada } \\
\cline { 3 - 8 } & & Mínima & Máxima & Média & Mínimo & Máximo & Médio \\
\hline Conv A & 3 & 4 & 5 & 4,07 & 170,7 & 186,1 & 178,9 \\
\hline Conv B & 10 & 11 & 16 & 12,50 & 270,3 & 299,5 & 285,2 \\
\hline Conv C & 6 & 7 & 9 & 7,90 & 305,8 & 347,2 & 324,7 \\
\hline Conv D & 3 & 4 & 5 & 4,37 & 576,2 & 603,8 & 587,1 \\
\hline Conv E & 3 & 5 & 6 & 5,43 & 626,6 & 742,4 & 691,5 \\
\hline Conv F & 2 & 3 & 4 & 3,03 & 146,5 & 166,9 & 159,8 \\
\hline Conv G & 15 & 13 & 18 & 15,80 & 386,5 & 431,8 & 407,6 \\
\hline Conv H & 12 & 13 & 17 & 15,07 & 385,4 & 419,3 & 406,0 \\
\hline Conv I & 3 & 4 & 4 & 4,00 & 455,8 & 472,2 & 465,8 \\
\hline Conv J & 4 & 5 & 6 & 5,03 & 578,2 & 615,3 & 596,9 \\
\hline Conv K & 6 & 7 & 9 & 7,97 & 338,5 & 389,0 & 369,8 \\
\hline Conv L & 3 & 4 & 6 & 4,83 & 186,6 & 222,5 & 202,6 \\
\hline Conv M & 5 & 6 & 9 & 7,53 & 346,4 & 413,8 & 380,8 \\
\hline Conv N & 2 & 3 & 3 & 3,00 & 480,6 & 510,3 & 492,8 \\
\hline Conv O & 7 & 8 & 10 & 8,73 & 216,0 & 254,3 & 235,3 \\
\hline Conv P & 8 & 10 & 12 & 11,13 & 752,4 & 837,6 & 789,8 \\
\hline Conv Q & 15 & 18 & 20 & 18,90 & 1026,4 & 1115,2 & 1072,0 \\
\hline Conv R & 9 & 11 & 12 & 11,47 & 690,9 & 756,8 & 715,8 \\
\hline
\end{tabular}

Tabela 6.2: Resultados da aplicação do MRCMR às instâncias do conjunto Terashima 1.

ótimos (Conv P, Conv Q e Conv R), o tempo usado ultrapassa essa marca. As médias de tempos usados para resolver as instâncias dos conjuntos Conv D, Conv E e Conv J estão bem próximas de 10 minutos. Nestas instâncias, o número de recipientes ótimos é baixa, entre 3 e 4 recipientes, mas a quantidade de itens que devem ser alocados é considerada grande (60 itens). Como esperado, como a discretização é a mesma para todas as instâncias, o tempo do algoritmo cresce conforme aumentamos o número de itens e, principalmente, de recipientes.

A Tabela 6.3 apresenta um resumo dos resultados da aplicação de MRCMR ao conjunto de instância de Terashima 2. As instâncias estão agrupadas por classes e as colunas são as mesmas da Tabela 6.2. A coluna ótimo na Tabela 6.3 apresenta a quantidade mínima de recipientes de cada classe de instância. Os resultados reportados são a quantidade mínima, máxima e média de recipientes na solução obtida por MRCMR para cada classe de instância e tempos mínimo, máximo e médio (em segundos) para obter as soluções.

Como podemos, observar na Tabela 6.3, o resultado do MRCMR para o conjunto de instâncias de Terashima 2 é mais interessante que para o conjunto de instâncias de Terashima 1. Para esse conjunto, MRCMR resolveu 15 instância na otimalidade. O asterisco nas classes de instância destaca aquelas para as quais o MRCMR encontra ao menos uma solução ótima. O tempo médio gasto por MRCMR para resolver os conjuntos de instâncias de Terashima 2 é inferior a 10 minutos para a maioria das conjuntos. Como esperado, os conjuntos com as maiores quantidades de recipientes e itens obtiveram os maiores tempos médios, como pode ser observado 


\begin{tabular}{|r|r|r|r|r|r|r|r|}
\hline \multirow{2}{*}{ Classe } & \multirow{2}{*}{ Ótimo } & \multicolumn{2}{|c|}{ Quantidade de recipientes na solução encontrada } & \multicolumn{3}{|c|}{ Tempo gasto na solução encontrada } \\
\cline { 3 - 8 } & & Mínima & Máxima & Média & Mínimo & Máximo & Médio \\
\hline NConv A & 3 & 4 & 5 & 4,17 & 219,3 & 427,8 & 307,8 \\
\hline NConv B & 10 & 12 & 14 & 13,03 & 435,5 & 797,1 & 627,7 \\
\hline NConv C & 6 & 7 & 9 & 8,17 & 368,3 & 746,9 & 536,8 \\
\hline NConv F & 2 & 3 & 4 & 3,03 & 186,5 & 314,0 & 249,1 \\
\hline NConv H & 12 & 13 & 17 & 15,53 & 499,6 & 982,0 & 703,4 \\
\hline NConv L & 3 & 4 & 6 & 4,97 & 226,2 & 420,7 & 310,1 \\
\hline NConv M & 5 & 7 & 8 & 7,63 & 392,0 & 709,9 & 535,1 \\
\hline NConv O* & 7 & 7 & 10 & 8,90 & 294,1 & 510,9 & 395,7 \\
\hline NConv S* & 2 & 2 & 5 & 3,20 & 60,8 & 106,4 & 84,1 \\
\hline NConv T* & 10 & 10 & 14 & 11,67 & 291,1 & 486,7 & 396,3 \\
\hline NConv U & 5 & 6 & 8 & 7,37 & 106,4 & 292,6 & 198,3 \\
\hline NConv V* & 5 & 5 & 8 & 6,27 & 63,0 & 114,6 & 86,1 \\
\hline NConv W & 4 & 5 & 6 & 5,47 & 135,6 & 186,9 & 161,3 \\
\hline NConv X & 3 & 4 & 5 & 4,53 & 133,1 & 300,2 & 210,3 \\
\hline NConv Y & 6 & 7 & 9 & 8,13 & 375,5 & 581,4 & 472,8 \\
\hline NConv Z & 12 & 13 & 16 & 14,70 & 671,9 & 1111,7 & 983,8 \\
\hline
\end{tabular}

Tabela 6.3: Resultados da aplicação do MRCMR às instâncias do conjunto Terashima 2.

nos conjuntos NConv B, NConv H e NConv Z.

A Figura 6.2 apresenta dois histogramas com o resultado do MRCMR para as instâncias Terashima 1 e Terashima 2. Cada histograma apresenta no eixo y para quantas instâncias o MRCMR resolveu com um número $\mathrm{x}$ de recipientes extras. O gráfico da esquerda mostra $\mathrm{o}$ resultado do MRCMR para 510 instâncias de Terashima 1 (foram retiradas o conjunto de instâncias Conv G) e o gráfico da direita apresenta o resultado do MRCMR para todas as 480 instâncias de Terashima 2.
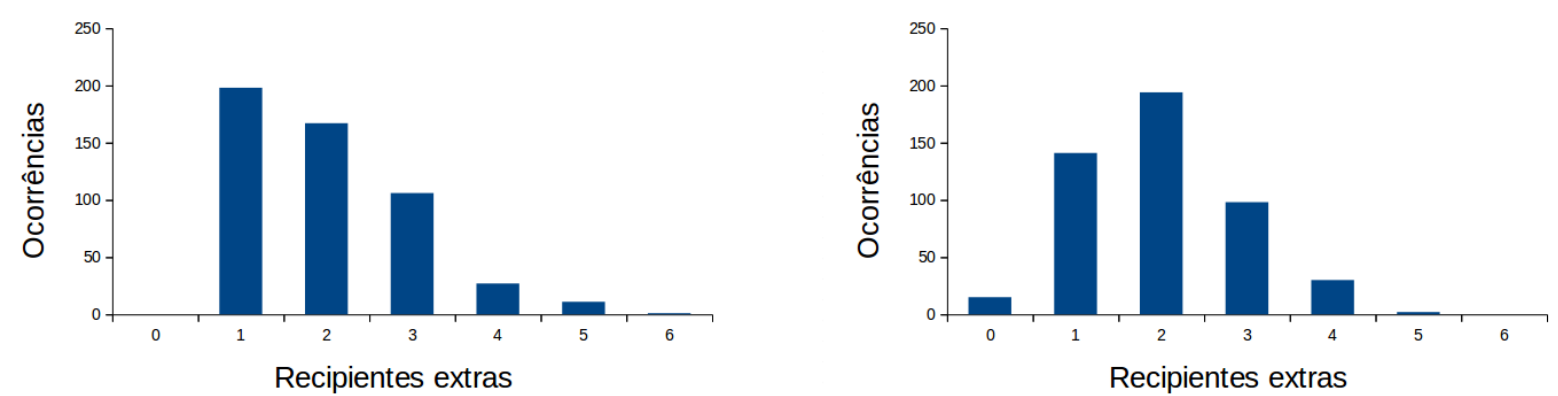

Figura 6.2: Histograma dos resultados do MRCMR para os conjuntos de instâncias Terashima 1 (lado esquerdo) e Terashima 2 (lado direito).

Podemos observar que para o conjunto de instâncias de Terashima 1, MRCMR obtém um número maior de instâncias que utilizam um recipientes a mais que o ótimo e que esse número reduz até chegar em uma instância onde o MRCMR utiliza seis recipientes a mais. Para o conjunto de instâncias de Terashima 2, MRCMR obtém um pequeno número de soluções ótimas e apresenta soluções mais próximas do ótimo. Além disso, MRCMR não uti- 
liza seis recipientes extras para nenhuma instância. O desenho das soluções ótimas estão no Apêndice A. Um arquivo PDF com o desenho de todas as soluções esta disponível na página http:www.icmc .usp.br/pessoas/andretta/mundim-2015/terashima/.

\subsection{Corte de itens irregulares em recipientes irregulares}

O corte de múltiplos recipientes irregulares ainda é um problema pouco explorado na literatura. Até onde sabemos, não existem instâncias públicas para o o corte de itens irregulares em recipientes irregulares. Nesta seção apresentamos uma adaptação de instância da literatura (Seção 6.2.1) e em seguida apresentamos os resultados (Seção 6.2.2).

\subsubsection{Instâncias}

Para validar o nosso método de resolução para recipientes irregulares (implementado em MRCMR) adaptamos um conjunto de instâncias do trabalho de Tay e Lee (2002). Neste trabalho os autores propõem um algoritmo genético para o problema da mochila irregular, no qual o valor de cada item é igual à sua área e o objetivo é maximizar a ocupação da mochila irregular. A adaptação é baseada nos experimentos computacionais de Tay e Lee (2002). Cada solução fornece uma lista de itens alocados em uma mochila. Assim, podemos considerar como entrada do nosso algoritmo a lista de itens a serem alocados (defeitos) e uma lista de recipientes idênticos aos recipientes do trabalho citado e, se conseguirmos alocar todos os itens, o MRCMR resolve instâncias com recipientes irregulares e pode ser competitivo.

A seguir temos uma visão detalhada das instâncias. A Figura 6.3 apresenta as instância extraídas de Tay e Lee (2002). Definimos os nomes de cada mochila como Tay1, Tay2, Tay3, Tay4 e Tay5, logo abaixo do desenho da mochila com os itens alocados.

Para não resolver instâncias com apenas um recipiente (ou mochila), como Tay e Lee (2002), estendemos nosso conjunto de soluções multiplicando a demanda das instâncias pelos valores de um a cinco. Sendo assim, cada uma das cinco instâncias apresentadas na Figura 6.3 contém cinco variações relacionadas às demanda dos itens. Por exemplo, a instância Tay1 receberá cinco variações, Tay1-j para $j$ de 1 a 5 . A instância Tay1-1 terá o mesmo recipiente da instância Tay1 (da Figura 6.3) com 9 pentágonos. Assim, a instância Tay1-j tem o mesmo recipiente de Tay1, com 9j pentágonos. Todas as instâncias Tay1, Tay2, Tay3, Tay4 e Tay5 seguem a mesma lógica. A instância Tay $i-j$ tem o mesmo recipiente da instância Tay $i$ com a mesma demanda de itens alocados na mochila $i$ multiplicados pelo fator $j$. 


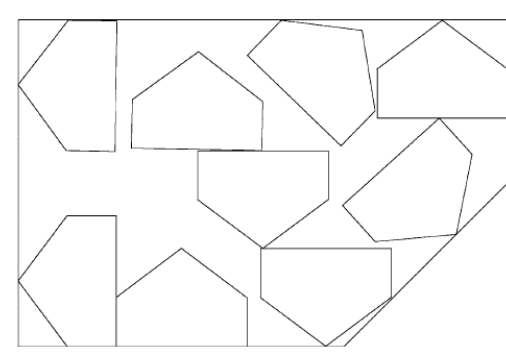

Tay 1

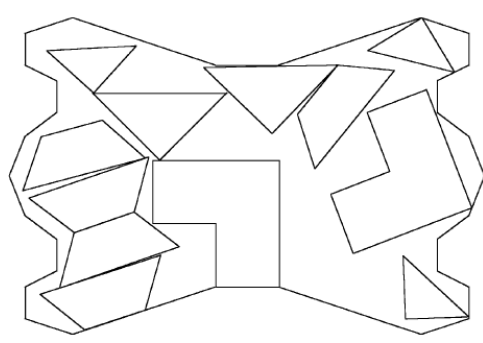

Tay2

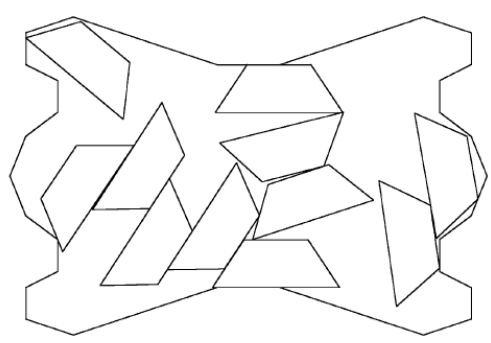

Tay3

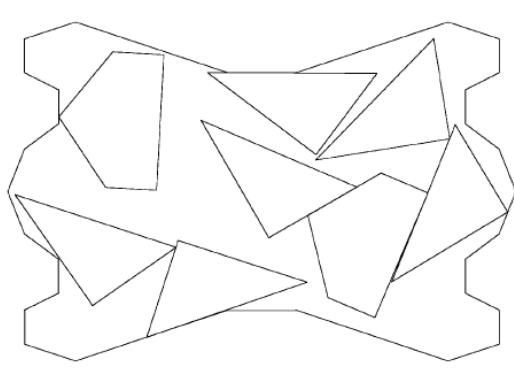

Tay4

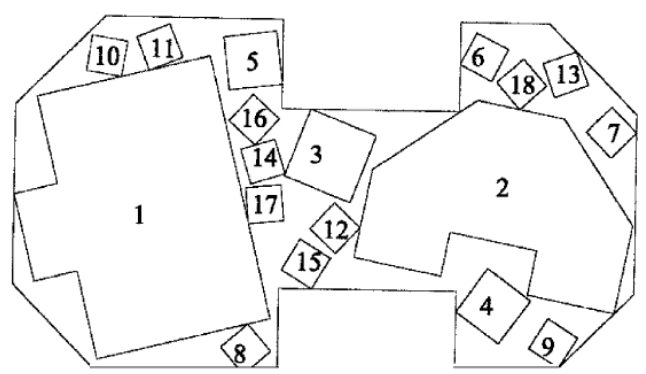

Tay5

Figura 6.3: Extraído de Tay e Lee (2002).

Tay e Lee (2002) considera rotações livres, mas, como nosso método não trata de rotações livres, consideramos rotações de $0^{\circ}, 90^{\circ}, 180^{\circ}$ e $270^{\circ}$. Estas instâncias estão disponíveis na página http: www.icmc.usp.br/pessoas/andretta/mundim-2015/tay/.

\subsubsection{Resultados numéricos}

Nesta seção apresentamos os resultados obtidos pelo MRCMR para o corte de itens irregulares em recipientes irregulares. Para os experimentos computacionais utilizamos a mesma discretização das instâncias originais, 1:1. Os parâmetros $\sigma$ e $\varepsilon$ receberam os valores 1000 e $10^{-5}$, obtidos por testes de calibração. Quanto maior a diferença entre os parâmetros $\sigma$ e $\varepsilon$, mais iterações o MRCMR realiza. A diferença entre os valores utilizados, para $\sigma$ e $\varepsilon$, para instância de Tay e Lee (2002) e os conjuntos de Terashima 1 e Terashima 2 está relacionada com o tamanho das instâncias. Enquanto todos os recipientes de Terashima 1 e Terashima 2 são $1000 \times 1000$, os três recipientes das instâncias apresentadas na Figura 6.3 são: $80 \times 120$, $100 \times 120$ e $80 \times 140$. Isso permite que o MRCMR faça mais iterações para malhas menos precisas (mais grossas), visto que o custo computacional do método é dependente da discretização. Ao fazer mais iterações com MRCMR, exploramos melhor o espaço de soluções do método, possibilitando encontrar soluções melhores.

Na Tabela 6.4 apresentamos os resultados do MRCMR para as instâncias Tay $i$ - $j$. As linhas da Tabela 6.4 representam as mochilas de cada instância $i$, enquanto as colunas mostram as cinco variações da demanda de itens $j$. Os resultados reportados para cada instância Tay $i$ - $j$ 
são a quantidade de recipientes utilizados (coluna Bins) e o tempo gasto em segundos (coluna Tетро).

\begin{tabular}{|r|r|r|r|r|r|r|r|r|r|r|}
\hline \multirow{2}{*}{ Tay $i$ - $j$} & \multicolumn{2}{|c|}{$j=1$} & \multicolumn{2}{|c|}{$j=2$} & \multicolumn{2}{|c|}{$j=3$} & \multicolumn{2}{|c|}{$j=4$} & \multicolumn{2}{|c|}{$j=5$} \\
\cline { 2 - 12 } & Bins & Tempo & Bins & Tempo & Bins & Tempo & Bins & Tempo & Bins & Tempo \\
\hline$i=1$ & 1 & 0,2 & 2 & 0,5 & 3 & 1,1 & 4 & 1,9 & 5 & 2,9 \\
\hline$i=2$ & 1 & 0,8 & 2 & 1,1 & $\mathbf{2}$ & $\mathbf{1 , 6}$ & $\mathbf{3}$ & $\mathbf{2 , 2}$ & $\mathbf{4}$ & $\mathbf{2 , 7}$ \\
\hline$i=3$ & 1 & 0,2 & 2 & 0,3 & $\mathbf{2}$ & $\mathbf{0 , 7}$ & $\mathbf{3}$ & $\mathbf{1 , 2}$ & $\mathbf{4}$ & $\mathbf{2 , 2}$ \\
\hline$i=4$ & 1 & 0,5 & 2 & 0,8 & 3 & 1,3 & 4 & 1,9 & 5 & 2,6 \\
\hline$i=5$ & 1 & 0,8 & 2 & 1,3 & 3 & 1,7 & 4 & 2,3 & 5 & 3,0 \\
\hline
\end{tabular}

Tabela 6.4: Resultados da aplicação do MRCMR para as instâncias Tay.

Os resultados mostram que para as cinco mochilas originais de Tay e Lee (2002), as instâncias Tayi-1 (para $i$ de 1 até 5), o MRCMR conseguiu alocar todos os itens utilizando apenas um recipiente considerando quatro rotações. Isso mostra que o nosso algoritmo foi competitivo, conseguindo alocar todos os itens em uma mochila, assim como Tay e Lee (2002), que utiliza rotações livres. Quando multiplicamos à demanda dos itens da mochila $i$ por $j$ (para $j$ de 2 até 5) o MRCMR conseguiu bons resultados, mantendo a proporção de recipientes para as instâncias Tay1- $j$, Tay4- $j$ e Tay5- $j$. Para instâncias Tay2- $j$ e Tay3- $j$, o MRCMR manteve a proporção de recipientes para $j$ igual a 2 e reduziu em uma unidade com relação à quantidade de recipientes esperados para as instâncias em negrito $(j=3,4,5)$. O desenho de todas as 25 instâncias estão no Apêndice B.

\subsection{Corte de itens irregulares em um único recipiente}

Nesta seção apresentamos adaptações do MRCMR para duas variações do problema da mochila. Na Seção 6.3.1 apresentamos o problema da mochila irrestrita e na Seção 6.3.2 o problema da mochila 0-1. Cada uma dessas seções apresenta a definição do problema e como o MRCMR foi adaptado para resolver o problema em questão. Em seguida, apresentamos os resultados computacionais. Os parâmetros utilizados para o $\sigma$ e $\varepsilon$, para as duas versões do problema da mochila, foram 1000 e $10^{-5}$, respectivamente. O desenho com todas as soluções da mochila ilimitada estão no Apêndice $\mathrm{C}$ e os desenhos com as soluções da mochila 0-1 estão no Apêndice D. 


\subsubsection{Mochila ilimitada}

No problema da mochila ilimitada, temos um conjunto de itens com demanda ilimitada e queremos maximizar a ocupação de apenas uma mochila retangular. Para adaptar o código para este problema, consideramos que a demanda de cada item é um número suficientemente grande para a mochila e retornamos o empacotamento com a melhor ocupação.

No trabalho de Valle et al. (2012), um conjunto de instâncias clássicas do strip packing problem é adaptado para o problema da mochila ilimitada. Os experimentos computacionais de Valle et al. (2012) foram feitos em um computador Intel ${ }^{\circledR} 2$ Quad de $2.40 \mathrm{GHz}$ e 4GB de memória no sistema operacional Linux. Na Tabela 6.5 apresentamos os resultados do MRCMR

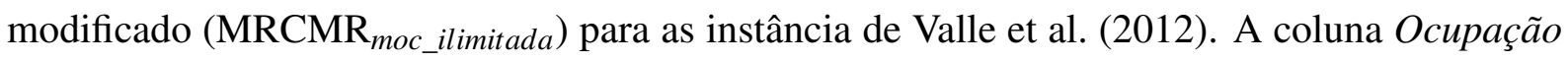
diz a porcentagem de ocupação da mochila e a coluna Tempo reporta o tempo dos algoritmos em segundos. Note que, como os ambientes computacionais são diferentes, a comparação entre os métodos usando tempo pode ser injusta. Estes dados são reportados por completude. A melhor ocupação de cada instância esta em negrito. Além disso, vale destacar que reportamos sempre a melhor ocupação encontrada por Valle et al. (2012).

\begin{tabular}{|r|r|r|r|r|}
\hline \multirow{2}{*}{ Instância } & \multicolumn{2}{|c|}{ Valle et al. (2012) } & \multicolumn{2}{|c|}{ MRCMR $_{\text {moc_ilimitada }}$} \\
\cline { 2 - 5 } & Ocupação & Tempo & Ocupação & Tempo \\
\hline FU & $\mathbf{9 8 , 9 2}$ & 5,0 & 98,61 & 2,6 \\
\hline JAKOBS1 & $\mathbf{1 0 0 , 0 0}$ & 49,6 & $\mathbf{1 0 0 , 0 0}$ & 3,4 \\
\hline JAKOBS2 & $\mathbf{1 0 0 , 0 0}$ & 66,1 & 98,98 & 9,0 \\
\hline SHAPES0 & 61,90 & 134,4 & $\mathbf{7 8 , 0 6}$ & 2,2 \\
\hline SHAPES1 & 69,49 & 248,2 & $\mathbf{7 6 , 9 1}$ & 3,2 \\
\hline SHAPES2 & $\mathbf{9 2 , 8 4}$ & 49,4 & 89,88 & 7,2 \\
\hline DIGHE1 & 76,31 & 7,6 & $\mathbf{8 0 , 2 2}$ & 19,9 \\
\hline DIGHE2 & 77,91 & 3,1 & $\mathbf{8 0 , 4 0}$ & 11,2 \\
\hline DAGLI & 92,56 & 51,0 & $\mathbf{9 6 , 9 2}$ & 110,7 \\
\hline MARQUES & 96,06 & 43,8 & $\mathbf{9 6 , 7 1}$ & 235,3 \\
\hline SHIRTS & $\mathbf{1 0 0 , 0 0}$ & 508,9 & 94,65 & 462,3 \\
\hline TROUSERS & $\mathbf{1 0 0 , 0 0}$ & 193,5 & 99,37 & 124,5 \\
\hline
\end{tabular}

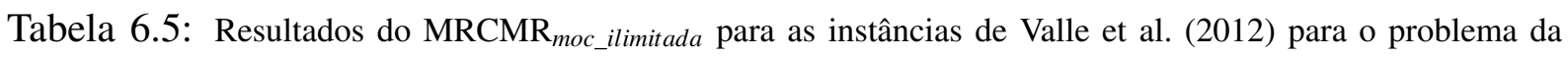
mochila ilimitada.

Das 12 instâncias analisadas, considerando as ocupações encontradas, o MRCMR moc_ilimitada foi estritamente melhor para 6 instâncias enquanto o algoritmo de Valle et al. (2012) foi superior em 5 instâncias. Ambos empataram com 100\% de ocupação para a instância JAKOBS1. Podemos observar que, além da instância JAKOBS1, o algoritmo proposto por Valle et al. (2012) conseguiu a ocupação de $100 \%$ para três outras instâncias (JAKOBS2, SHIRTS e TROUSERS) 


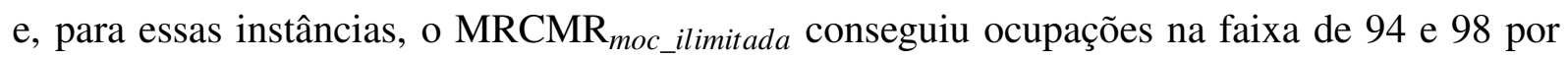
cento. A maior diferença entre os métodos foi na instância SHAPES0, onde a solução do MRCMR $_{\text {moc_ilimitada }}$ é mais de $16 \%$ superior ao algoritmo de Valle et al. (2012).

\subsubsection{Mochila 0-1}

No problema da mochila 0-1, temos um conjunto de itens com uma demanda máxima e queremos maximizar a ocupação de uma mochila retangular ou irregular. Cada item pode ser empacotado no máximo até satisfazer a demanda. A solução é ótima se conseguimos empacotar todos os itens, satisfazendo a demanda, dentro da mochila. Para adaptar o código para este problema, consideramos a demanda dos itens igual a demanda da instância original e retornamos o empacotamento com a melhor ocupação. $\mathrm{O}$ método pára se a solução ótima foi encontrada. $\mathrm{O}$ método modificado recebe o nome de $\mathrm{MRCMR}_{m o c} \_-1$.

Valle et al. (2012) propôs a adaptação de um conjunto de instâncias clássicas para o problema da mochila 0-1 e adaptou algumas instancias de Martins e Tsuzuki (2010). Na Tabela 6.6

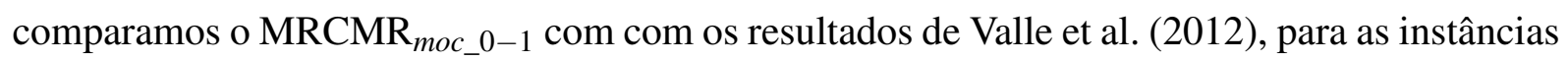
clássicas. Novamente a coluna Ocupação reporta a melhor ocupação e a coluna Tempo o tempo do algoritmo em segundos.

\begin{tabular}{|c|c|c|c|c|}
\hline \multirow{2}{*}{ Instância } & \multicolumn{2}{|c|}{ Valle et al. (2012) } & \multicolumn{2}{|c|}{$\mathrm{MRCMR}_{m o c \_0-1}$} \\
\hline & Ocupação & Tempo & Ocupação & Tempo \\
\hline $\mathrm{FU}^{*}$ & 83,82 & 21,8 & $\mathbf{8 3 , 8 2}$ & 0,5 \\
\hline JAKOBS1* & 75,38 & 8,3 & $\mathbf{7 5 , 3 8}$ & 0,1 \\
\hline JAKOBS2* & 68,44 & 565,7 & 68,44 & 0,1 \\
\hline SHAPES0 & 60,16 & 1552,5 & 60,83 & 4,9 \\
\hline SHAPES1 & 64,24 & 3891,6 & 65,55 & 8,4 \\
\hline SHAPES2 & 72,89 & 1048,1 & 75,56 & 3,3 \\
\hline DIGHE1* & 72,40 & 17,0 & 72,40 & 20,3 \\
\hline DIGHE2* & 74,60 & 1,0 & 74,60 & 0,3 \\
\hline DAGLI* & 75,86 & 1106,4 & 78,02 & 4,5 \\
\hline MARQUES* & 82,74 & 217,8 & 82,74 & 0,4 \\
\hline SHIRTS* & 77,02 & 14317,1 & 85,58 & 270,4 \\
\hline TROUSERS & 78,66 & 5796,6 & 85,09 & 104,4 \\
\hline
\end{tabular}

Tabela 6.6: Resultados do MRCMR ${ }_{m o c}{ }_{0-1}$ para as instâncias de Valle et al. (2012) para o problema da mochila $0-1$.

Na Tabela 6.6 destacamos, em negrito, a melhor solução de cada instância. Observe que

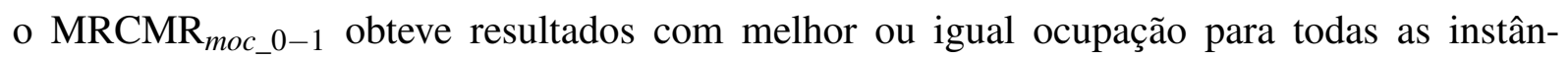
cias. Para seis instâncias a ocupação foi estritamente melhor. As instâncias para as quais o 
MRCMR $_{m o c \_0-1}$ obteve solução ótima são destacadas com um asterisco. O algoritmo de Valle et al. (2012) obteve soluções ótimas para seis instancias: FU, JAKOBS1, JAKOBS2, DIGHE1, DIGHE2 e MARQUES. Além destas instâncias, o MRCMR moc_o-1 $_{-1}$ obteve soluções ótimas para as instâncias DAGLI e SHIRTS. Para os experimentos realizados até aqui, o comportamento do nosso algoritmo é gastar um tempo menor nas instâncias com dimensões pequenas dos objetos (recipientes e itens) e um tempo elevado em instâncias com objetos maiores. $\mathrm{Na}$ Tabela 6.6, algumas instâncias como a DAGLI e a MARQUES, que possuem dimensões consideradas grandes, são resolvidas em um pequeno tempo computacional. Isso acontece porque, assim que o $\mathrm{MRCMR}_{m o c \_}$-1 1 consegue empacotar todos os itens, o algoritmo é finalizado.

Para completar os experimentos feitos por Valle et al. (2012) para a mochila 0-1, a Tabela 6.7 apresenta os resultados do $\mathrm{MRCMR}_{m o c_{-} 0-1}$ para as instâncias de Martins e Tsuzuki (2010). As quatro primeiras foram adaptadas por Valle et al. (2012) e possuem mochilas retangulares. Neste trabalho, incluímos as duas últimas instâncias neste grupo de experimentos. A instância Container with hole é uma mochila retangular com um buraco e a instância Irregular Container é uma mochila não convexa.

Os experimentos computacionais de Martins e Tsuzuki (2010) foram realizados em um Phenom 9550 com $2.21 \mathrm{GHz}$. Neste trabalho, as rotações dos itens não são definidas a priori e o algoritmo busca encontrar posições onde os itens não se sobreponham. Na adaptação de Valle et al. (2012), e estendida no presente trabalho, as instâncias Container with hole e Irregular Container os itens possuem apenas uma rotação.

\begin{tabular}{|r|r|r|r|r|r|r|}
\hline \multirow{2}{*}{ Instância } & \multicolumn{2}{|c|}{ Martins e Tsuzuki (2010) } & \multicolumn{2}{|c|}{ Valle et al. (2012) } & \multicolumn{2}{|c|}{ MRCMR $_{\text {moc_0-1 }}$} \\
\cline { 2 - 7 } & Ocupação & \multicolumn{1}{c|}{ Tempo } & Ocupação & Tempo & Ocupação & Tempo \\
\hline BLFP & - & - & 0 & 112,3 & $\mathbf{7 1 , 1 8}$ & 0,1 \\
\hline LFFP & 93,5 & 212,6 & $\mathbf{1 0 0 , 0 0}$ & 9,5 & $\mathbf{1 0 0 , 0 0}$ & 0,4 \\
\hline SMALL PUZZLE & $\mathbf{1 0 0 , 0 0}$ & 153,6 & $\mathbf{1 0 0 , 0 0}$ & 7,3 & $\mathbf{1 0 0 , 0 0}$ & 6,3 \\
\hline TANGRAM & 77,4 & 2614,8 & 86,67 & 45,2 & $\mathbf{1 0 0 , 0 0}$ & 4,8 \\
\hline Container with hole & $\mathbf{1 0 0 , 0 0}$ & 1615,1 & - & - & $\mathbf{1 0 0 , 0 0}$ & 0,2 \\
\hline Irregular Container & 76,7 & 1726,6 & - & - & $\mathbf{1 0 0 , 0 0}$ & 0,1 \\
\hline
\end{tabular}

Tabela 6.7: Resultados do MRCMR moc_0-1 $_{-1}$ para uma adaptação das instâncias de Martins e Tsuzuki (2010) para o problema da mochila $0-1$.

Devemos analisar a Tabela 6.7 com muito cuidado. As instâncias apresentadas nesta tabela são instâncias artificiais propostas por Martins e Tsuzuki (2010) para validar o seu método de rotações livres. A nossa intenção com a Tabela 6.7 é completar os experimentos feitos por Valle et al. (2012) e estender os experimentos para mochilas irregulares. Sendo assim, não é justo comparar os nossos resultados com os obtidos por Martins e Tsuzuki (2010), que resolve 
outro problema. Mesmo assim, devemos destacar a qualidade do método MRCMR moc_0-1 $_{1}$ para este conjunto de instâncias, para o qual consegue o encaixe perfeito para cinco instâncias, com ocupação de $100 \%$, e uma ocupação ótima para a instância BLFP, que não possui encaixe perfeito (veja o desenho das soluções no Apêndice D). 


\section{CAPÍTULO 7}

\section{CONCLUSÕES E TRABALHOS FUTUROS}

Neste trabalho, estudamos o problema de corte de itens irregulares em recipientes retangulares ou irregulares. O objetivo é cortar todos os itens utilizando o menor número de recipientes possível. Os itens são representados por um conjunto de polígonos convexos, enquanto os recipientes são representados por um retângulo (dados por uma largura e uma altura) e uma lista de defeitos, que pode estar vazia. Os defeitos são polígonos convexos e são utilizados para representar regiões onde os itens não podem ser empacotados.

Uma das maiores dificuldades ao se trabalhar com itens e recipientes irregulares é evitar a sobreposição de itens e encontrar posições viáveis dentro do recipiente. A estratégia utilizada neste trabalho para evitar a sobreposição é uma malha de pontos baseada no no-fit polygon. Esta malha de pontos permite encontrar encaixes não ortogonais, devido à utilização do no-fit polygon, o que permite encontrar soluções com encaixe perfeito.

Para calcular as malhas de no-fit polygons, e assim evitar a sobreposição de itens, implementamos a abordagem de Cuinghame-Green (1989). Para obter a malha de posições viáveis dentro do recipiente, formalizamos uma nova abordagem, onde calculamos os no-fit polygons entre os defeitos e os itens. Em seguida, consideramos que os defeitos estão alocados em um recipiente retangular. Essa maneira de lidar com recipientes irregulares simplifica o cálculo de posições viáveis dentro do recipiente, visto que não precisamos calcular o inner-fit polygon do item no recipiente. Além disso, desta forma conseguimos representar grande parte dos 
recipientes irregulares com aproximação poligonal.

Foram implementadas quatro heurísticas de baixo nível que utilizam as malhas de pontos para evitar a sobreposição e encontrar posições viáveis. As heurísticas desenvolvidas alocam um item por vez, seguindo um caminho dos pontos nas malhas de pontos. As quatro heurísticas foram inspiradas nas heurísticas com política bottom left e se baseiam na ordenação dos itens. O método proposto neste trabalho é um algoritmo que gerencia as quatro heurísticas desenvolvidas. O diferencial deste método é a maneira com que ele seleciona a heurística a cada iteração. Além disso, o método calcula a sequência em que os itens serão inseridos pelas heurísticas por meio de um algoritmo que privilegia a ordenação, de forma decrescente, pela área dos itens.

Os experimentos computacionais foram divididos em três grupos: (1) corte de múltiplos recipientes retangulares, (2) corte de múltiplos recipientes irregulares e (3) adaptações do método para os problemas das mochilas ilimitada e $0-1$.

No primeiro grupo de experimentos, foram realizados dois grandes conjuntos de experimentos computacionais para recipientes retangulares. Terashima 1, com 540 instâncias, e Terashima 2, com 480 instâncias. Duas características importantes destes conjuntos de experimentos são a grande dimensão dos recipientes e o encaixe perfeito dos itens. Estas características são os gargalos e os desafios do método proposto, visto que o método trabalha com malhas. Poderíamos reduzir estes gargalos aumentando a escala das malhas, mas com isso perderíamos o encaixe ótimo dos itens. Considerando a escala 1:1, onde a escala das malhas é igual às dimensões dos itens, os resultados demonstram que o método conseguiu resolver bem estas instâncias. O método proposto conseguiu resultados muito próximos dos ótimos, com ocupação de $100 \%$ para 1801 dos 8326 recipientes utilizados nos conjuntos de experimentos Terashima 1 e Terashima 2. Devemos destacar que 15 instâncias foram resolvidas na otimalidade.

O segundo grupo de experimentos lida com recipientes irregulares. Como não são conhecidas instâncias públicas para recipientes irregulares, foram adaptadas 25 instâncias de Tay e Lee (2002). As instâncias propostas possuem recipientes irregulares e itens convexos e não convexos. Os experimentos computacionais validam o método proposto e mostram que a abordagem é muito eficiente. Resolvendo todas as instâncias no tempo máximo de 3 segundos. O baixo tempo computacional é justificado pela dimensão dos objetos, que pode ser considerada média, com os lados dos recipientes na faixa das 80-140 unidades.

Por fim, o terceiro grupo de experimentos traz a versatilidade do método que foi adaptado para duas versões do problema da mochila (ilimitada e 0-1) e comparado com dois trabalhos recentes da literatura. Foram analisadas 12 instâncias com mochilas retangulares para o problema da mochila ilimitada. Destas, o método proposto neste trabalho foi melhor ou igual em 
7 instâncias quando comparado com Valle et al. (2012), conseguindo um leiaute com 100\% de ocupação. Para o problema da mochila 0-1 foram analisadas mochilas retangulares e irregulares. Das 18 instâncias analisadas para a mochila 0-1, o método proposto conseguiu solução ótima de 14 instâncias. Com isso, podemos concluir que a adaptação do método proposto para múltiplos recipientes também é muito competitiva com a literatura, melhorando vários resultados.

Por fim, como trabalhos futuros pretendemos implementar novas heurísticas de baixo nível, propor métodos de busca local, considerar diferentes regiões de qualidade nos recipientes e aplicar algoritmos de compactação nas soluções obtidas. 


\section{REFERÊNCIAS BIBLIOGRÁFICAS}

ABNT. NBR 100004 :Resíduos sólidos. [S.1.]: Associação Brasileira de Normas Técnicas, Rio de Janeiro, 2004.

ALVAREZ-VALDES, R.; MARTINEZ, A.; TAMARIT, J. A branch and bound algorithm for cutting and packing irregularly shaped pieces. Int. J. Production Economics, v. 145, p. 463-477, 2013.

ALVES, C.; BRAS, P.; CARVALHO, J. M. V.; PINTO, T. New constructive algorithms for leather nesting in the automotive industry. Computers and Operations Research, v. 39, p. 1487$1505,2012$.

ALVES, C.; BRAS, P.; CARVALHO, J. M. V.; PINTO, T. A variable neighborhood search algorithm for the leather nesting problem. Mathematical Problems in Engineering, v. 183, p. 28, 2012.

BAKER, B. S.; COFFMAN, E. G.; RIVEST, R. L. Orthogonal packing in two dimensions. SIAM Journal on Computing, v. 9, p. 846-855, 1980.

BALDACCI, R.; BOSCHETTI, M. A.; GANOVELLI, M.; MANIEZZO, V. Algorithms for nesting with defects. Discrete Applied Mathematics, v. 163, p. 17-33, 2014.

BENNELL, J. A.; OLIVEIRA, J. F. The geometry of nesting problems: A tutorial. European Journal of Operational Research, v. 184, p. 397-415, 2008.

BENNELL, J. A.; SONG, X. A beam search implementation for the irregular shape packing problem. Journal of Heuristics, v. 16, p. 167-188, 2010.

BURKE, E.; HELLIER, R.; KENDALL, G.; WHITWELL, G. A new bottom-left-fill heuristic algorithm for the two-dimensional irregular packing problem. Operational Research, v. 54, p. 587-601, 2006.

BURKE, E.; HELLIER, R.; KENDALL, G.; WHITWELL, G. Irregular packing using the line and arc no-fit polygon. Operational Research, v. 58, p. 948-970, 2010. 
CARRAVILLA, M. A.; RIBEIRO, C.; OLIVEIRA, J. F. Solving nesting problems with nonconvex polygons by constraint logic programming. International Transactions in Operational Research, v. 10, p. 651-663, 2003.

CHUNG, F. R. K.; GAREY, M. R.; JOHNSON, D. S. On packing two-dimensional bins. SIAM Journal on Algebraic and Discrete Methods, v. 3, p. 66-76, 1982.

CRISPIN, A.; CLAY, P.; TAYLOR, G.; BAYES, T.; REEDMAN, D. Genetic algorithm coding methods for leather nesting. Applied Intelligence, v. 23, p. 9-20, 2005.

CUINGHAME-GREEN, R. Geometry, shoemaking and the milk tray problem. New Scientist, v. 123, p. 6-20, 1989.

DALALAH, D.; KHRAIS, S.; BATAINEH, K. Waste minimization in irregular stock cutting. Journal of Manufacturing Systems, v. 33, p. 27-40, 2014.

DANIELS, K. K.; MILENKOVIC, V. J.; LI, Z. Multiple containment methods. Technical Report 12-94, Center for Research in Computing Technology, Harvard University, Cambridge, p. 12-94, 1994.

DOWSLAND, K. A.; DOWSLAND, W. B.; BENNELL, J. A. Jostling for position: local improvement for irregular cutting patterns. Journal of Operational Research Society, v. 49, p. 647-658, 1998.

DOWSLAND, K. A.; VAID, S.; DOWSLAND, W. B. An algorithm for polygon placement using a bottom-left strategy. European Journal of Operational Research, v. 141, p. 371-381, 2002.

EGEBLAD, J.; NIELSEN, B. K.; ODGAARD, A. Fast neighborhood search for two and threedimensional nesting problems. European Journal of Operational Research, v. 183, p. 12491266, 2007.

ELKERAN, A. A new approach for sheet nesting problem using guided cuckoo search and pairwise clustering. European Journal of Operational Research, v. 231, p. 757-769, 2013.

FISCHETTI, M.; LUZZI, I. Mixed-integer programming models for nesting problems. Journal Heuristics, v. 15, p. 201-226, 2009.

GOMES, A. M.; OLIVEIRA, J. F. A 2-exchange heuristic for nesting problems. European Journal of Operational Research, v. 141, p. 359-370, 2002.

GOMES, A. M.; OLIVEIRA, J. F. Solving irregular strip packing problems by hybridising simulated annealing and linear programming. European Journal of Operational Research, v. 171, p. 811-829, 2006.

GONÇALVES, J. F.; RESENDE, M. G. C. A biased random key genetic algorithm for $2 \mathrm{~d}$ and 3d bin packing problems. Int. J. Production Economics, v. 145, p. 500-510, 2013.

HALAVATI, R.; SHOURAKI, S. B.; NOROOZIAN, M.; ZADEH, S. H. Optimizing allocation of two dimensional irregular shapes using an agent based approach. International Science Index, v. 1, p. 11-27, 2007. 
HALAVATI, R.; SHOURAKI, S. B.; ZADEH, S. H. A novel evolutionary approach for two dimensional bin packing. The CSI Journal on Computer Science and Engineering, v. 6, p. 5867, 2008.

HEISTERMANN, J.; LENGAUER, T. The nesting problem in the leather manufacturing industry. Annals of Operations Research, v. 57, p. 147-173, 1995.

HIFI, M.; M'HALLAH, R. A hybrid algorithm for the two-dimensional layout problem: the cases of regular and irregular shapes. International Transactions in Operational Research, v. 10, p. 195-216, 2003.

HU-YAO, L.; YUAN-JUN, H. Algorithm for 2d irregular-shaped nesting problem based on the nfp algorithm and lowest-gravity-center principle. Journal of Zhejiang University SCIENCE A, v. 7, p. 570-576, 2006.

JAKOBS, S. On genetic algorithms for the packing of polygons. European Journal of Operational Research, v. 88, p. 165-181, 1996.

LI, Z.; MILENKOVIC, V. Compaction and separation algorithms for non-convex polygons and their applications. European Journal of Operational Research, v. 84, p. 539-561, 1995.

LIU, D.; TENG, H. An improved bl-algorithm for genetic algorithm of the orthogonal packing of rectangle. European Journal of Operational Research, v. 112, p. 413-419, 1999.

LODI, A. Algorithms for two-dimensional bin packing and assignment problems. Università di Bologna: Tese de doutorado, 1999. 208 p.

LODI, A.; MARTELLO, S.; VIGO, D. Heuristic and metaheuristic approaches for a class of two-dimensional bin packing problems. INFORMS Journal on Computing, v. 11, p. 345-357, 1999.

LODI, A.; MARTELLO, S.; VIGO, D. Recent advances on two-dimensional bin packing problems. Discrete Applied Mathematics, v. 123, p. 379-396, 2002.

LÓPEZ-CAMACHO, E. An Evolutionary Framework for Producing Hyper-heuristics for Solving the 2D Irregular Bin Packing Problem. Tecnológico de Monterrey: Tese de doutorado, 2012. $176 \mathrm{p}$.

LÓPEZ-CAMACHO, E.; OCHOA, G.; TERASHIMA-MARÍN, H.; BURKE, E. K. An effective heuristic for the two-dimensional irregular bin packing problem. Annals of Operations Research, v. 206, p. 241-264, 2013.

LÓPEZ-CAMACHO, E.; TERASHIMA-MARÍN, H.; ROSS, P. Defining a problem-state representation with data mining within a hyper-heuristic model which solves $2 \mathrm{~d}$ irregular bin packing problems. Lecture Notes in Computer Science, v. 6433, p. 204-213, 2010.

MARTELLO, S.; VIGO, D. Exact solution of the two-dimensional finite bin packing problem. Management science, v. 44, p. 388-399, 1998.

MARTINS, T. C. Estudo do recozimento simulado e do polígono de obstrução aplicados ao problema de empacotamento rotacional de polígonos irregulares não-convexos em recipientes fechado. Universidade de São Paulo, Departamento de Engenharia de Mecatrônica e de Sistemas Mecânicos: Tese de doutorado, 2007. 103 p. 
MARTINS, T. C.; TSUZUKI, M. S. G. Simulated annealing applied to the irregular rotational placement of shapes over containers with fixed dimensions. Expert Systems with Applications, v. 37, p. 1955-1972, 2010.

MILENKOVIC, V. J.; DANIELS, K. Translational polygon containment and minimal enclosure using mathematical programming. [S.1.: s.n.], 1996. 109-118 p.

OLIVEIRA, J. F.; FERREIRA, J. S. Algorithms for nesting problems, applied simulated annealing. Econ. and Maths Systems, v. 396, p. 255-274, 1993.

OLIVEIRA, J. F.; GOMES, A. M.; FERREIRA, J. S. Topos - a new constructive algorithm for nesting problems. OR Spectrum, v. 22, p. 263-284, 2000.

PASHA, A. Geometric bin packing algorithm for arbitrary shapes. University of Florida, Department of Mechanical and Aerospace Engineering: Dissertação de mestrado, 2003. 99 p.

RIBEIRO, C.; CARRAVILlA, M. A.; OLIVEIRA, J. F. Applying constraint logic programming to the resolution of nesting problems. Pesquisa Operacional, v. 19, p. 239-247, 1999.

ROSS, P.; SCHULENBURG, S.; MARÍN-BLÁZQUEZ, J. G.; HART, E. Hyper-heuristics: learning to combine simple heuristics in bin-packing problems. In Lecture notes in computer science. Conference on genetic and evolutionary computation, p. 942-948, 2002.

SEGENREICH, S. A.; BRAGA, L. M. Optimal nesting of general plane figures: a monte carlo heuristical approach. Computers and Graphics, v. 10, p. 229-237, 1986.

STOYAN, Y. G.; SCHEITHAUER, G.; GIL, N.; ROMANOVA, T. Phi-functions for complex 2d-objects. 4OR quarterly journal of the Belgian, French and Italian Operations Research Societies, v. 2, p. 69-84, 2004.

STOYAN, Y. G.; TERNO, J.; SCHEITHAUER, G.; GIL, N.; ROMANOVA, T. Phi-functions for primary 2d-objects. Studia Informatica Universalis, v. 1, p. 1-32, 2001.

TAY, F. E. H.; LEE, C. F. C. Pattern nesting on irregular-shaped stock using genetic algorithms. Engineering Applications of Artificial Intelligence, v. 15, p. 551-558, 2002.

TERASHIMA-MARÍN, H.; ROSS, P.; FARÍAS-ZÁRATE, C. J.; LÓPEZ-CAMACHO, E.; VALENZUELA-RENDÓN, M. Generalized hyper-heuristics for solving $2 \mathrm{~d}$ regular and irregular packing problems. Annals of Operations Research, v. 179, p. 369-392, 2010.

TOLEDO, F. M. B.; CARRAVILLA, M. A.; RIBEIRO, C.; OLIVEIRA, J. F.; GOMES, A. M. The dotted-board model: A new mip model for nesting irregular shapes. Int. J. Production Economics, v. 145, p. 478-487, 2013.

UDAY, A.; GOODMAN, E. D.; DEBNATH, A. A. Nesting of irregular shapes using feature matching and parallel genetic algorithms. In: In. [S.1.: s.n.], 2001. p. 429-434.

VALle, A. M. D. Problema da mochila com itens irregulares. Universidade Estadual de de Campinas, Instituto de Computação: Dissertação de mestrado, 2010. 84 p.

VALLE, A. M. D.; QUEIROZ, T. A.; MIYAZAWA, F. K.; XAVIER, E. C. Heuristics for twodimensional knapsack and cutting stock problems with items of irregular shape. Expert Systems with Applications, v. 39, p. 12589-12598, 2012. 
WASCHER, G.; HAUBNER, H.; SCHUMANN, H. An improved typology of cutting and packing problems. European Journal of Operational Research, v. 183, p. 1109-1130, 2007.

YANG, X. S.; DEB, S. Cuckoo search via lévy flights. World congress on nature and biologically inspired computing (NaBIC), p. 210-214, 2010.

YUPING, Z.; SHOUWEI, J.; CHUNLI, Z. A very fast simulated re-annealing algorithm for the leather nesting problem. International Journal of Advanced Manufacturing Technology, p. 1113-1118, 2005. 


\section{APÊNDICE A}

\section{SOLUÇÕES ÓTIMAS TERASHIMA 2}

Neste capítulo serão apresentadas as quinze soluções ótimas encontradas no conjunto de instâncias Terashima 2. O nome de cada instância é o mesmo de Terashima 2 e esta escrito logo abaixo do desenho da solução.

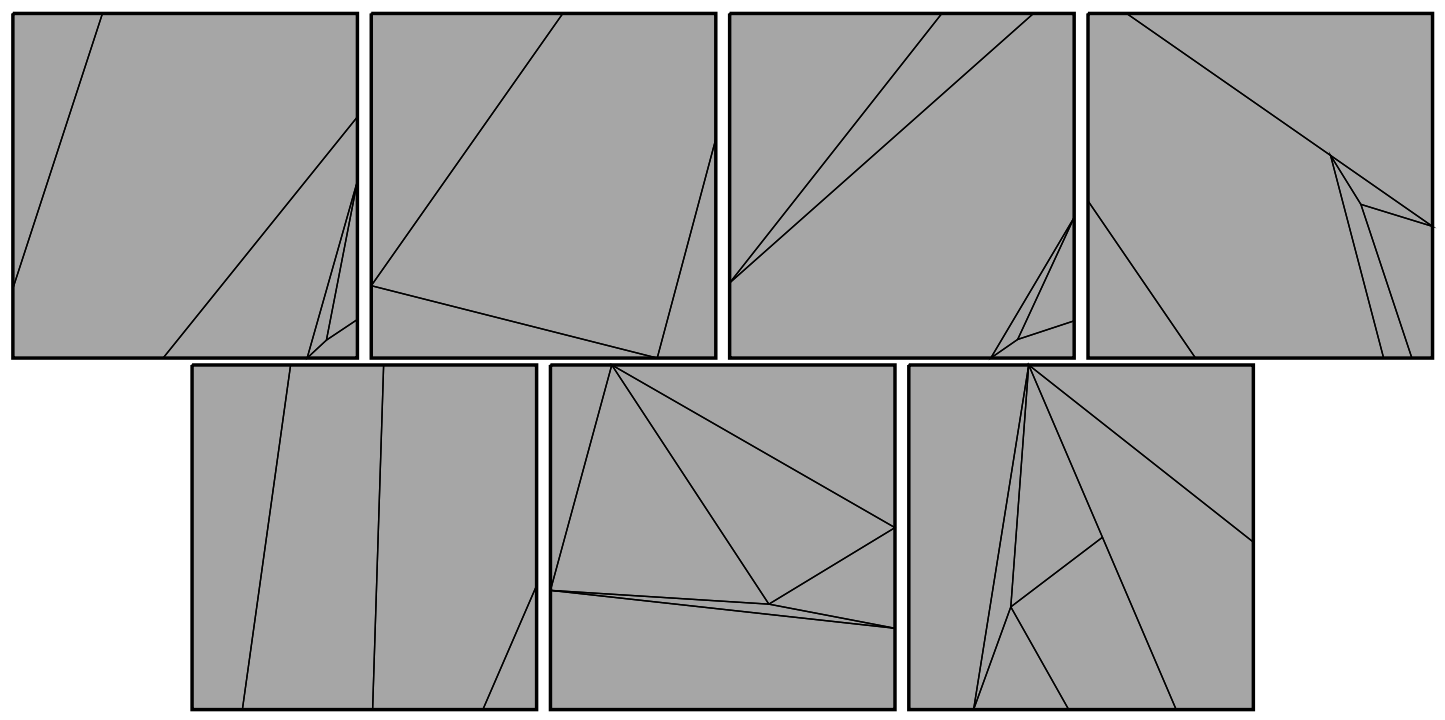

Figura A.1: TO003C5 


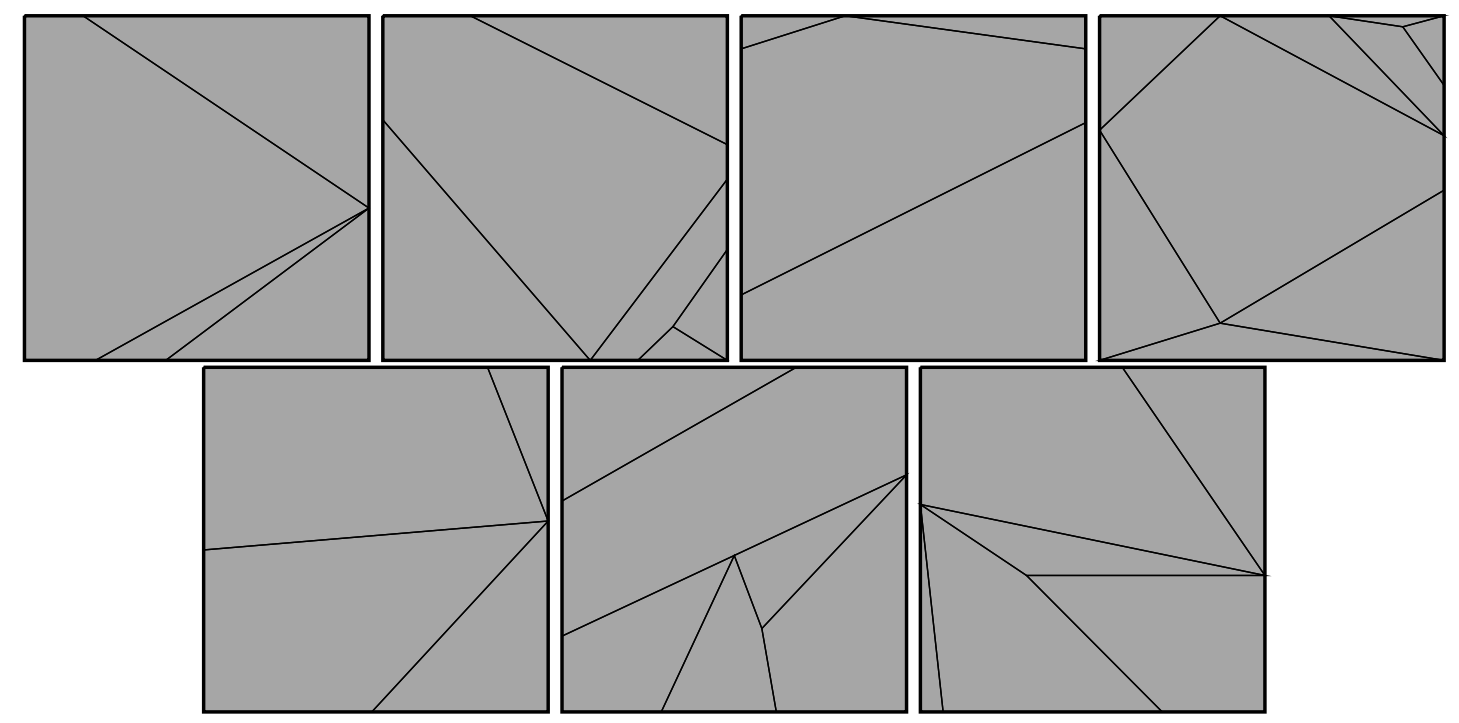

Figura A.2: TO009C5

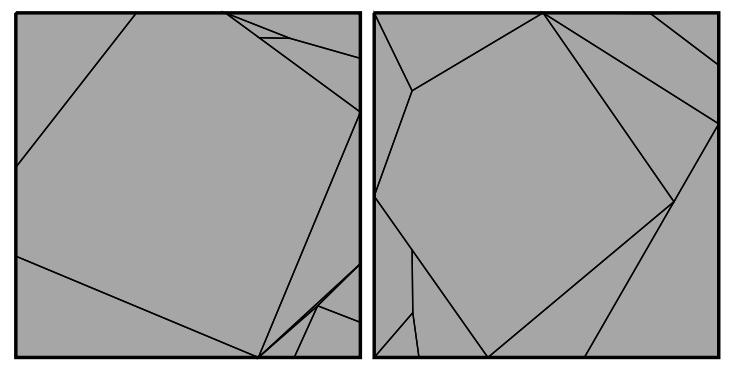

Figura A.3: TS001C5

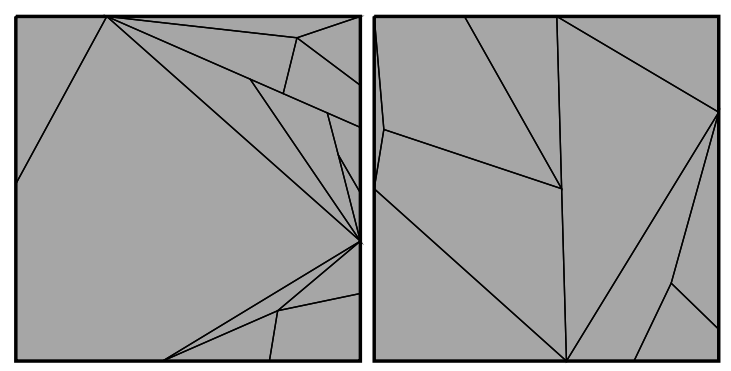

Figura A.4: TS009C5

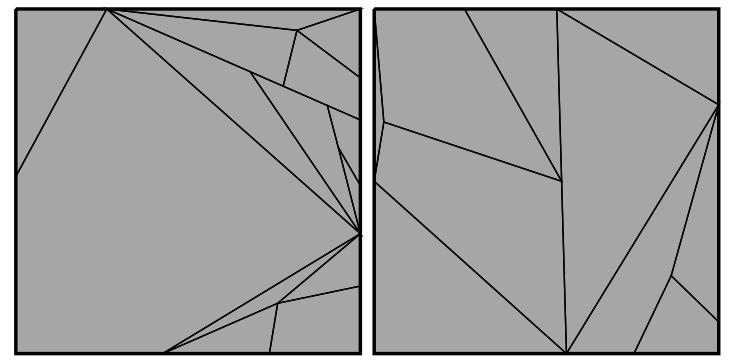

Figura A.5: TS009C5 


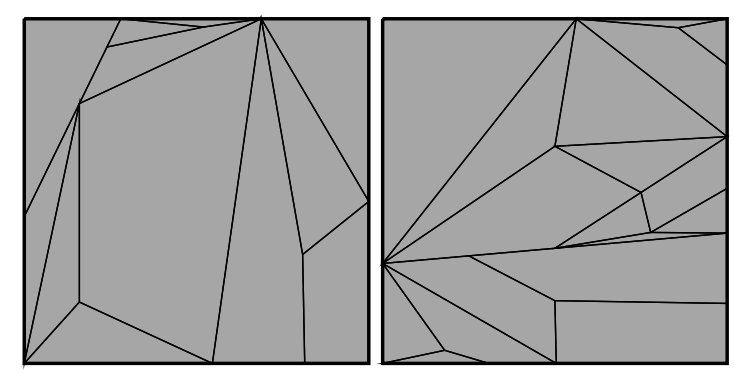

Figura A.6: TS012C8

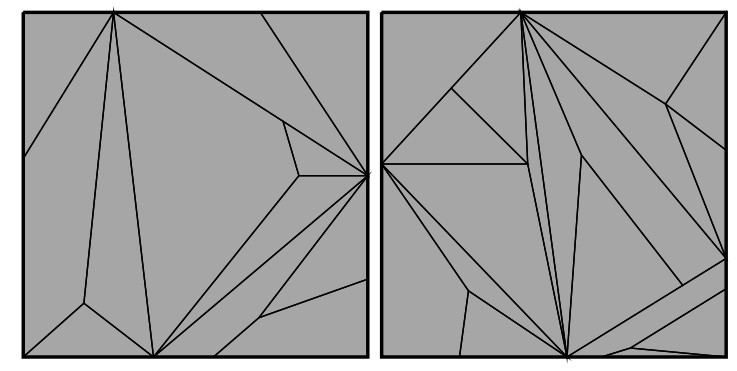

Figura A.7: TS029C8

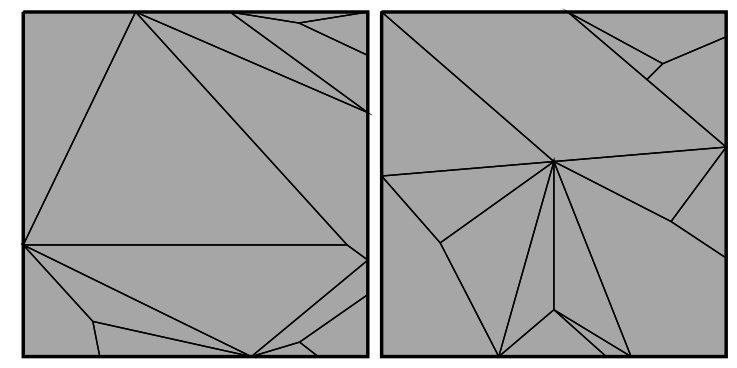

Figura A.8: TS030C8 


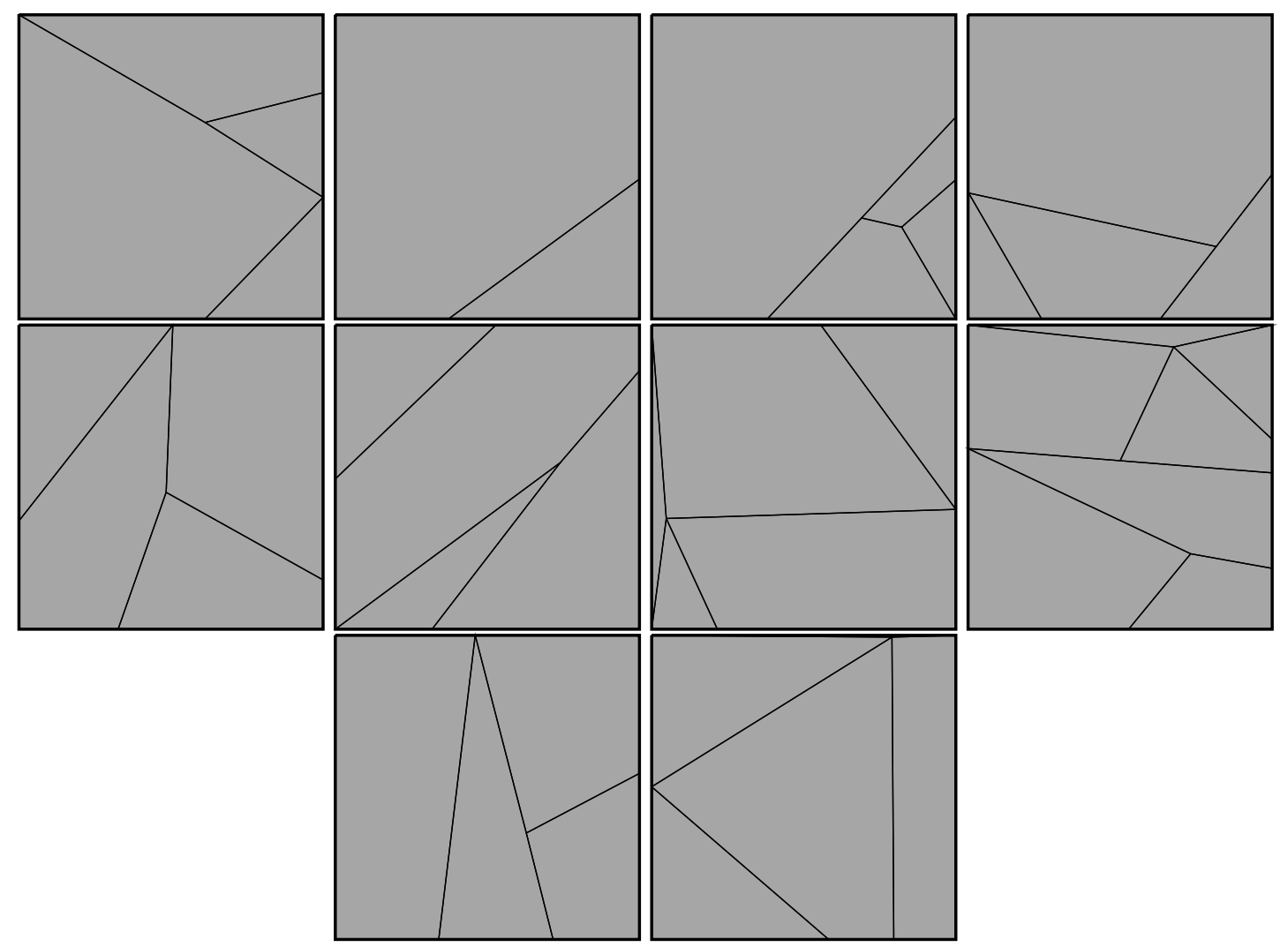

Figura A.9: TT004C10

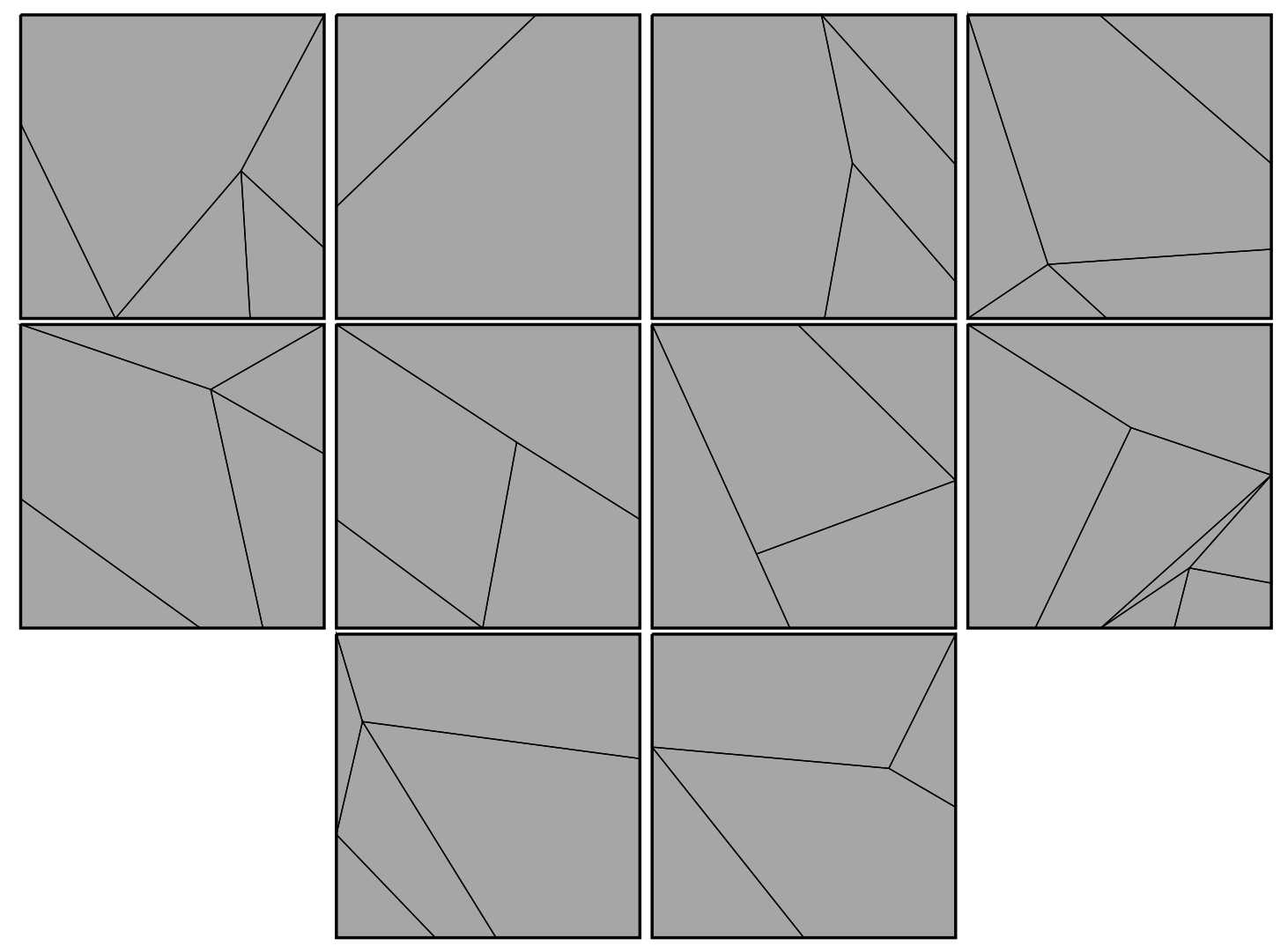

Figura A.10: TT005C10 


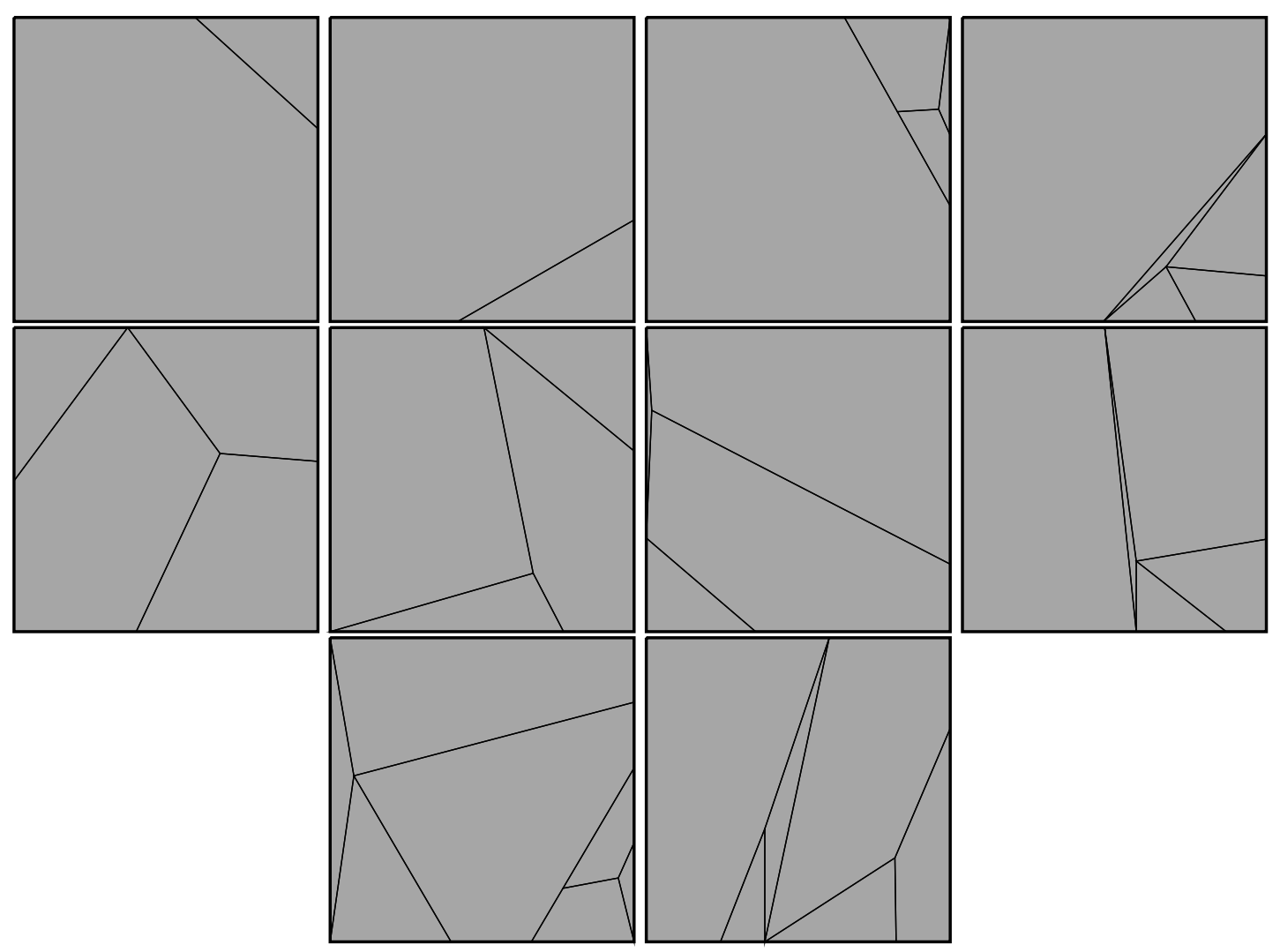

Figura A.11: TT009C10
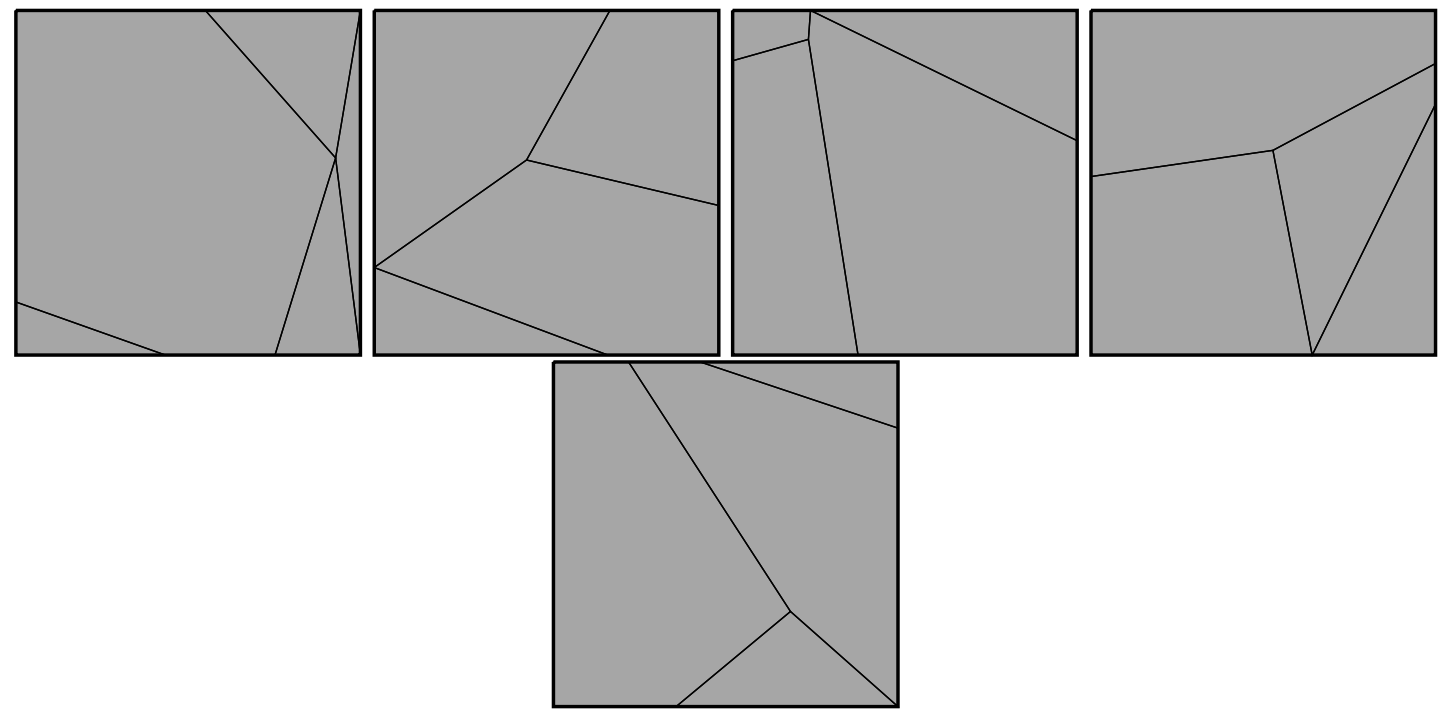

Figura A.12: TV008C5 


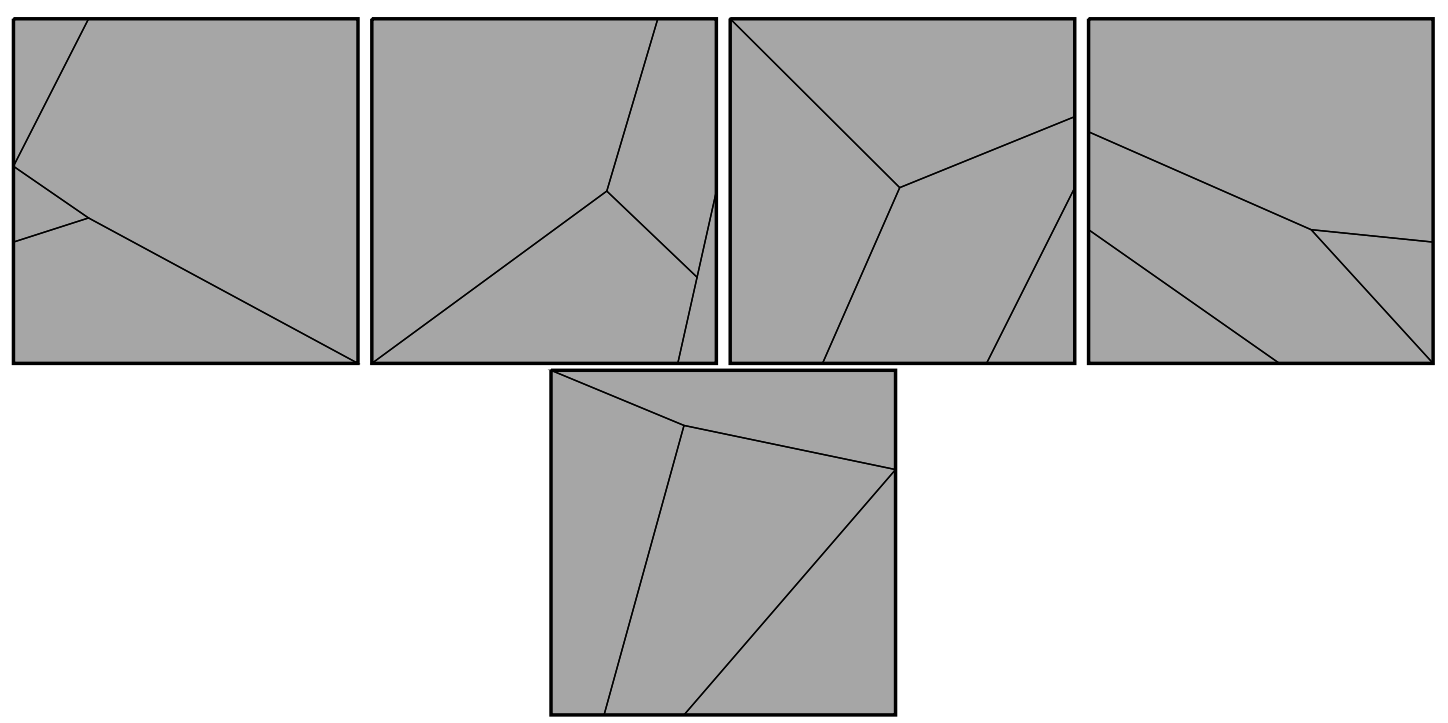

Figura A.13: TV009C5

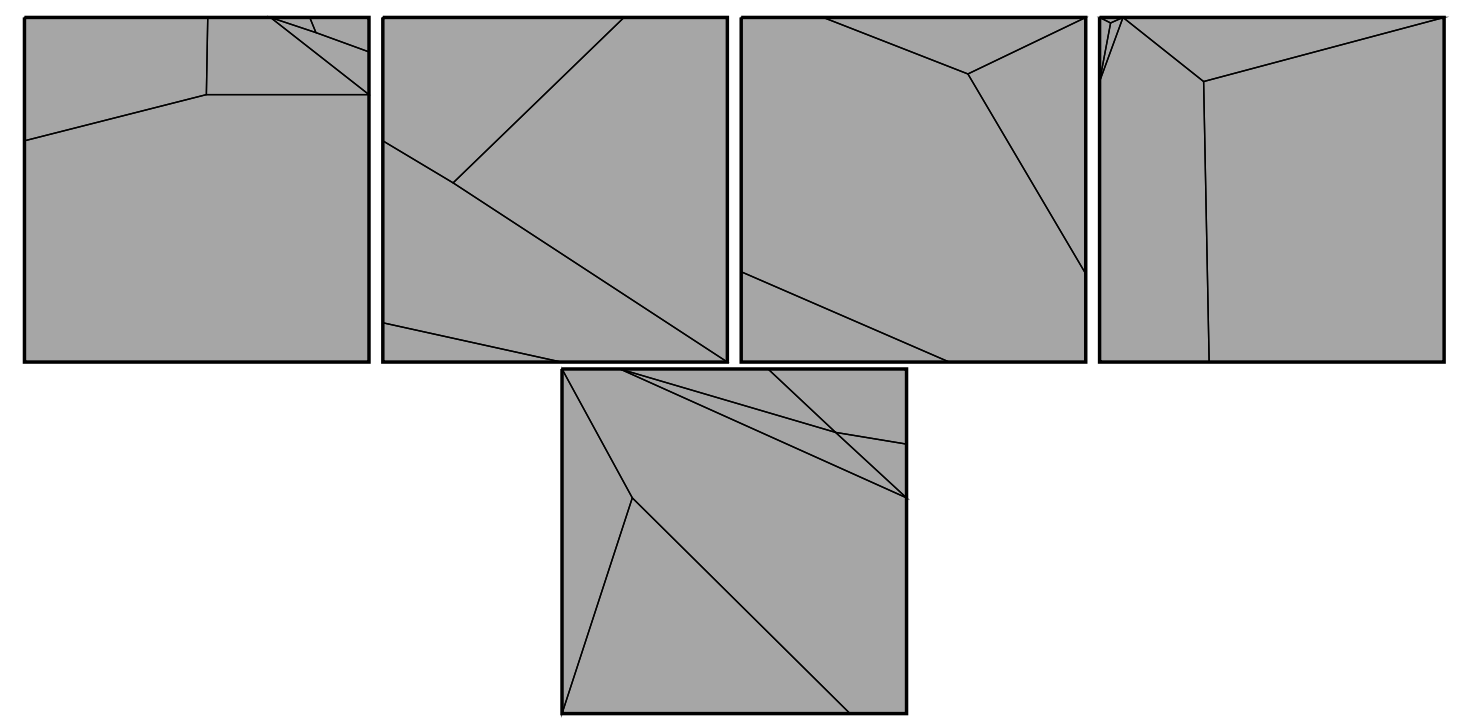

Figura A.14: TV018C8 


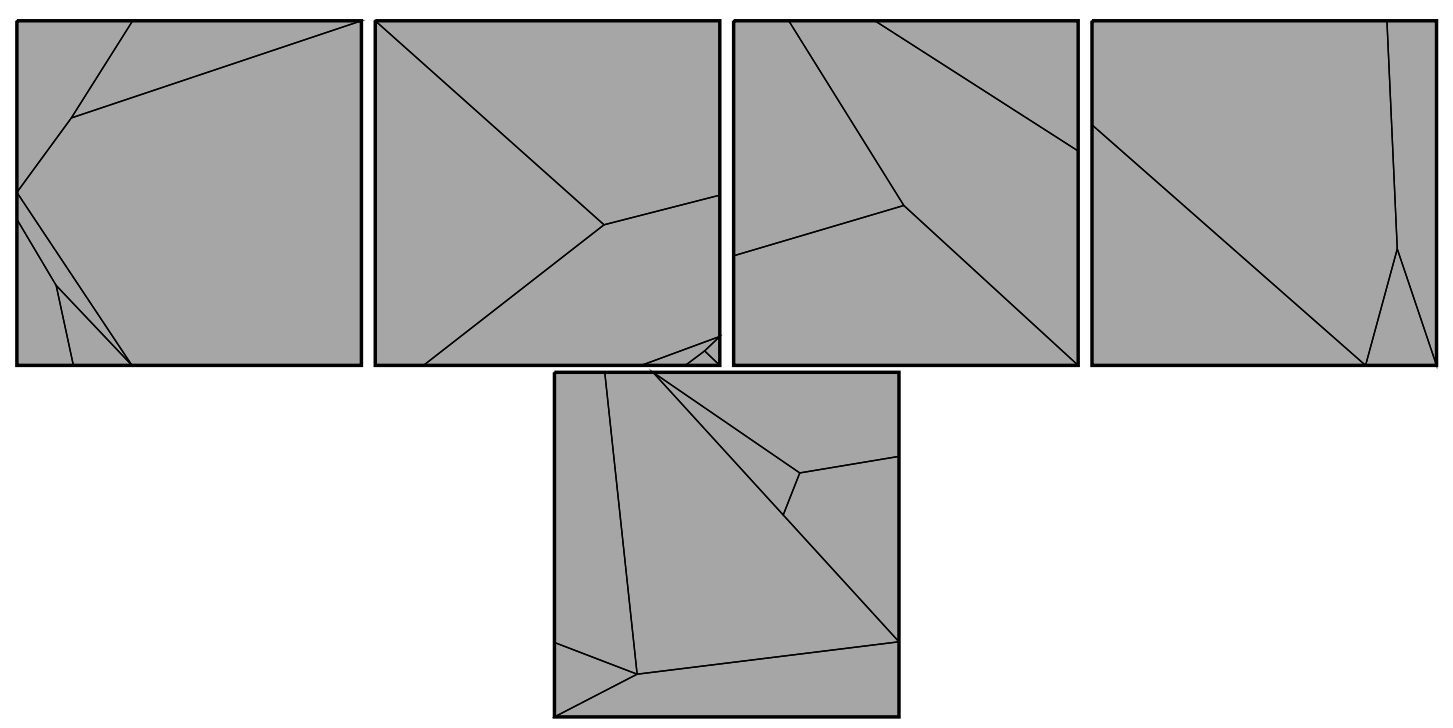

Figura A.15: TV023C8 


\section{APÊNDICE B}

\section{SOLUÇÕES TAY}

Neste capítulo serão apresentadas as soluções encontradas para o conjunto de instâncias Tay. Todos os recipientes do conjunto de instâncias Tay1 é o mesmo. Apresentado na Figura A.16.

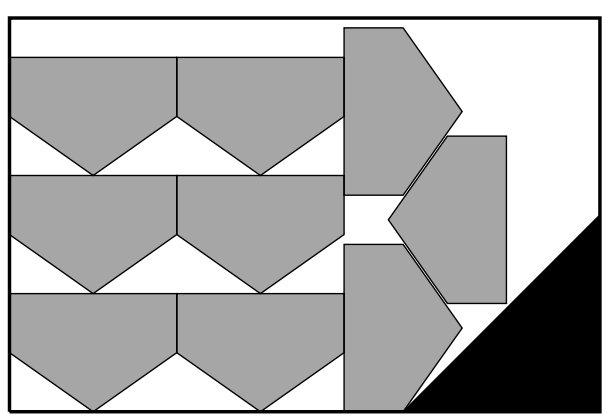

Figura B.1: Tay1-1

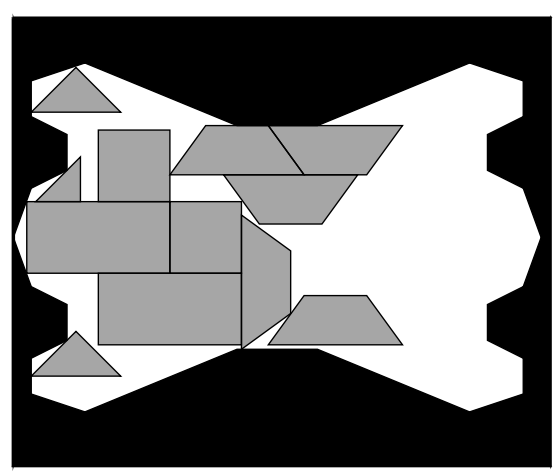

Figura B.2: Tay2-1 


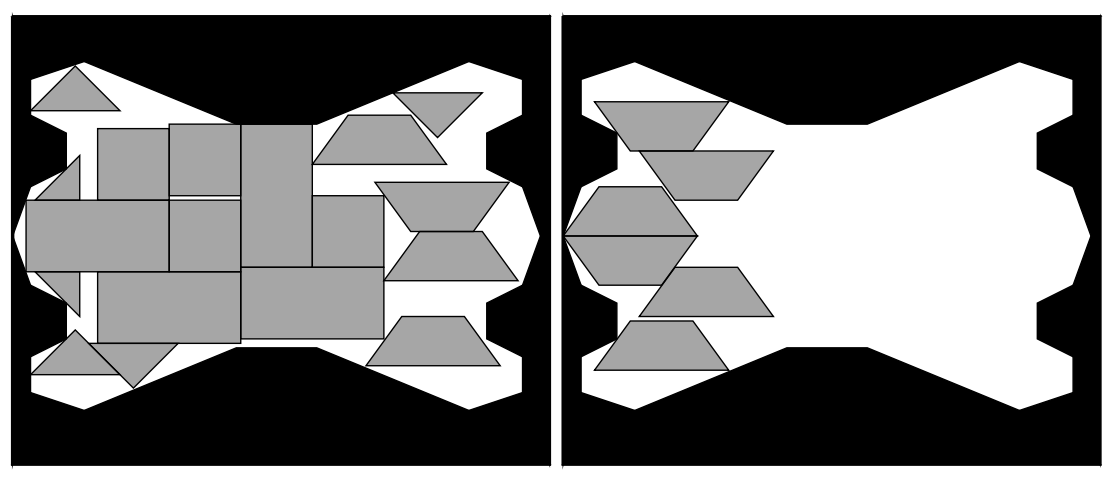

Figura B.3: Tay2-2

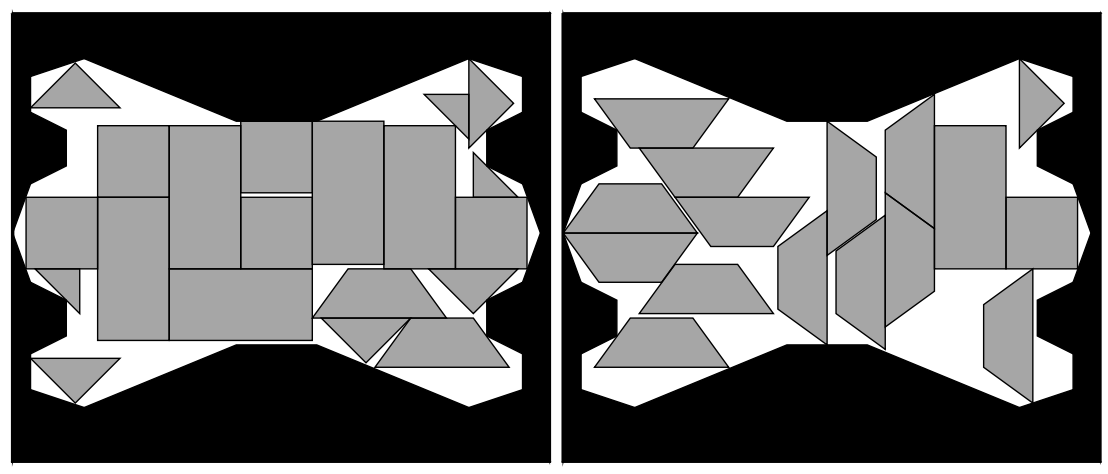

Figura B.4: Tay2-3
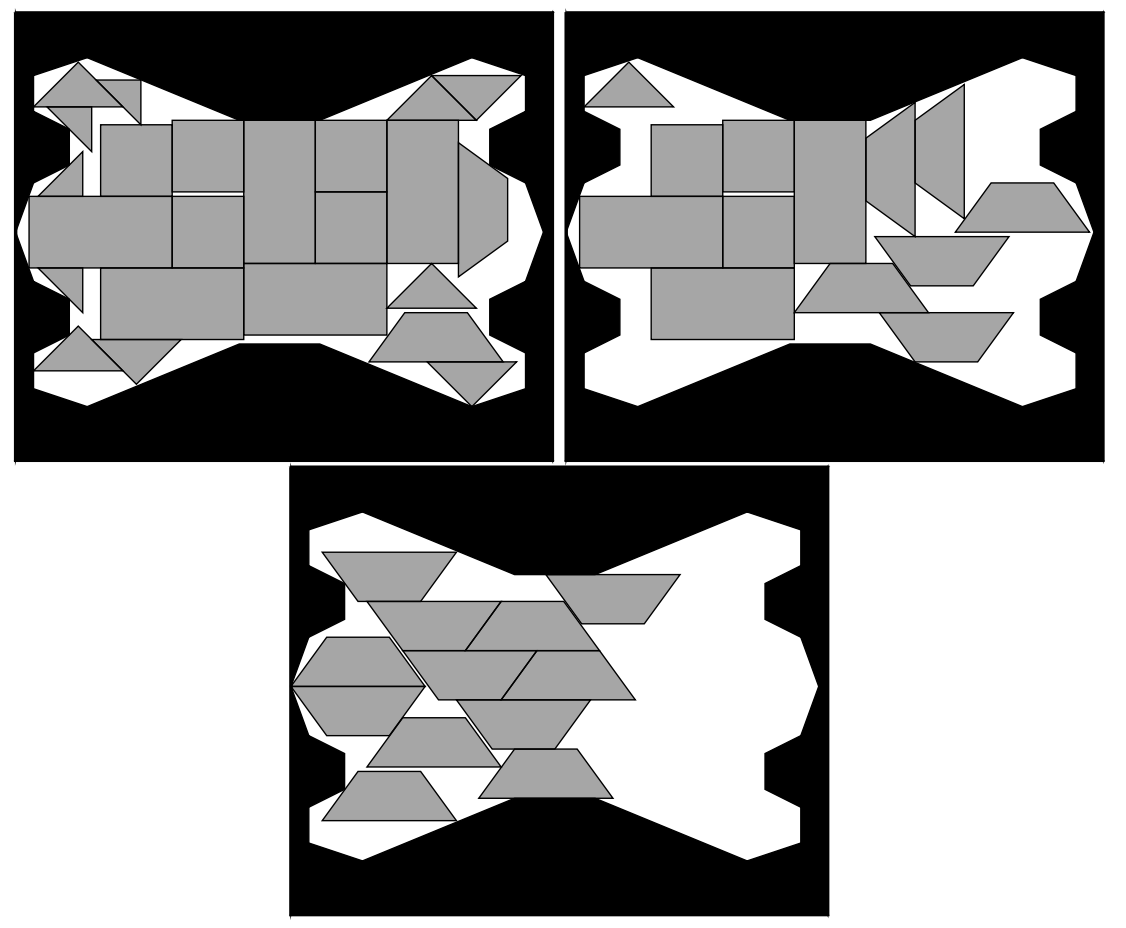

Figura B.5: Tay2-4 


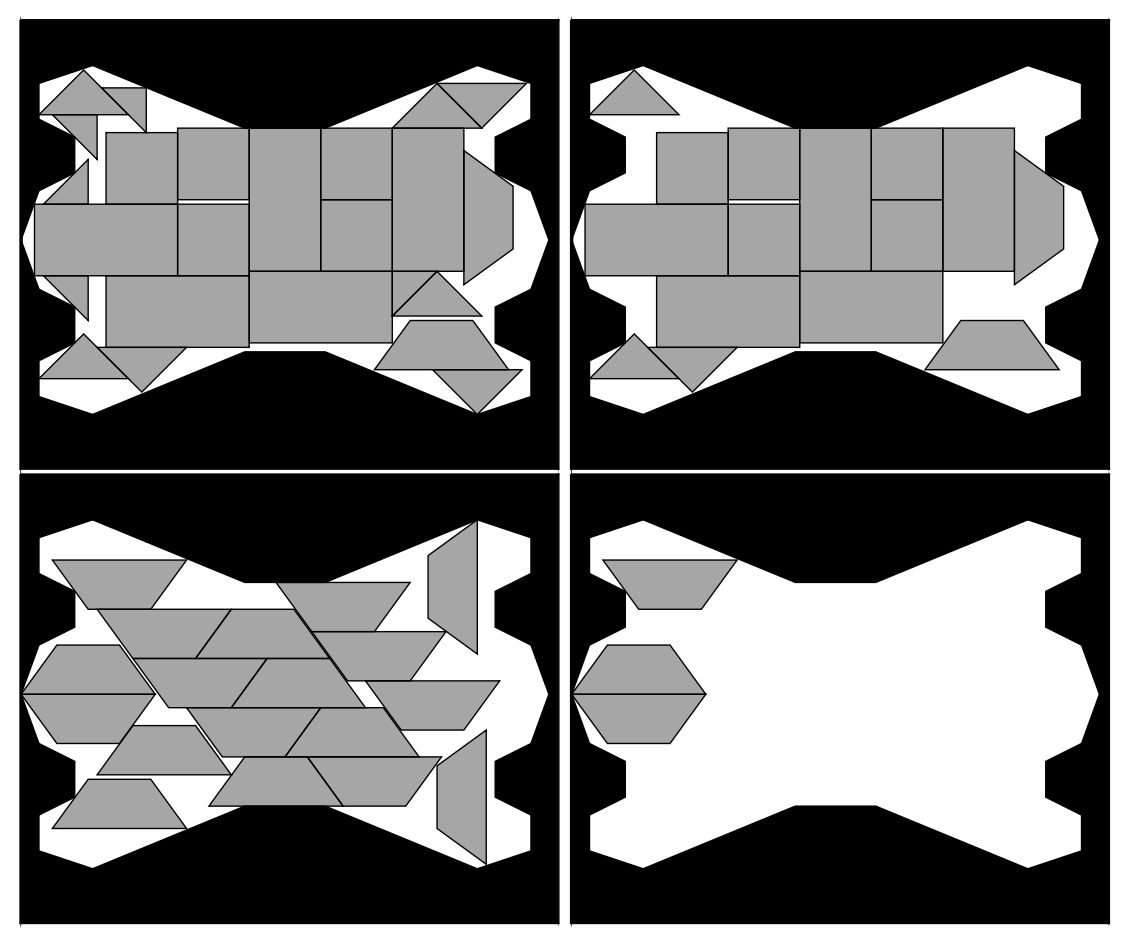

Figura B.6: Tay2-5

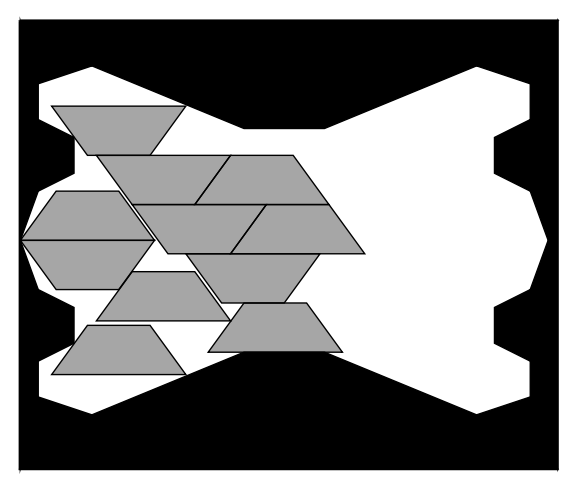

Figura B.7: Tay3-1

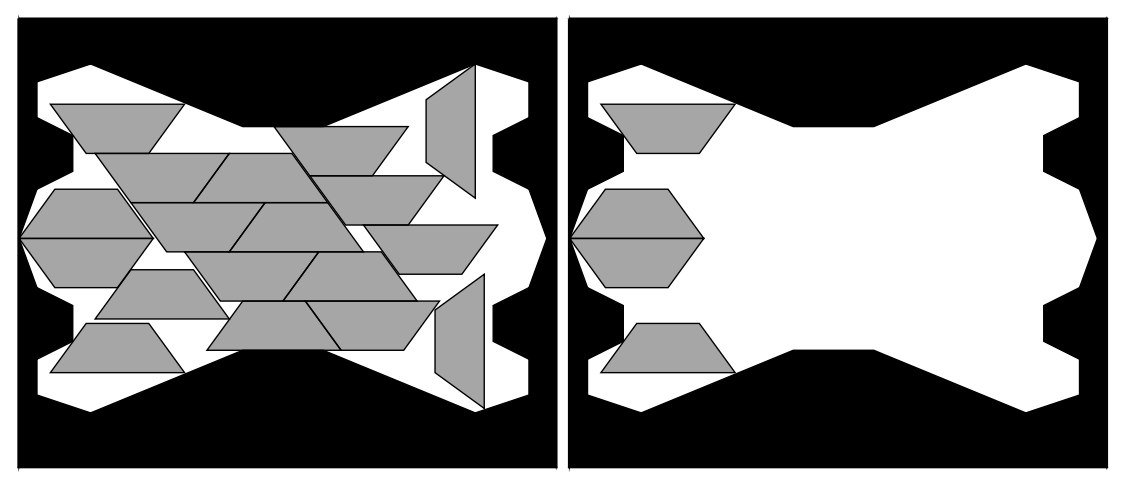

Figura B.8: Tay3-2 


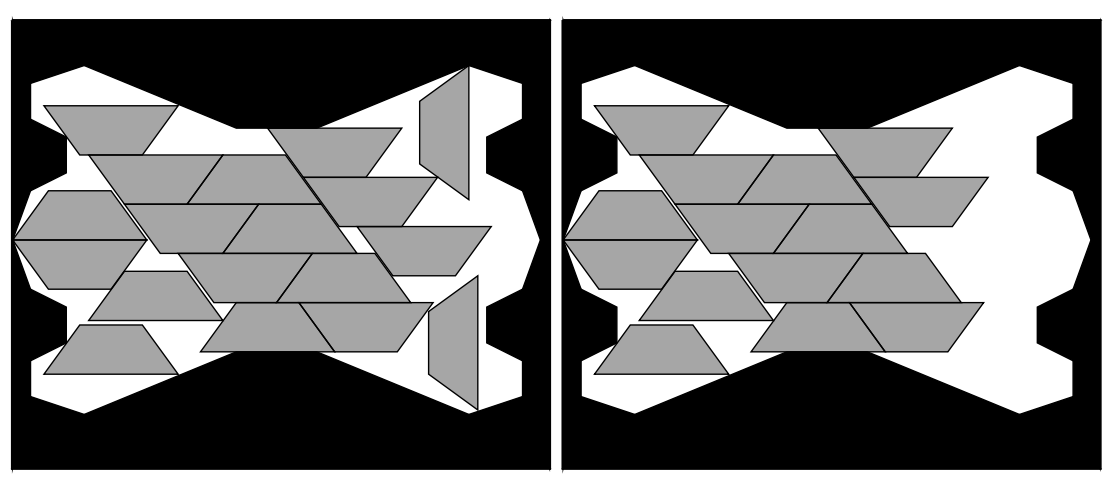

Figura B.9: Tay3-3
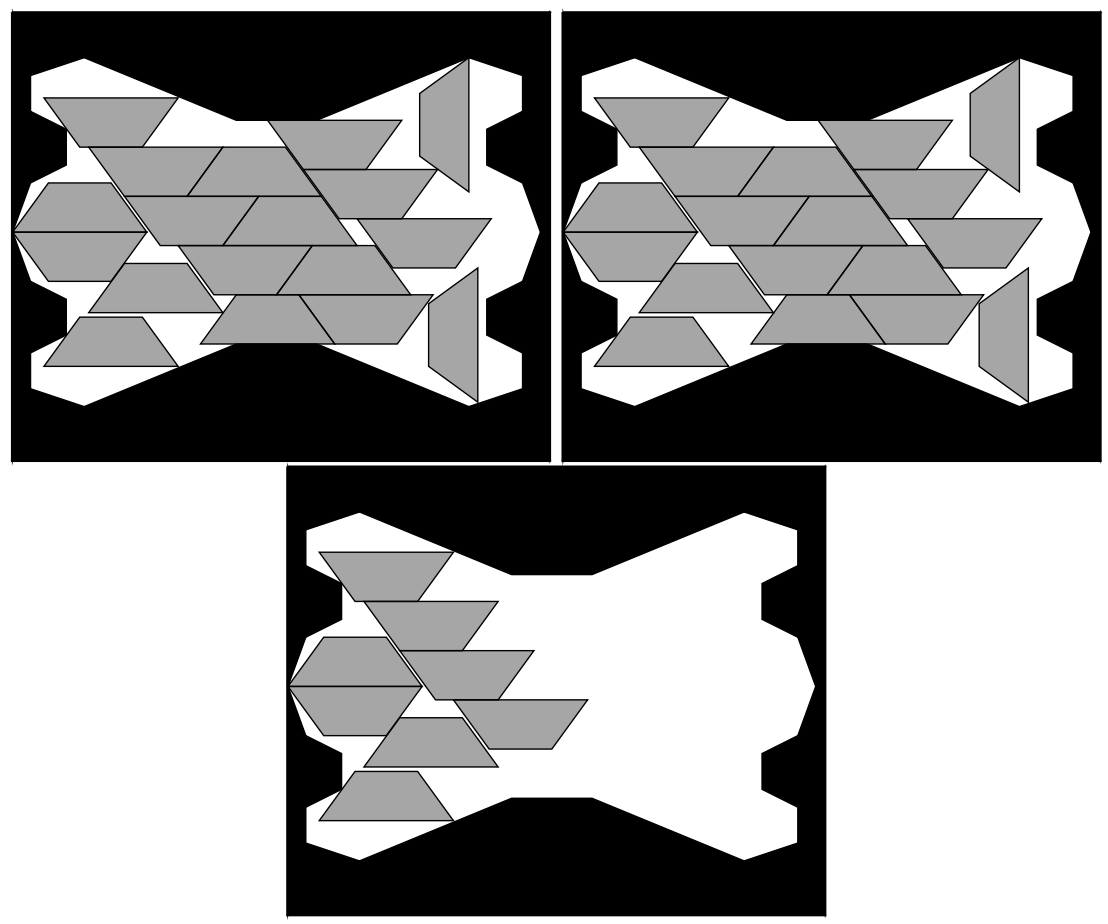

Figura B.10: Tay3-4 


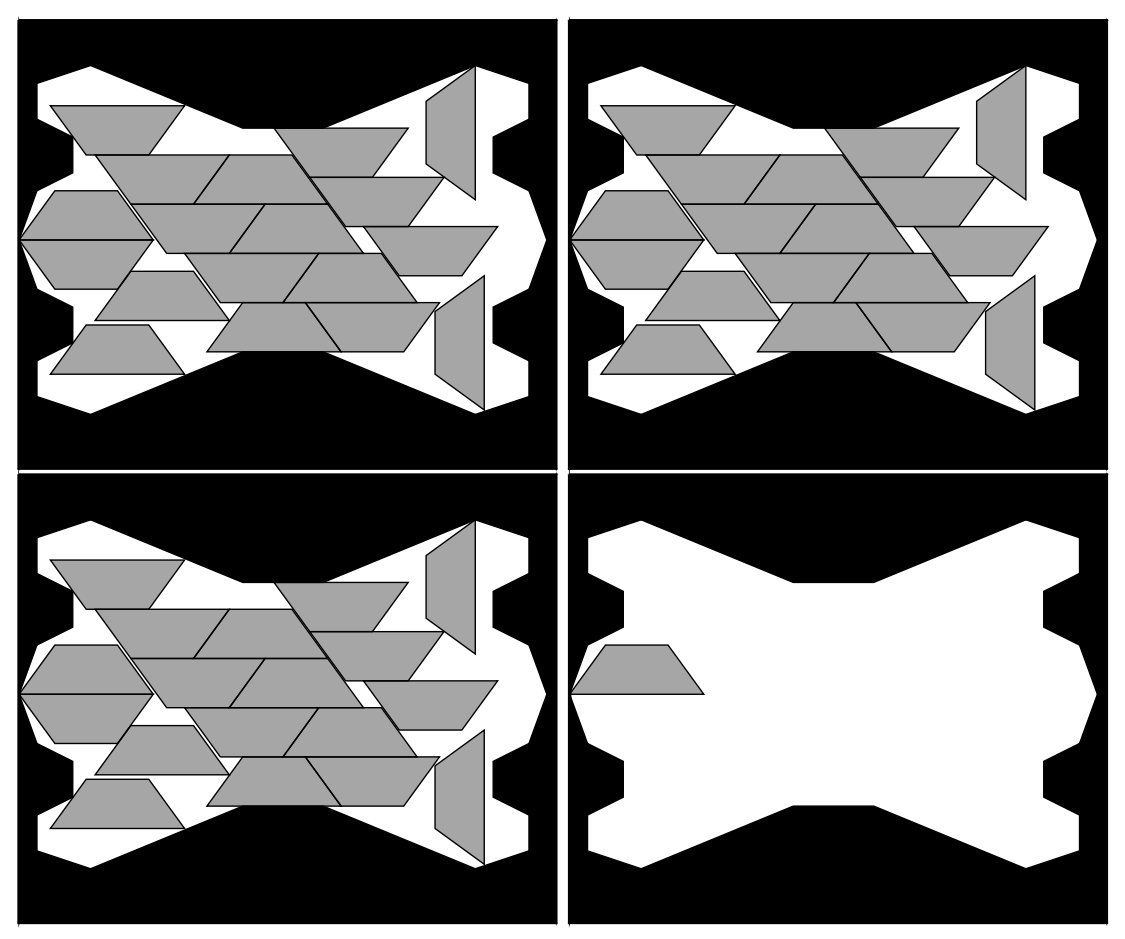

Figura B.11: Tay3-5

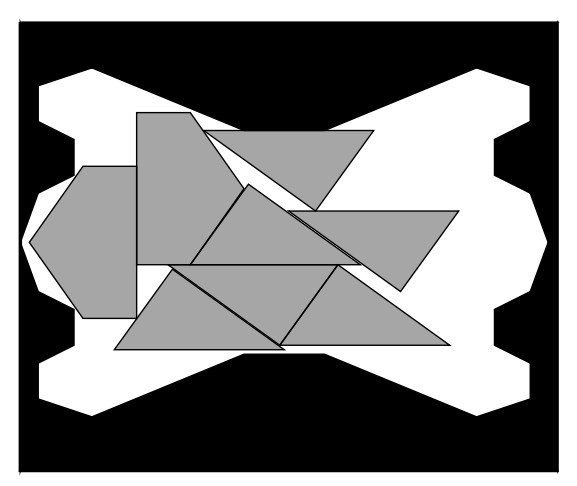

Figura B.12: Tay4-1

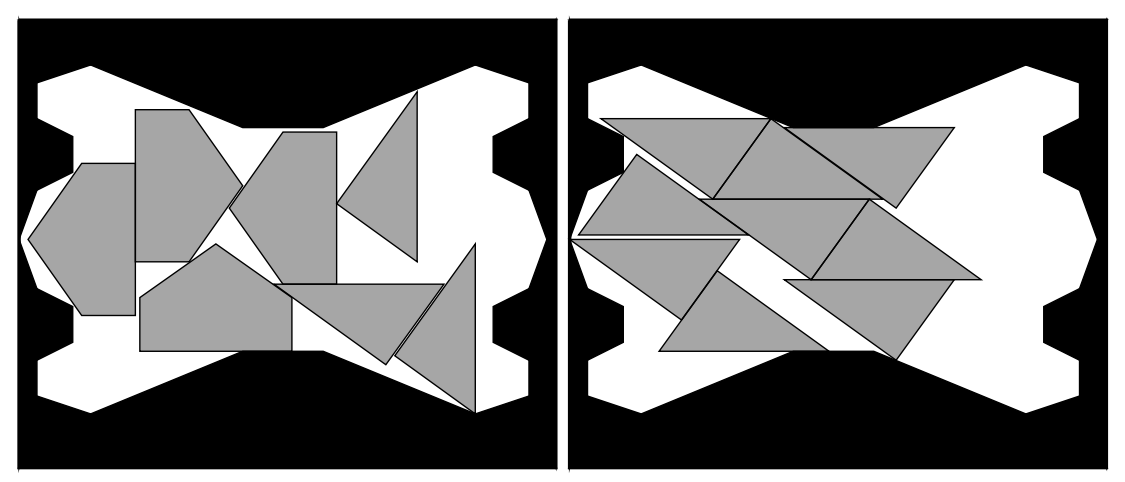

Figura B.13: Tay4-2 

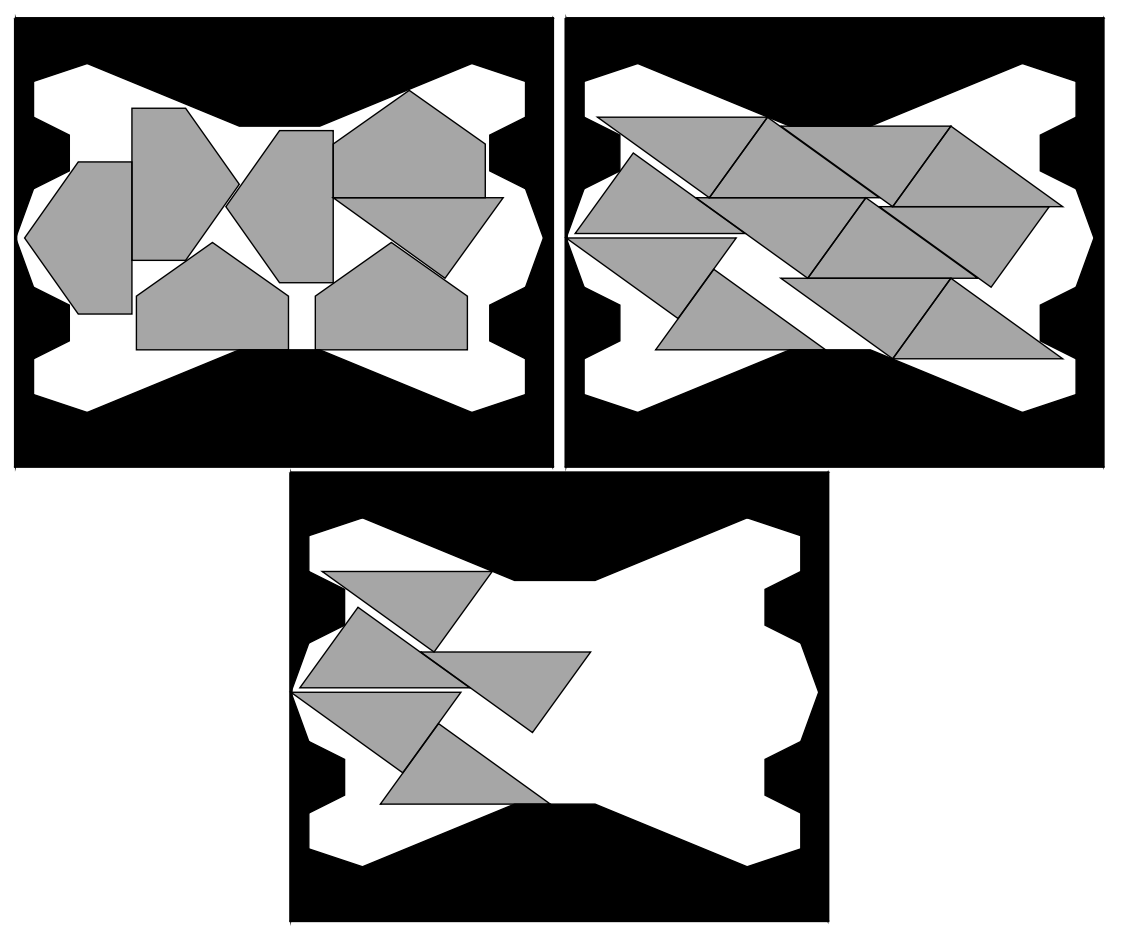

Figura B.14: Tay4-3

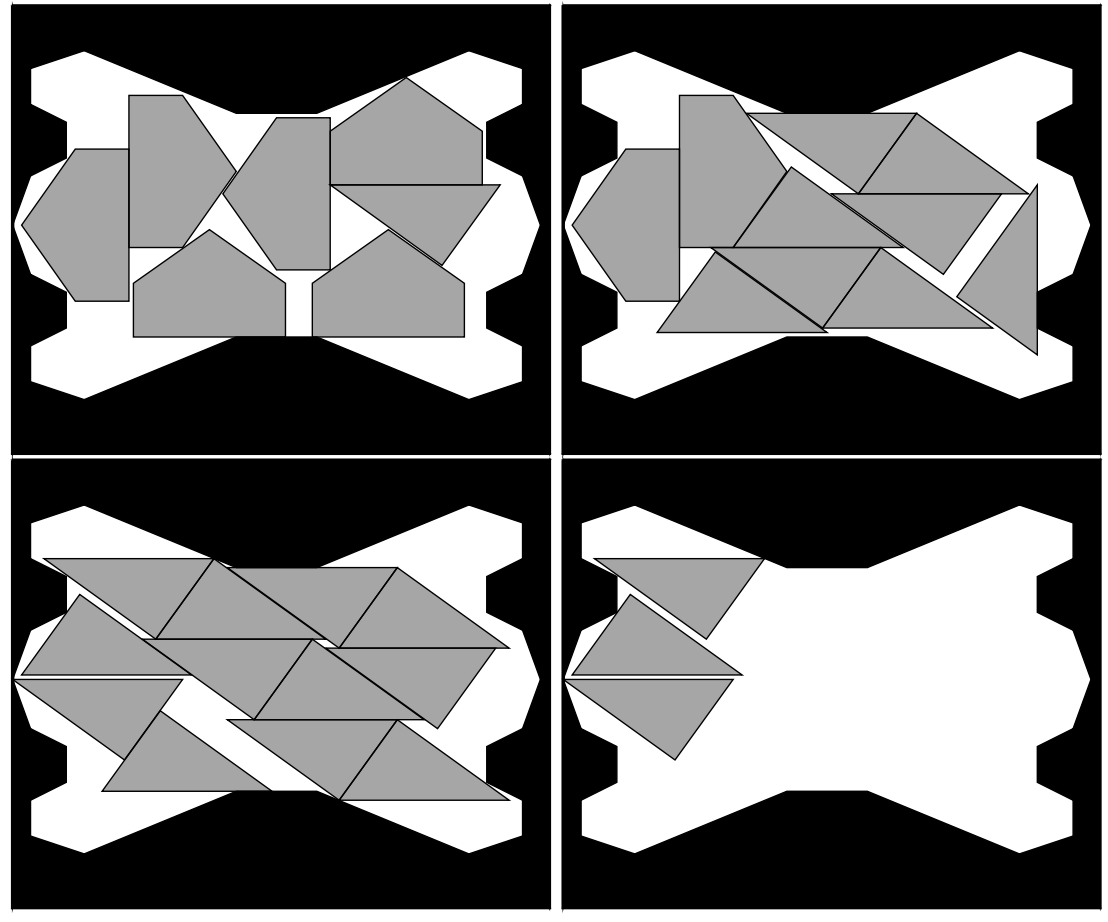

Figura B.15: Tay4-4 


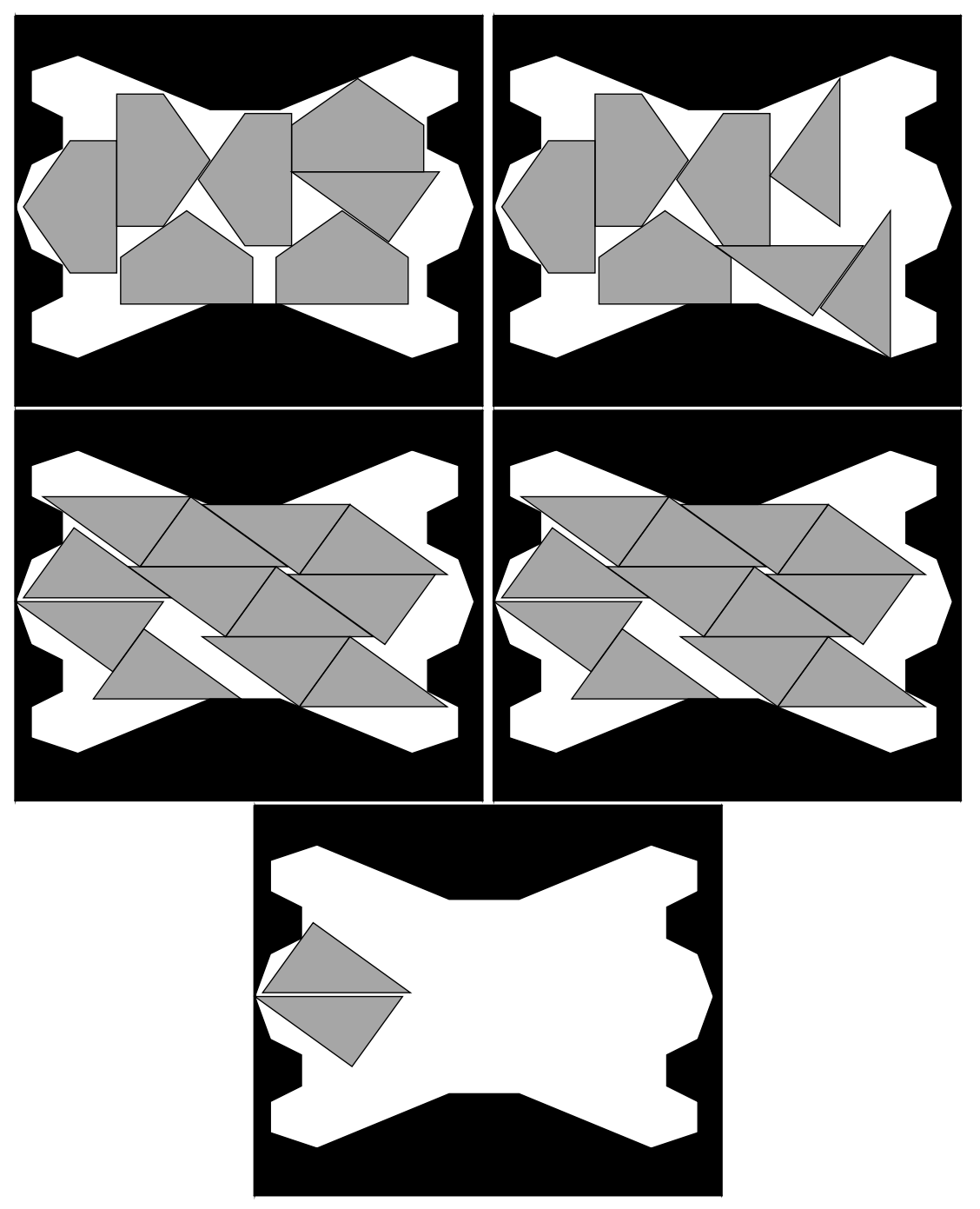

Figura B.16: Tay4-5

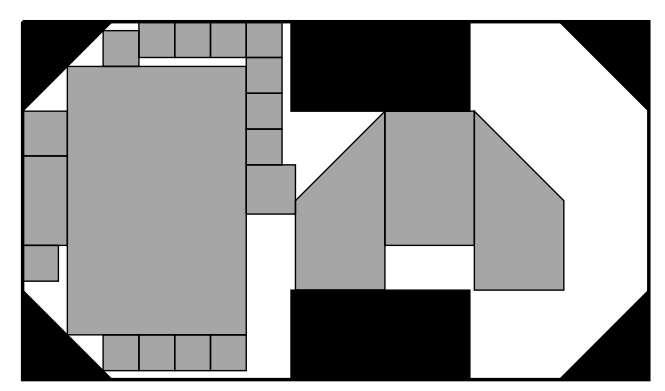

Figura B.17: Tay5-1 


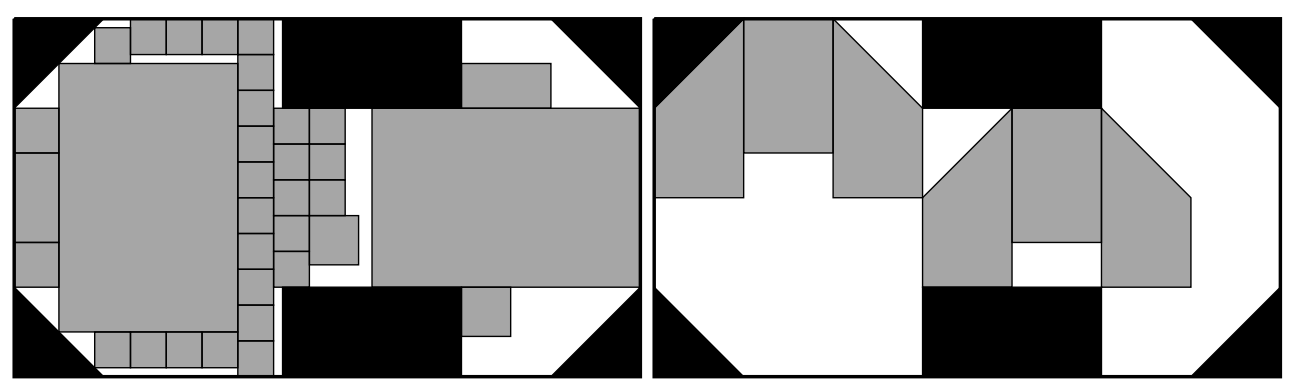

Figura B.18: Tay5-2

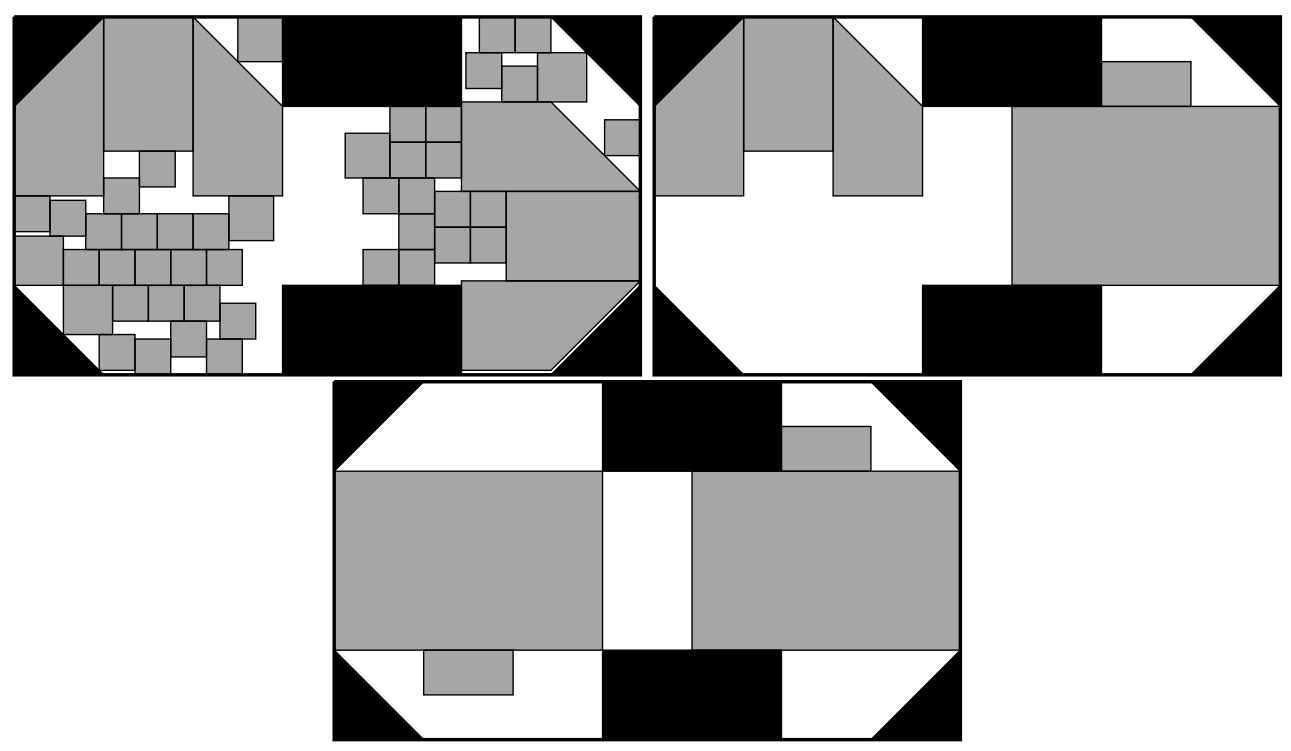

Figura B.19: Tay5-3

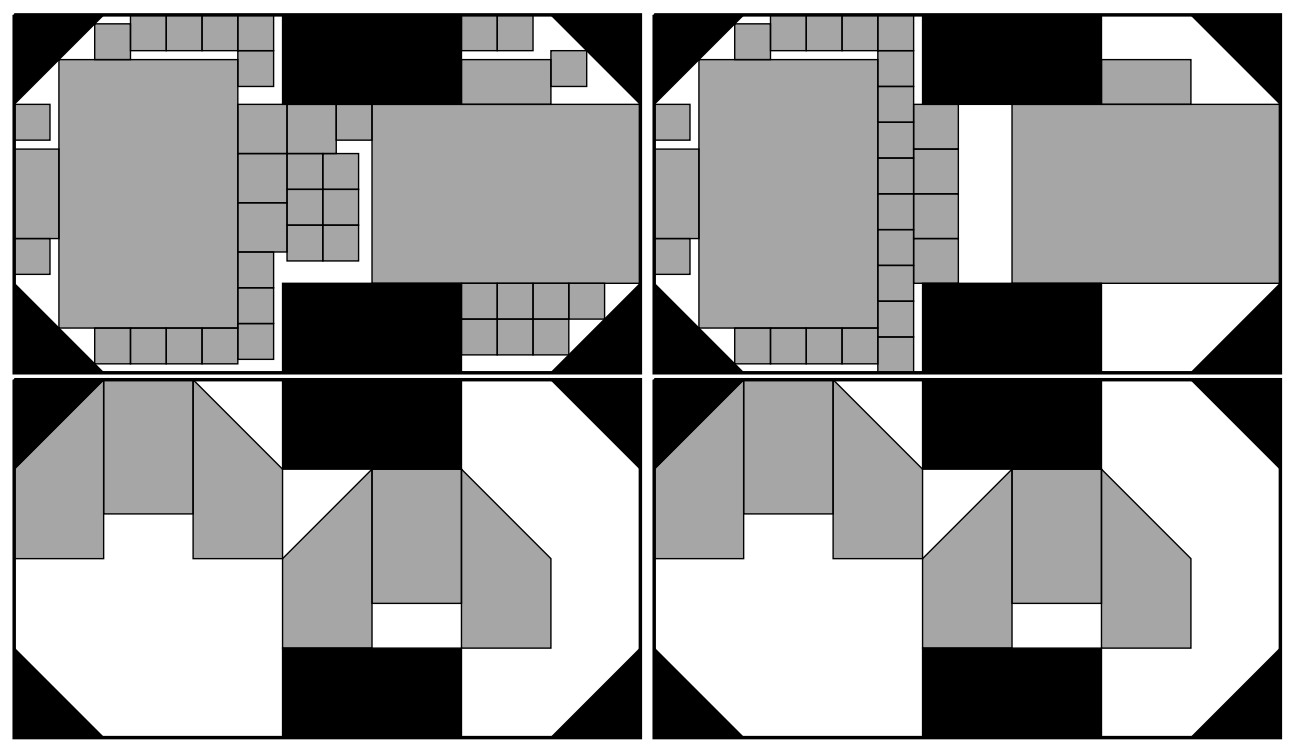

Figura B.20: Tay5-4 


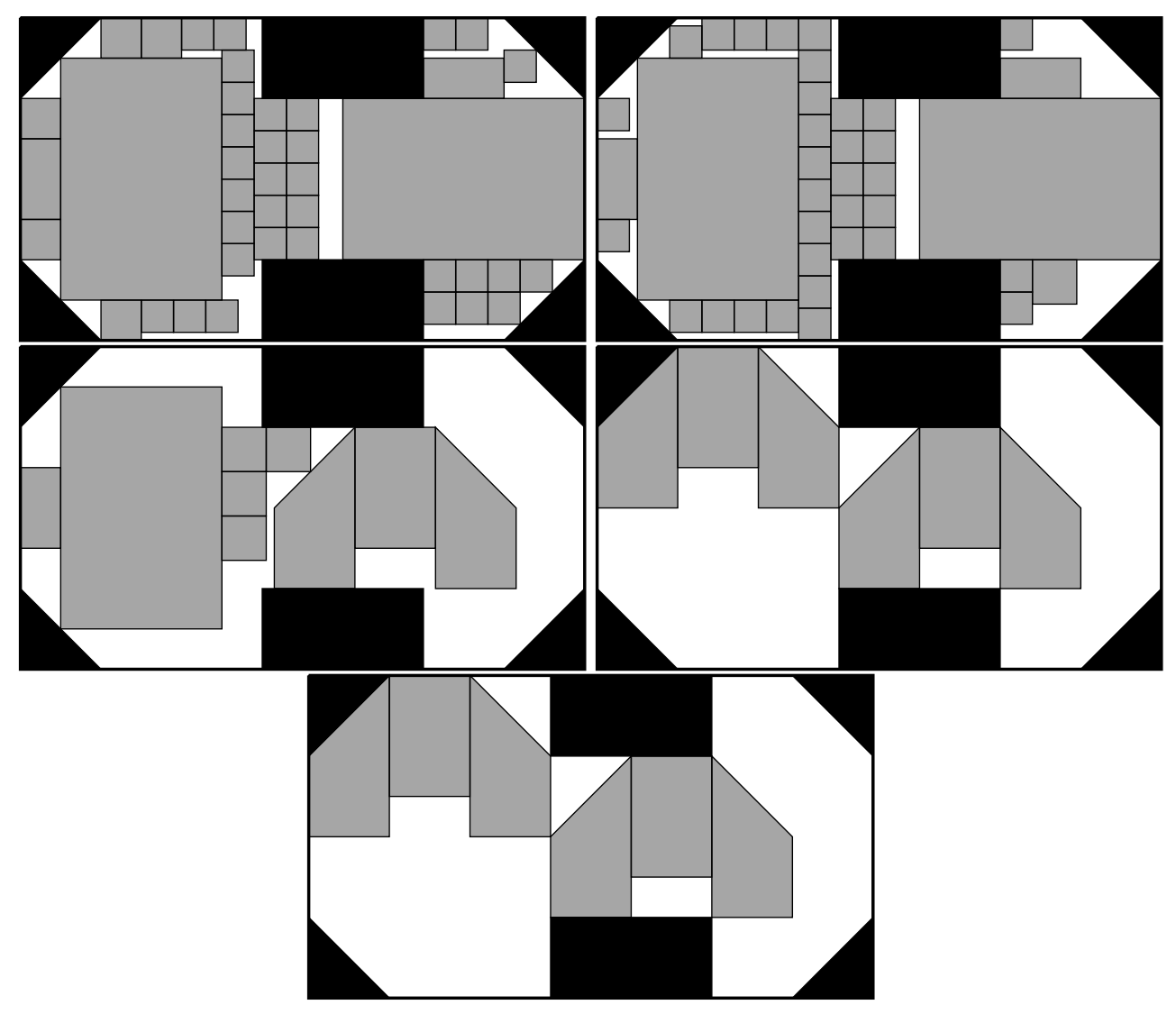

Figura B.21: Tay5-5 


\section{APÊNDICE C}

\section{SOLUÇÕES MOCHILA ILIMITADA}

Neste capítulo serão apresentadas todas as soluções encontradas para o problema da mochila ilimitada.

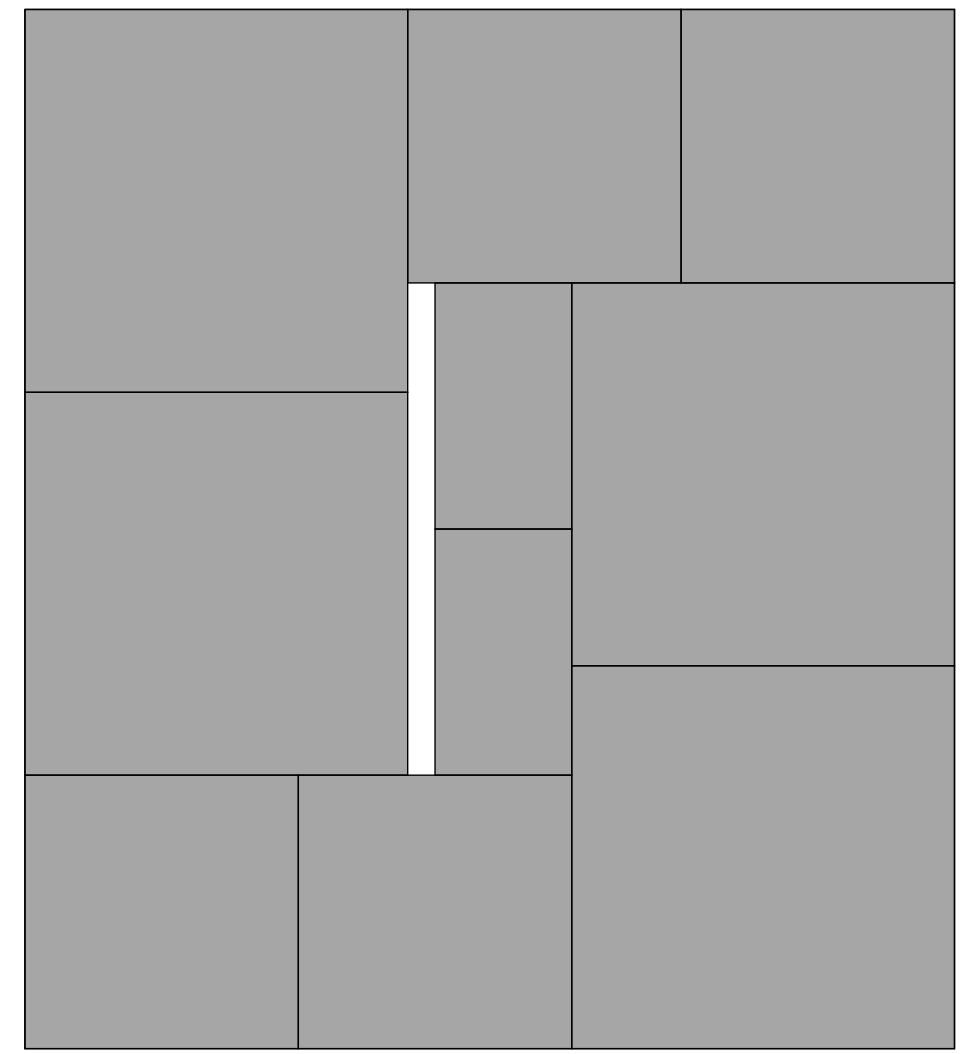

Figura C.1: FU 


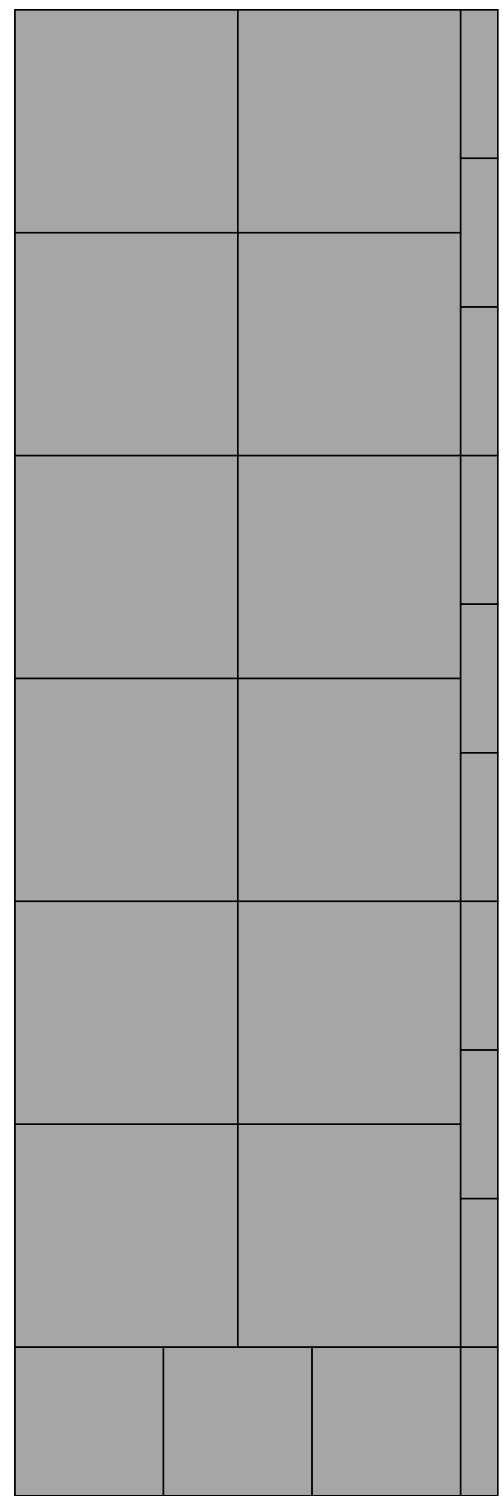

Figura C.2: JAKOBS1 


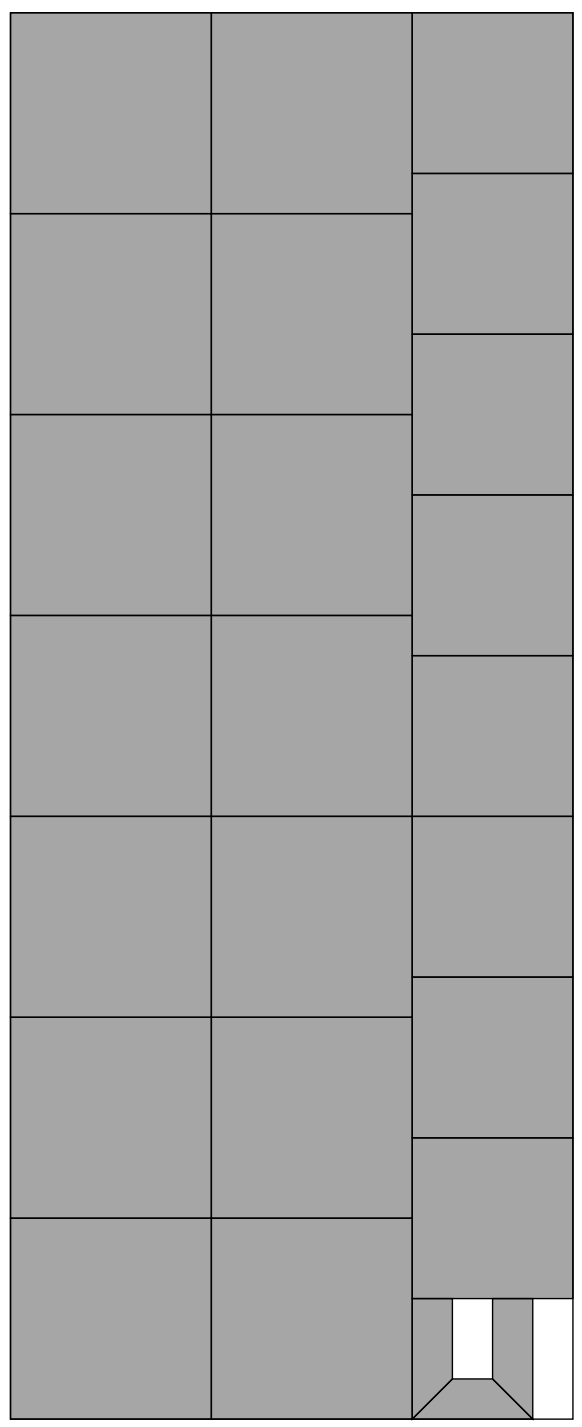

Figura C.3: JAKOBS2 


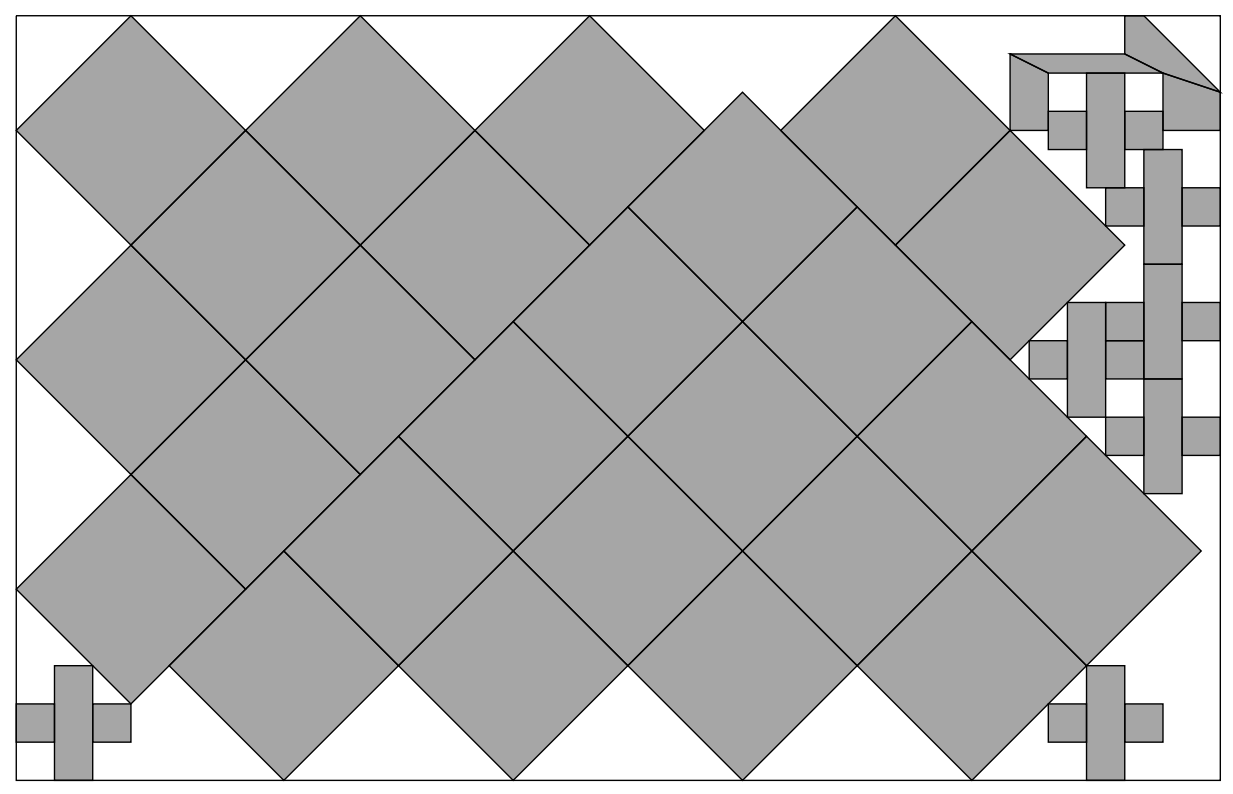

Figura C.4: SHAPES0

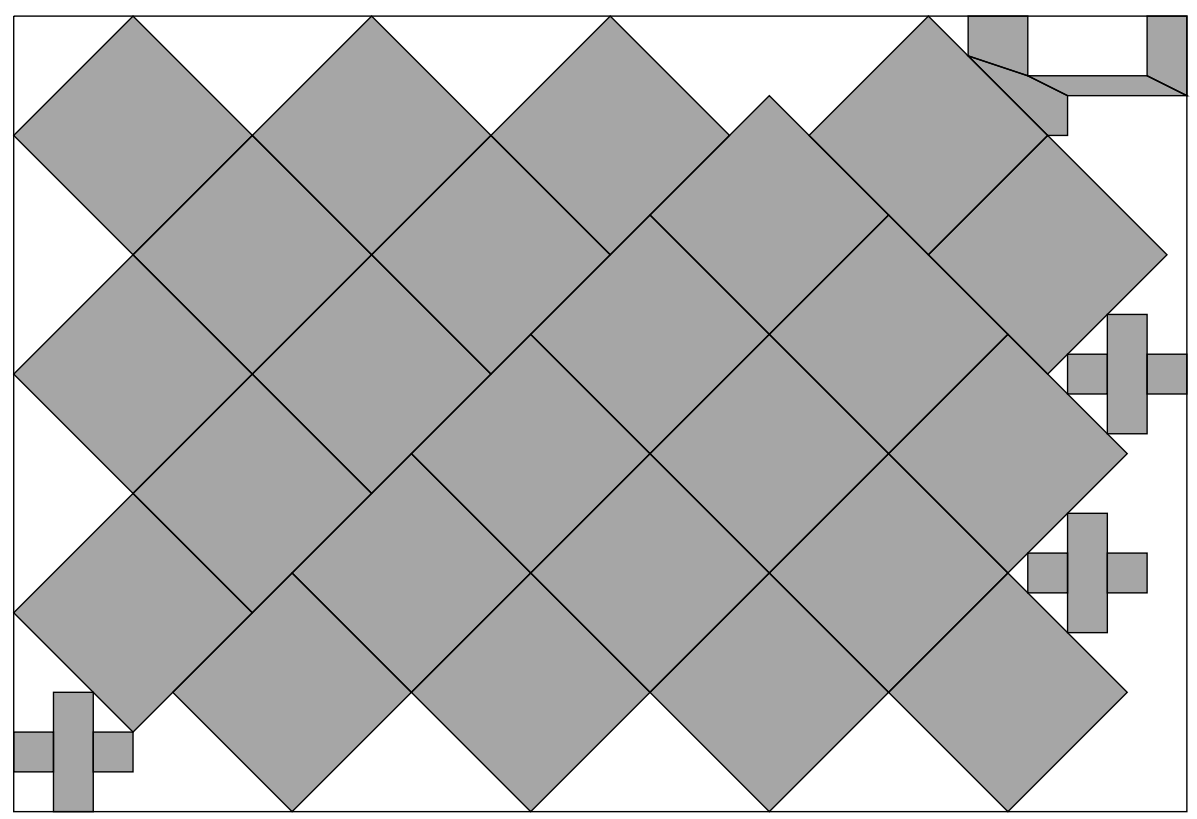

Figura C.5: SHAPES1 


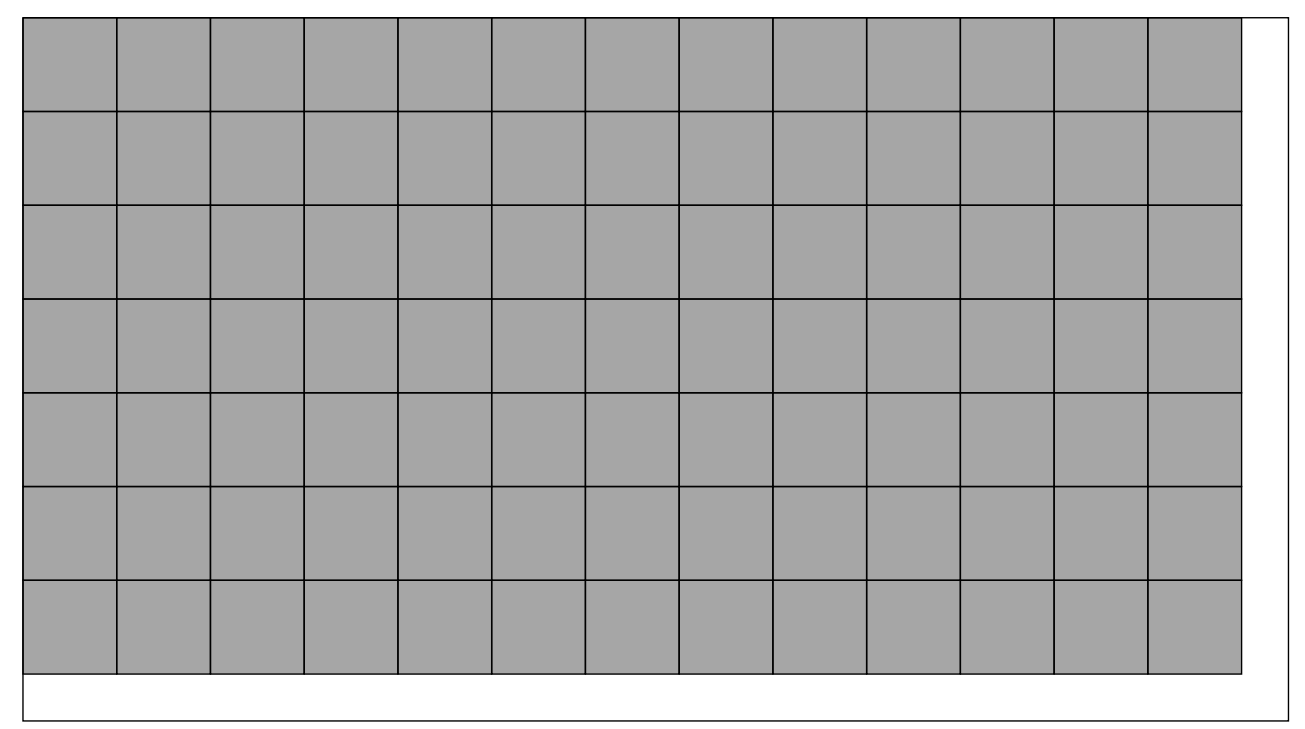

Figura C.6: SHAPES2

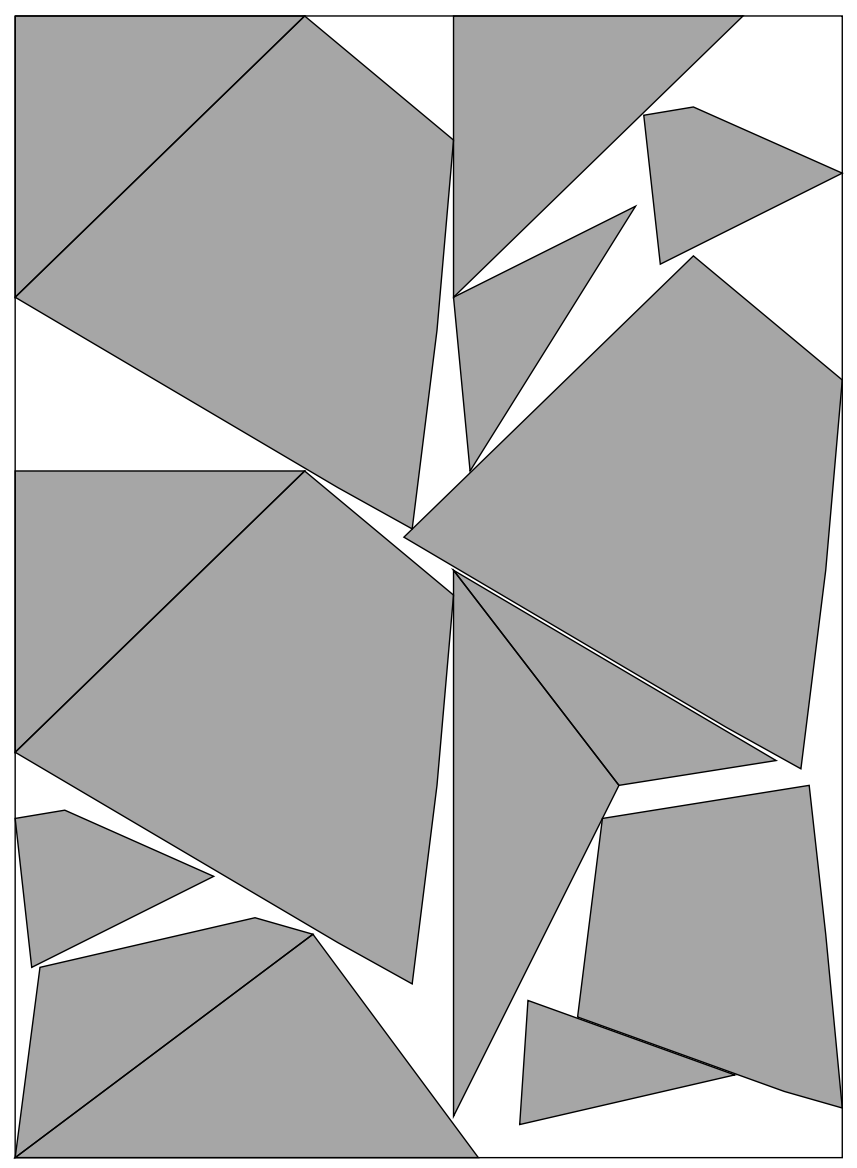

Figura C.7: DIGHE1 


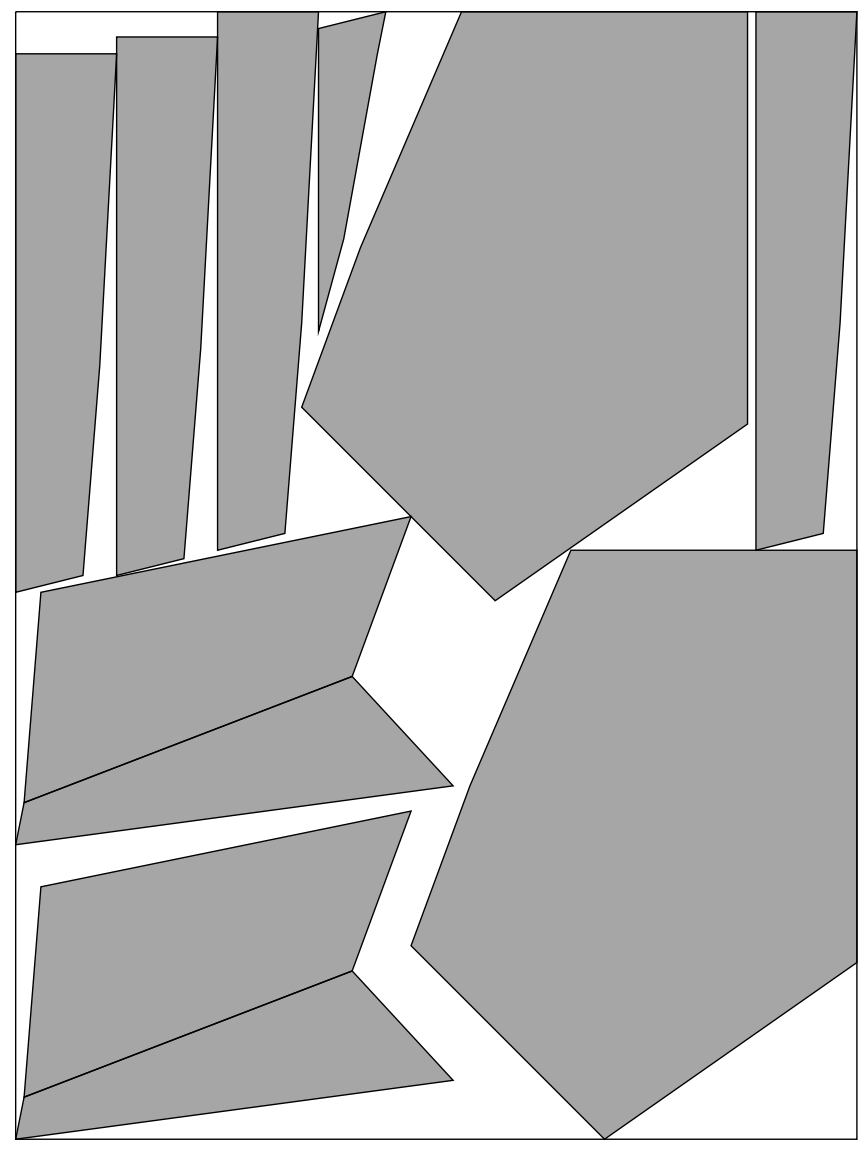

Figura C.8: DIGHE2

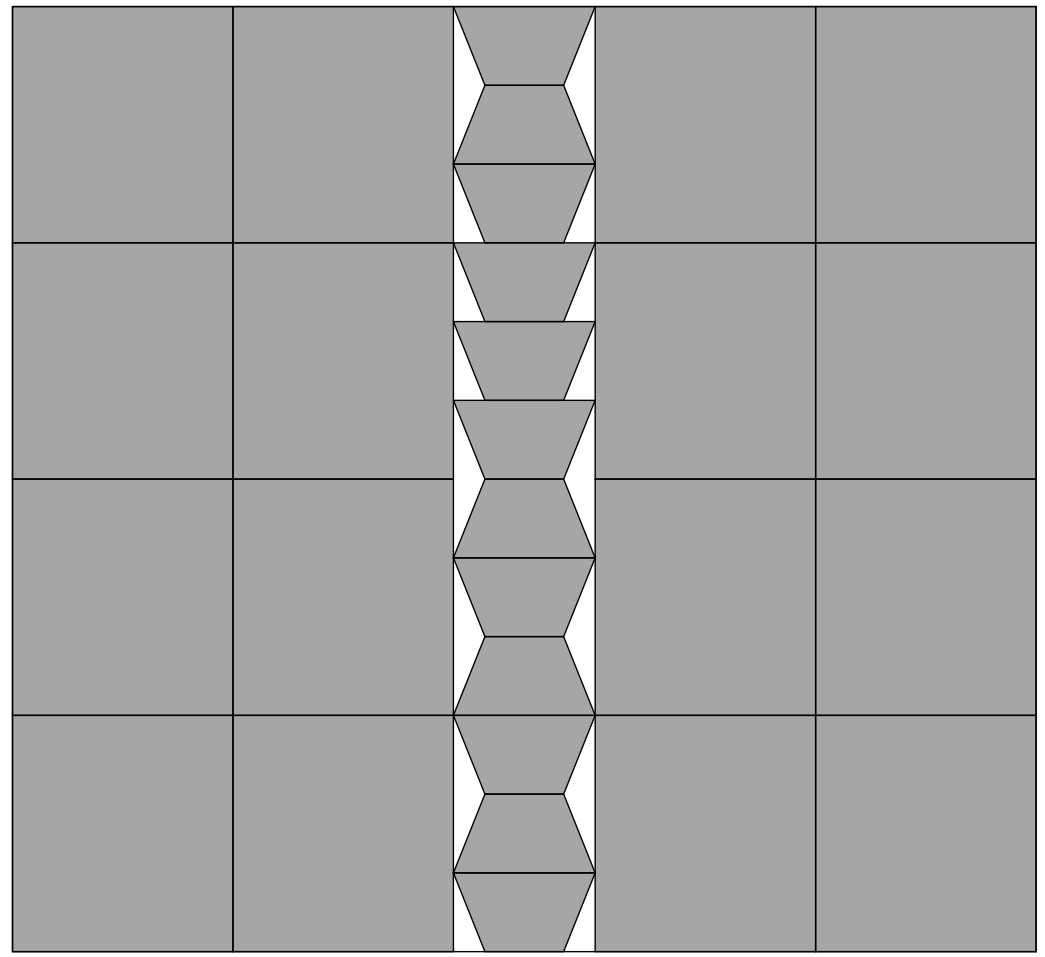

Figura C.9: DAGLI 


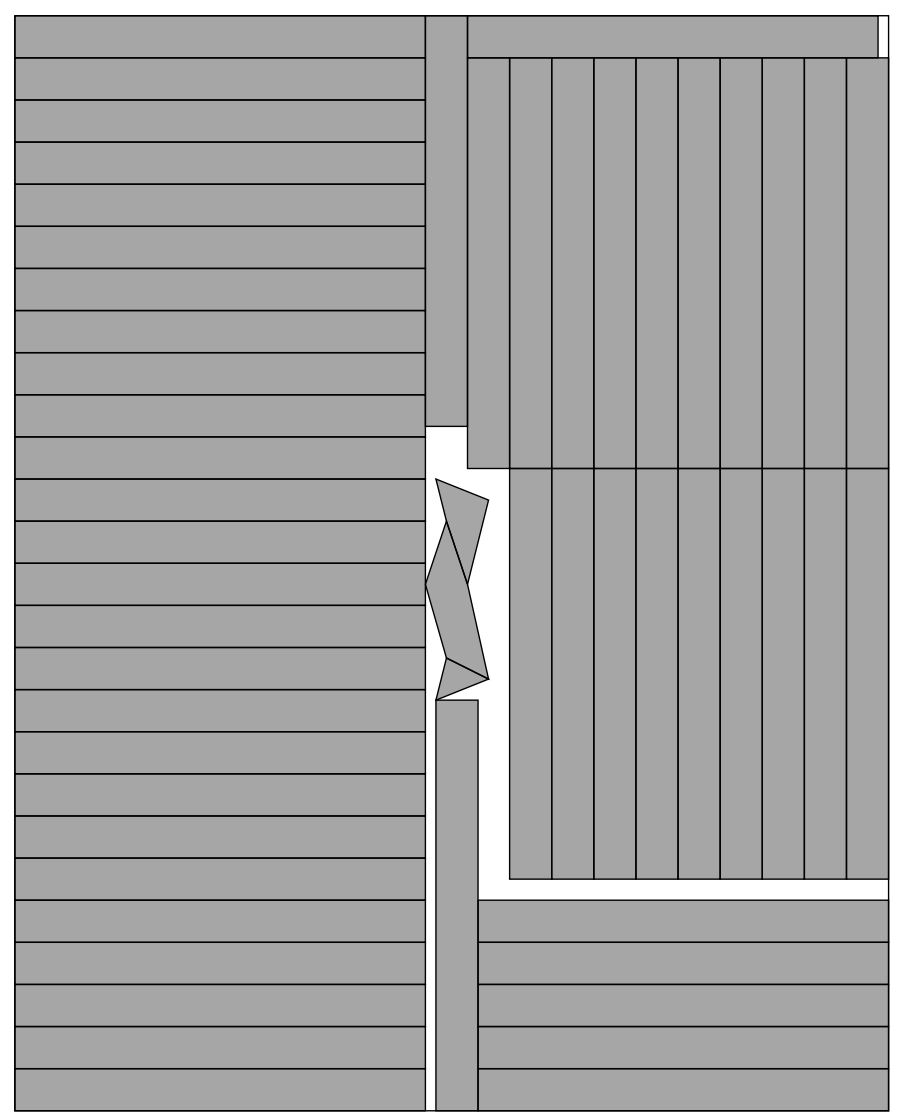

Figura C.10: MARQUES

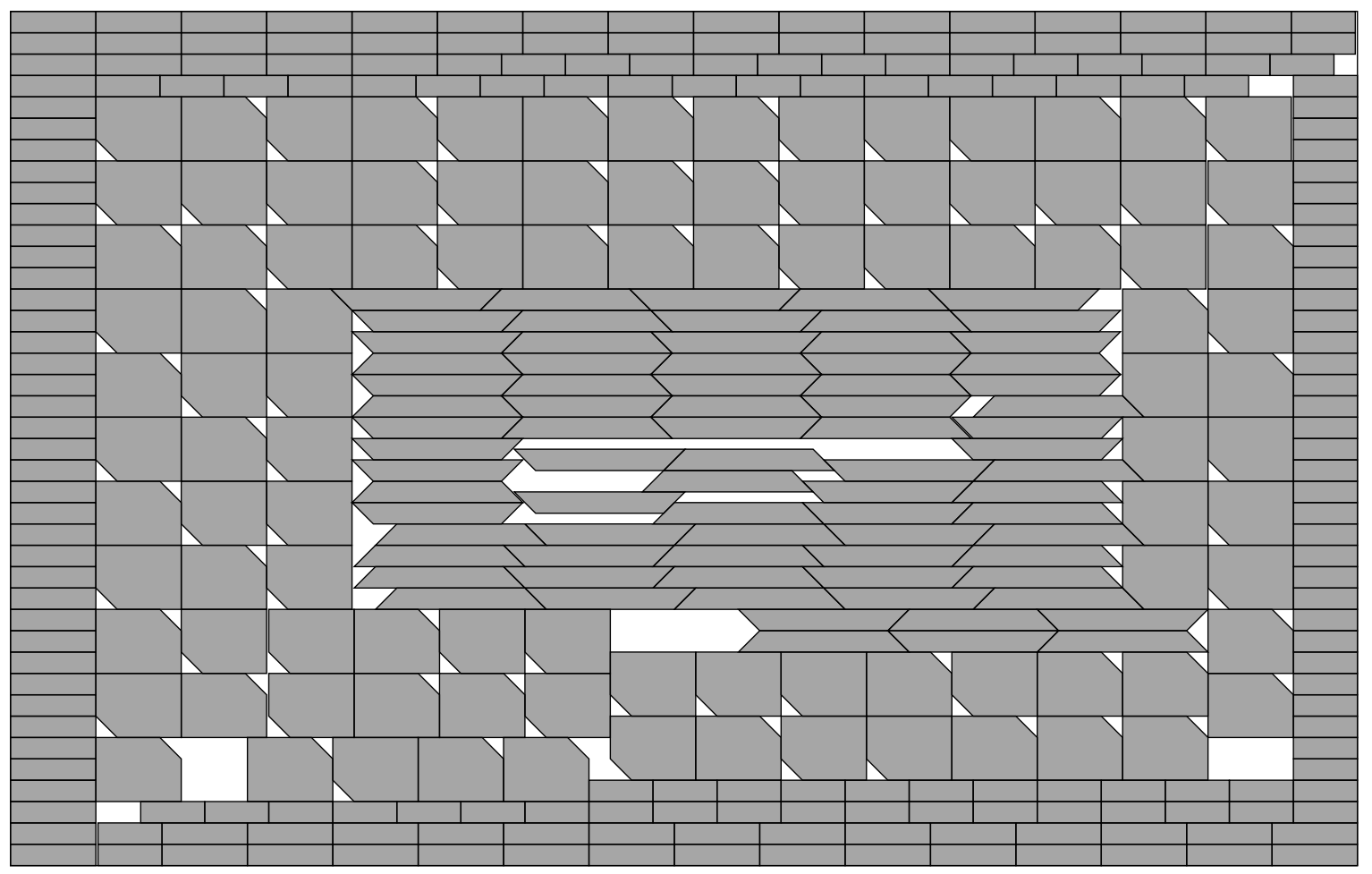

Figura C.11: SHIRTS 


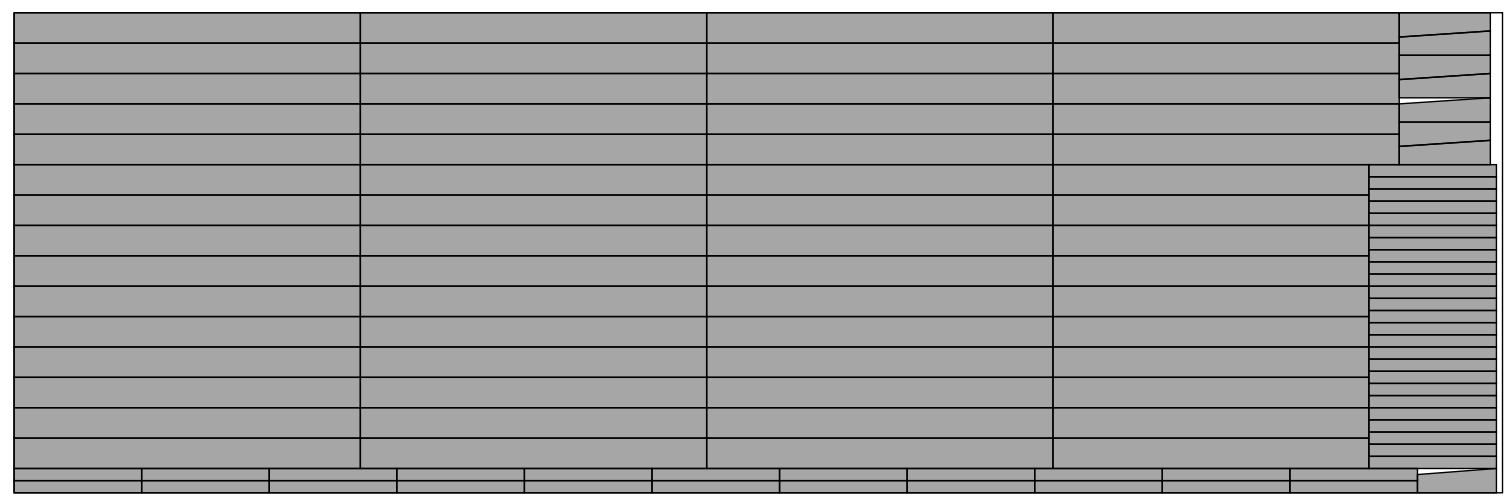

Figura C.12: TROUSERS 


\section{APÊNDICE D}

\section{SOLUÇÕES MOCHILA 0-1}

Neste capítulo serão apresentadas todas as soluções encontradas para o problema da mochila 0-1.

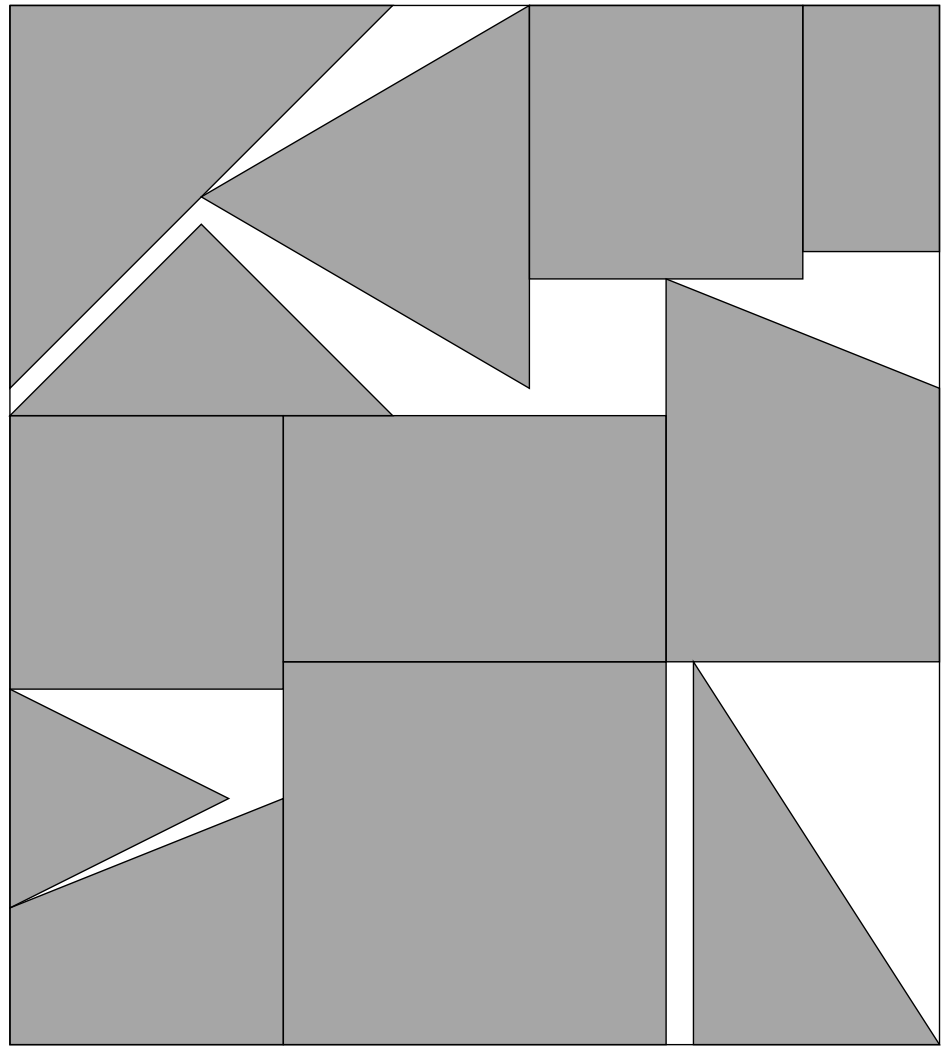

Figura D.1: FU 


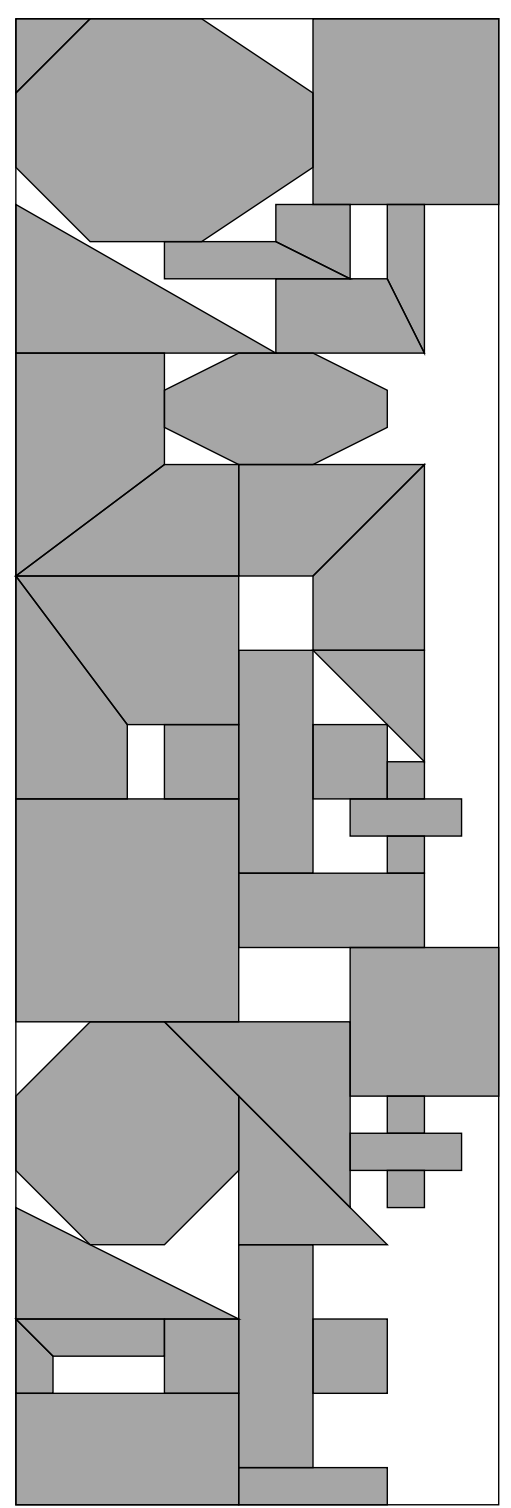

Figura D.2: JAKOBS1 


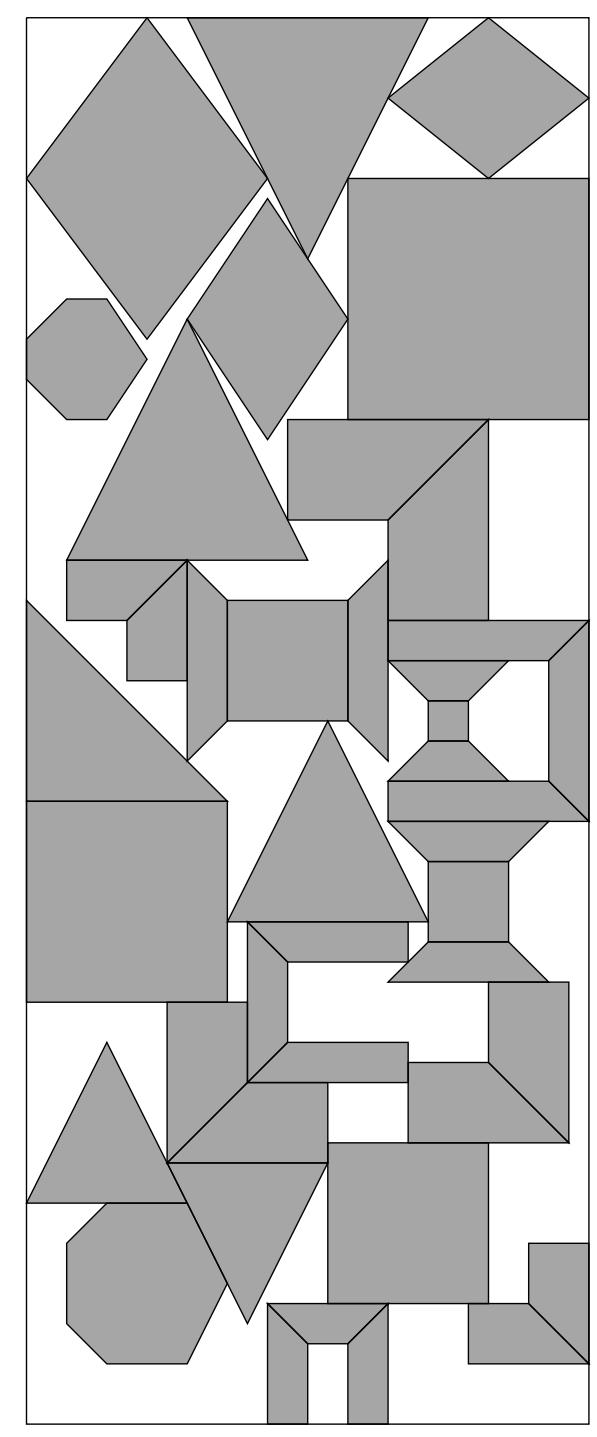

Figura D.3: JAKOBS2 


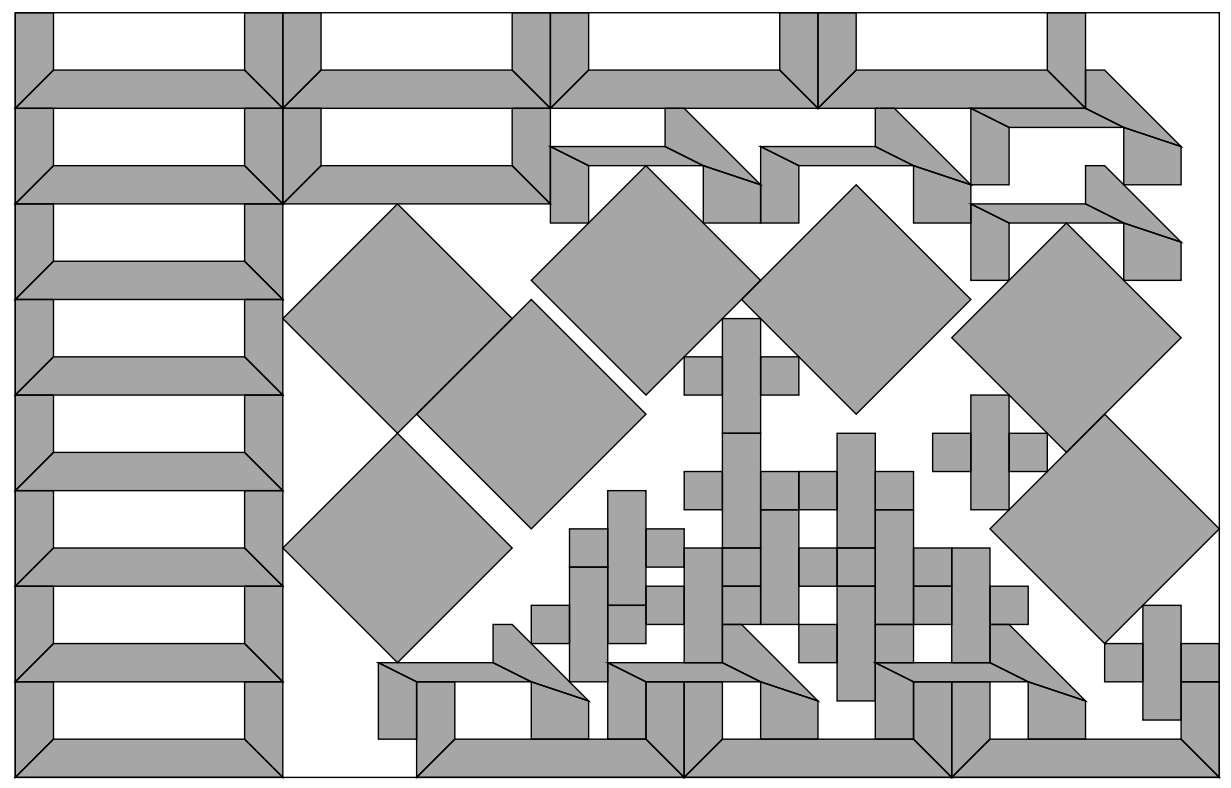

Figura D.4: SHAPES0

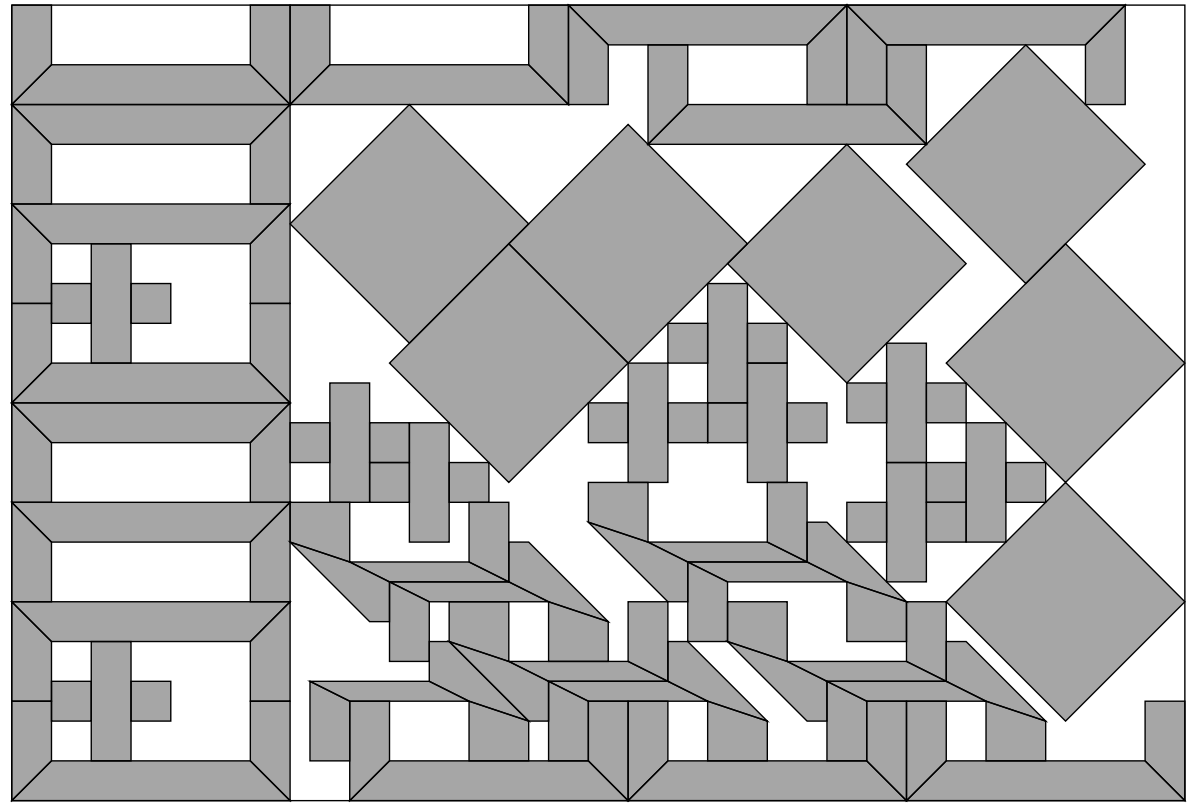

Figura D.5: SHAPES1 


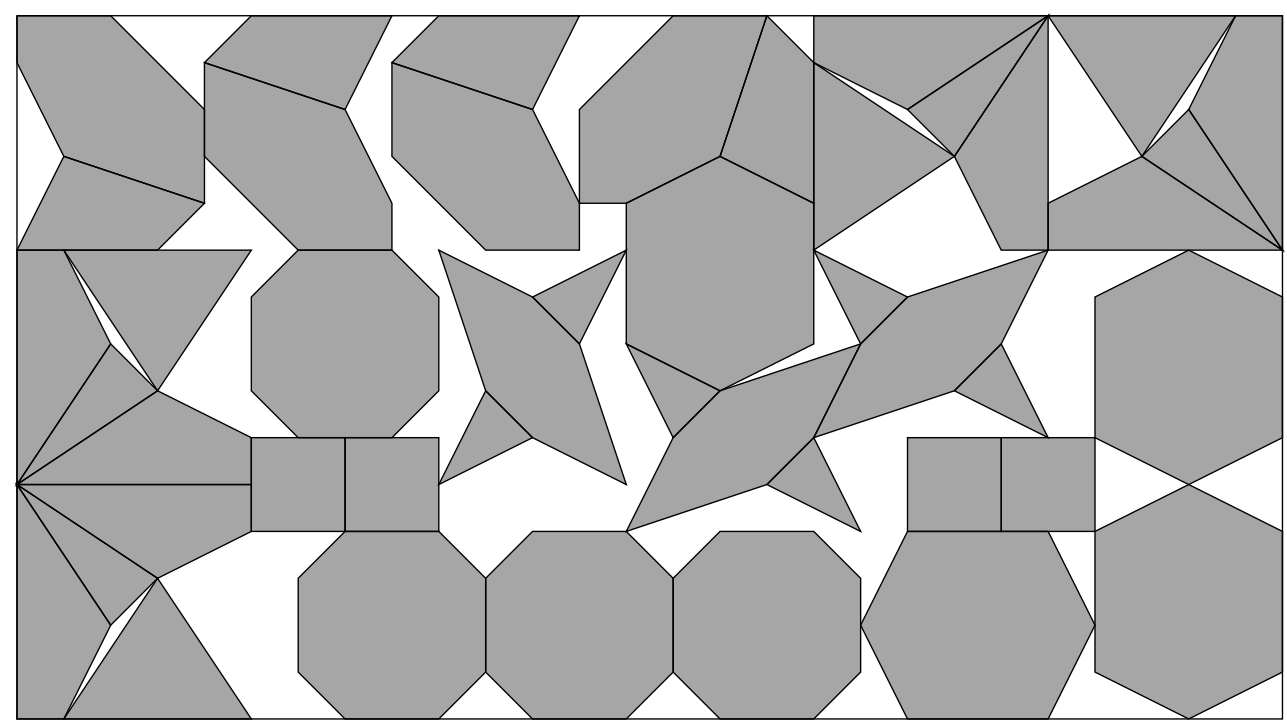

Figura D.6: SHAPES2

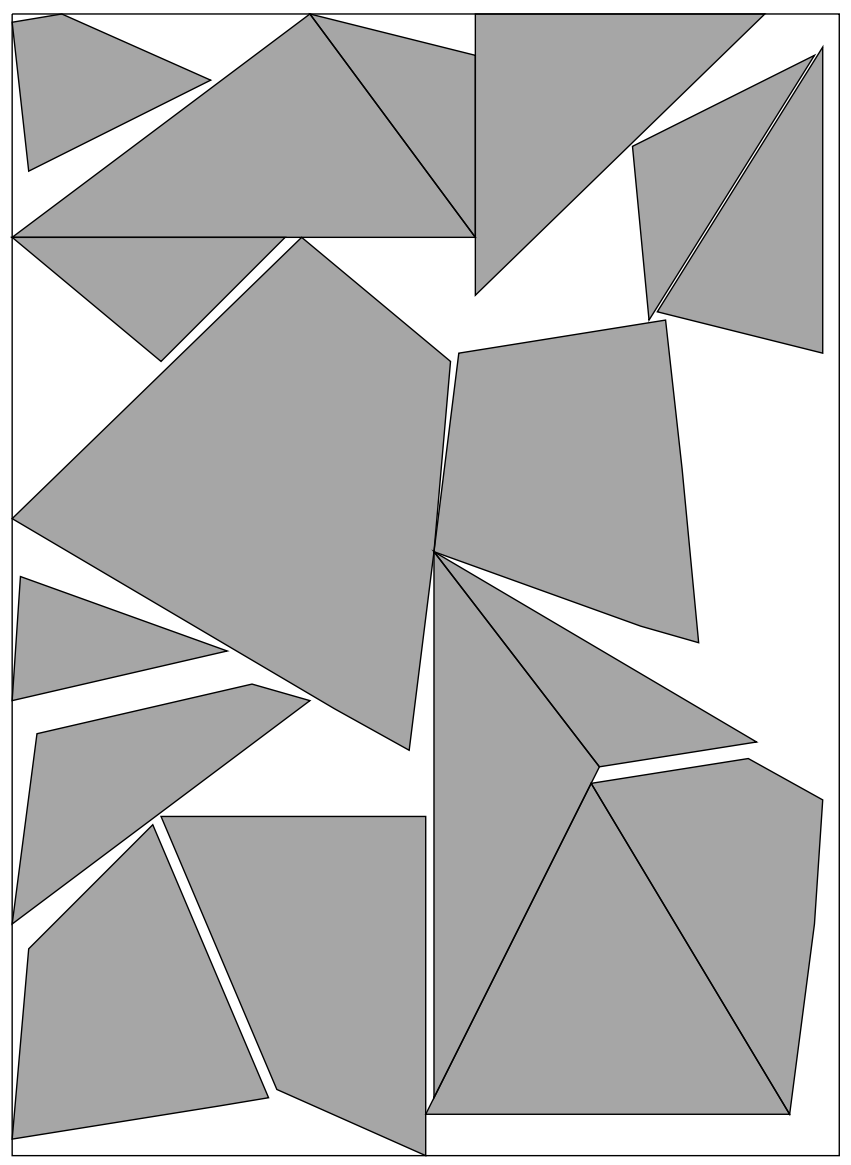

Figura D.7: DIGHE1 


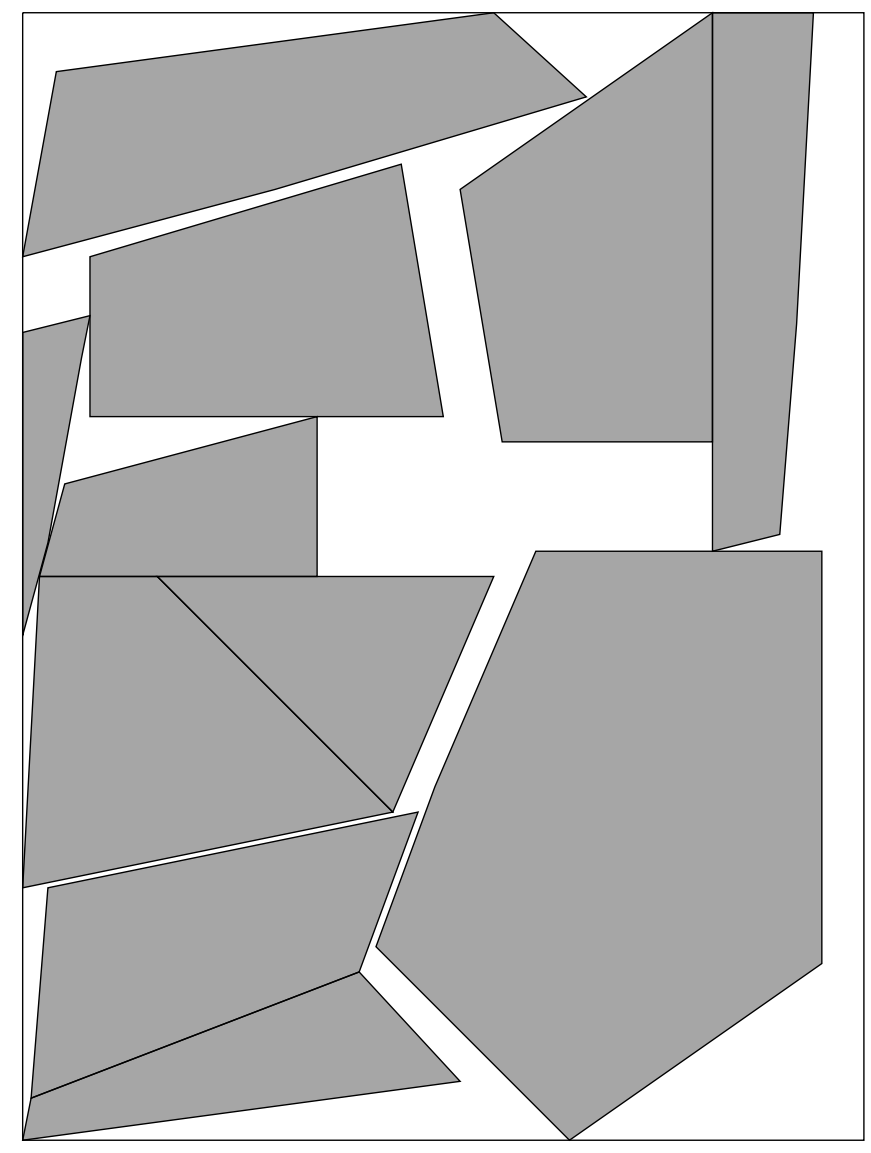

Figura D.8: DIGHE2

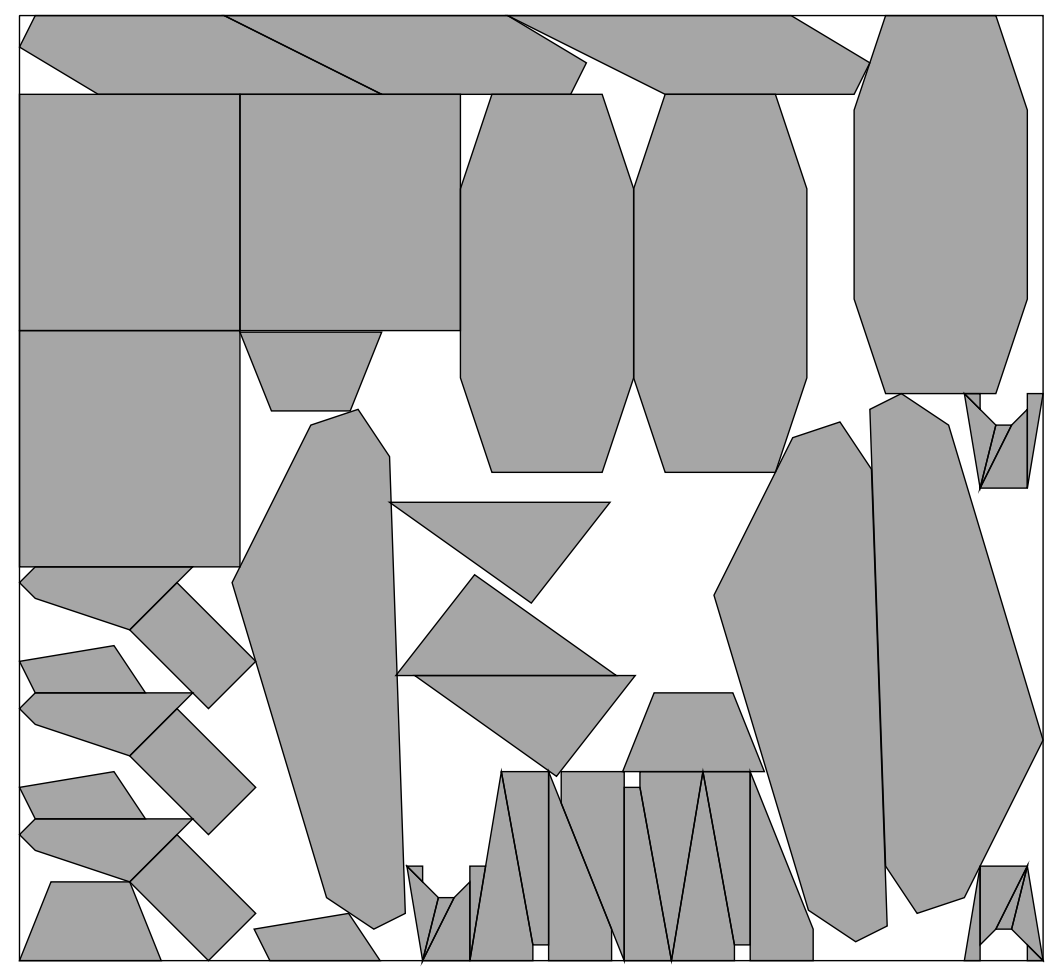

Figura D.9: DAGLI 


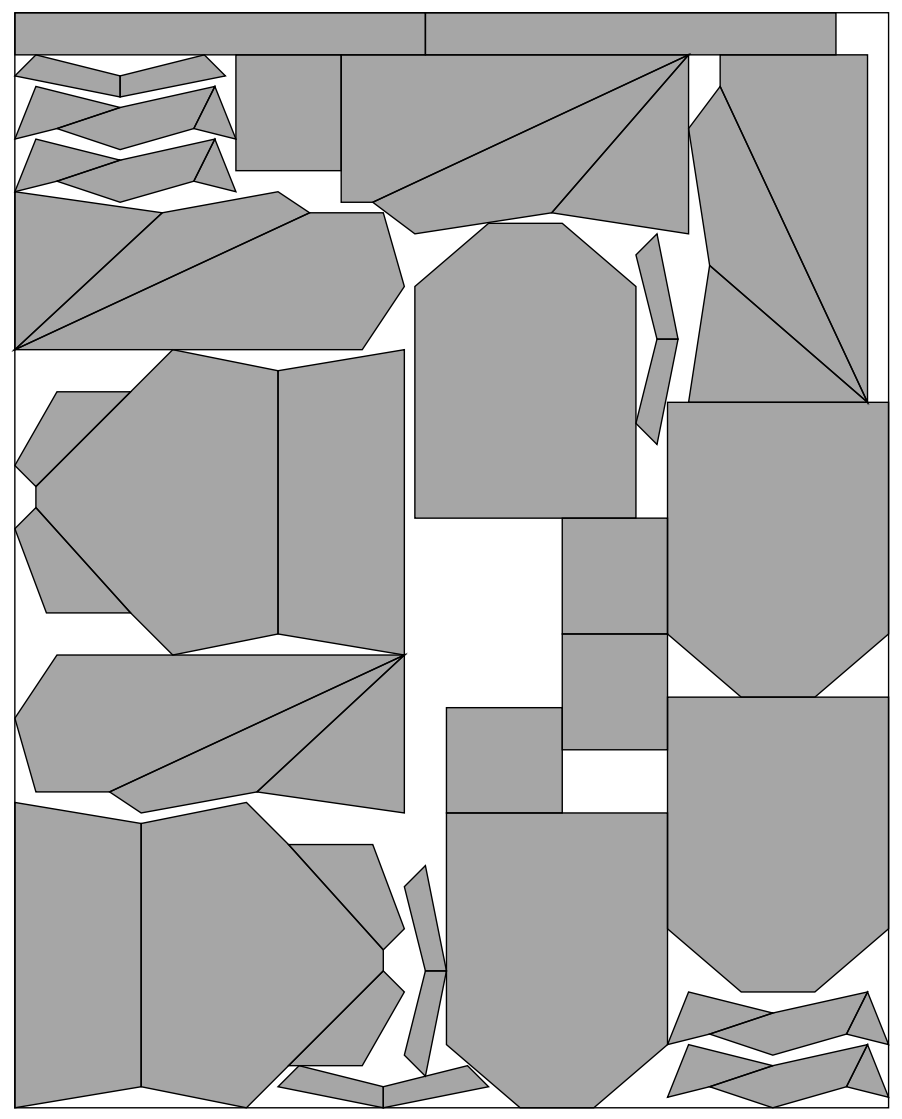

Figura D.10: MARQUES

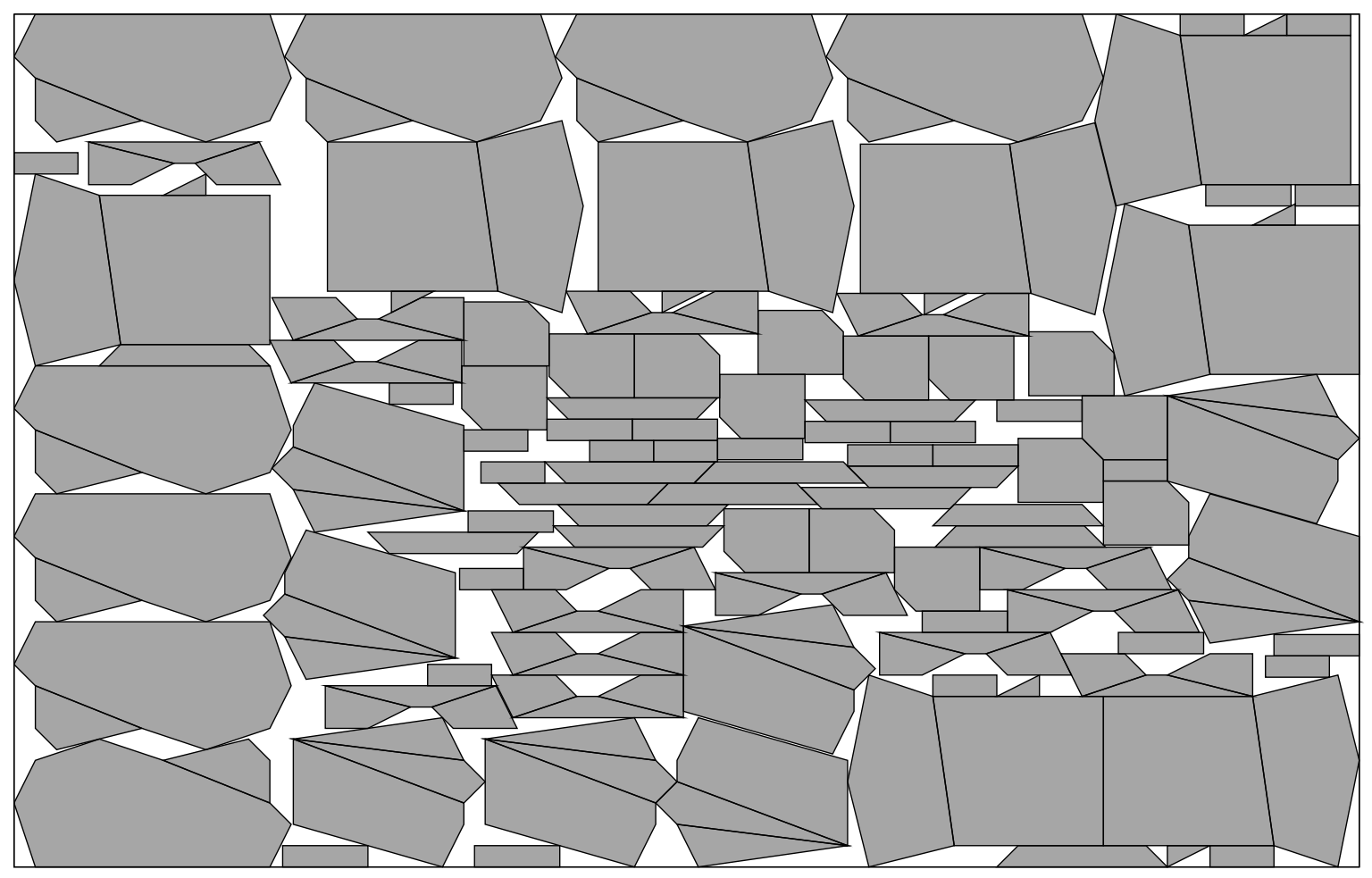

Figura D.11: SHIRTS 


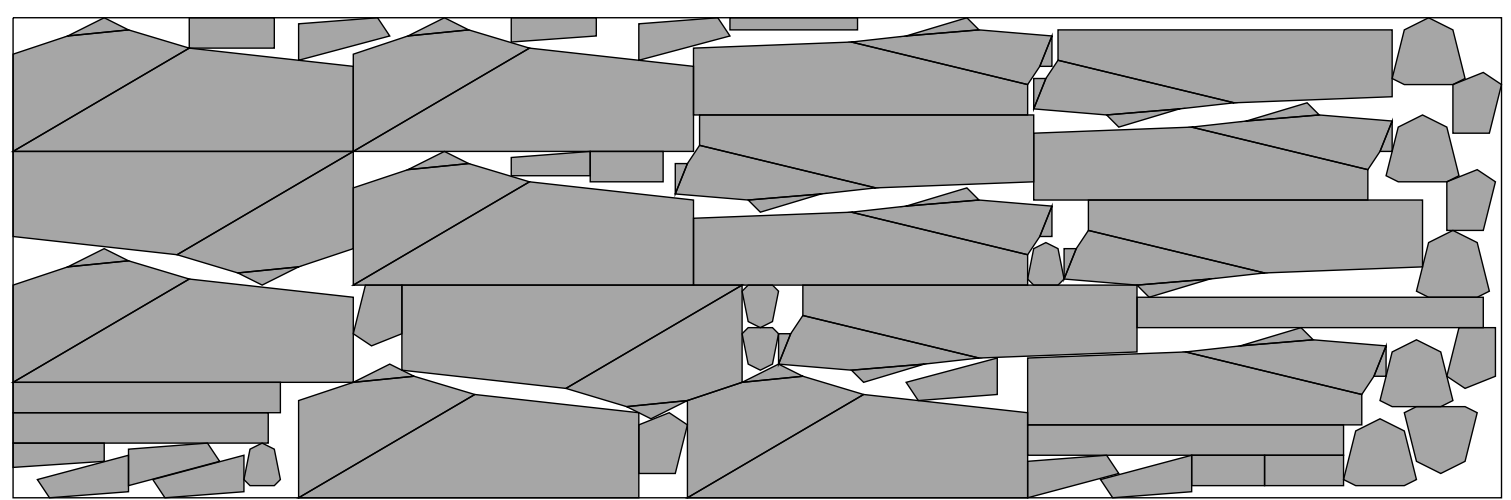

Figura D.12: TROUSERS

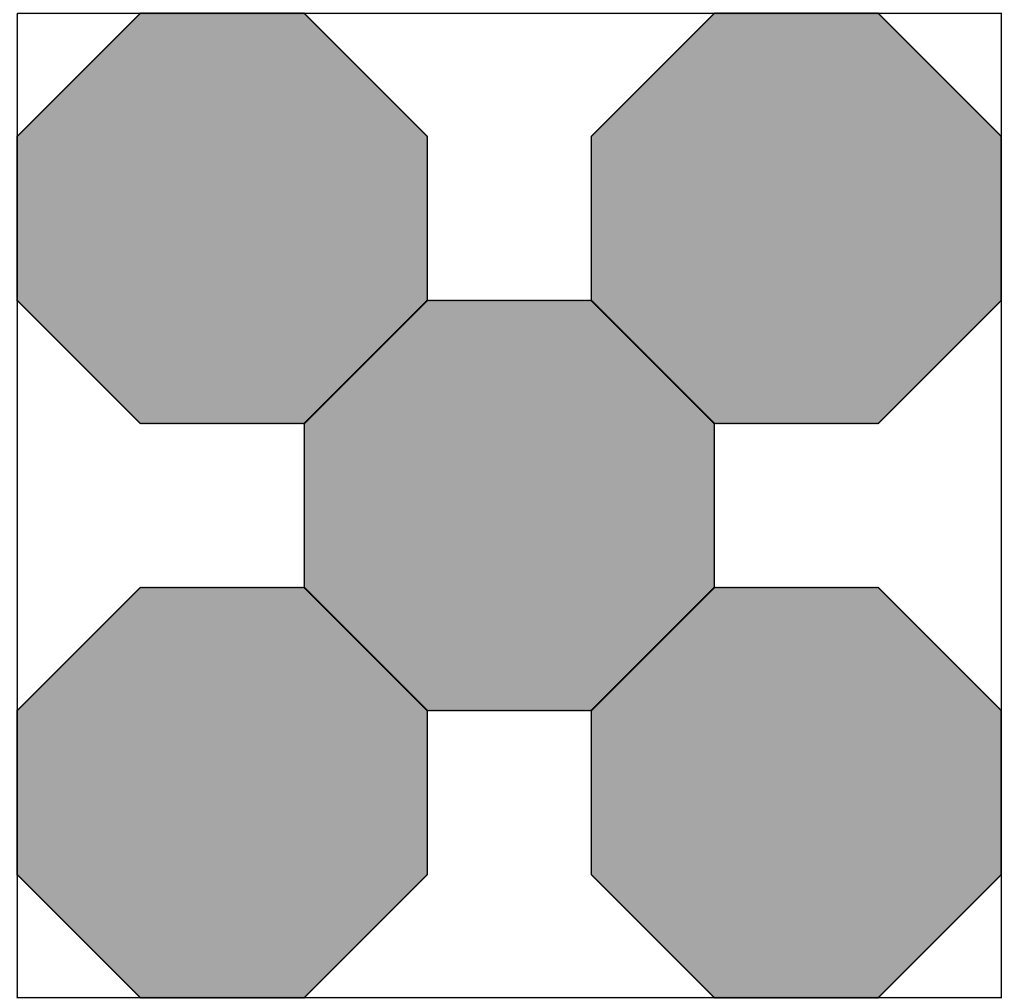

Figura D.13: BLFP 


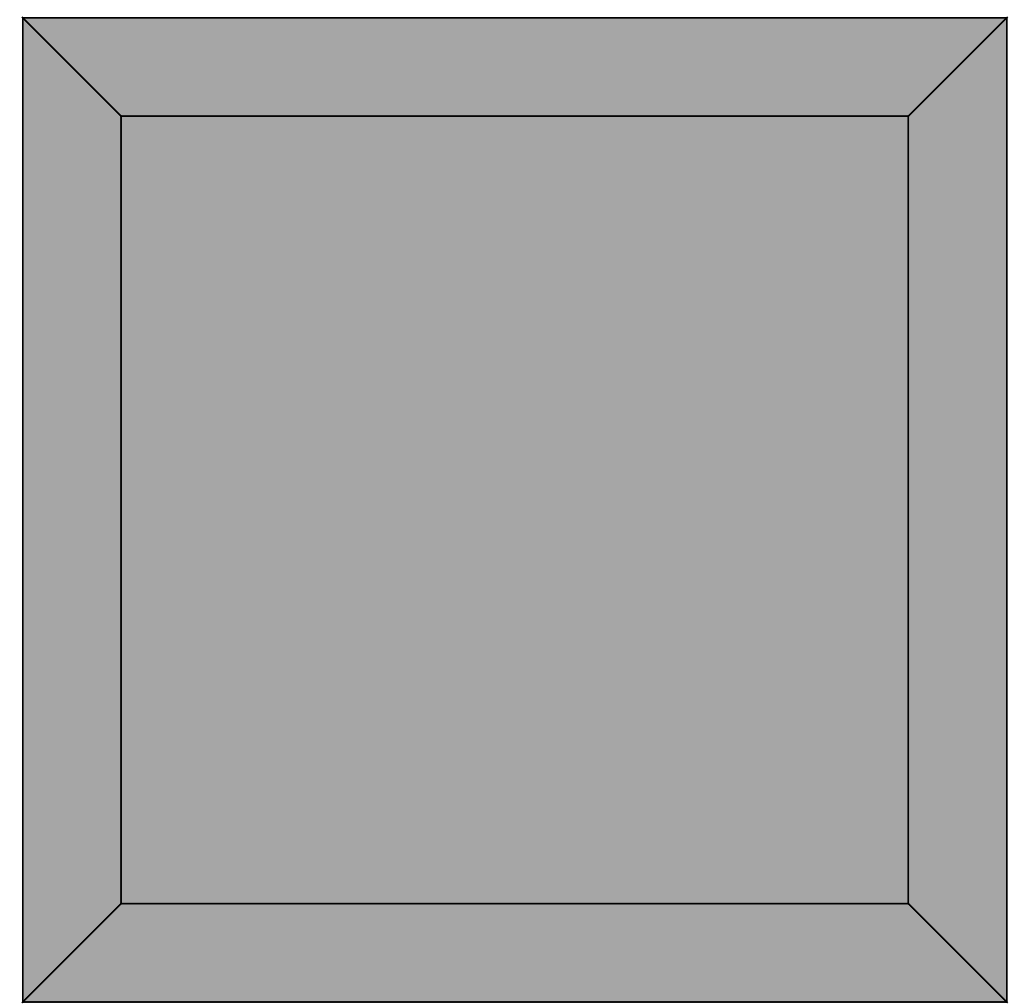

Figura D.14: LFFP

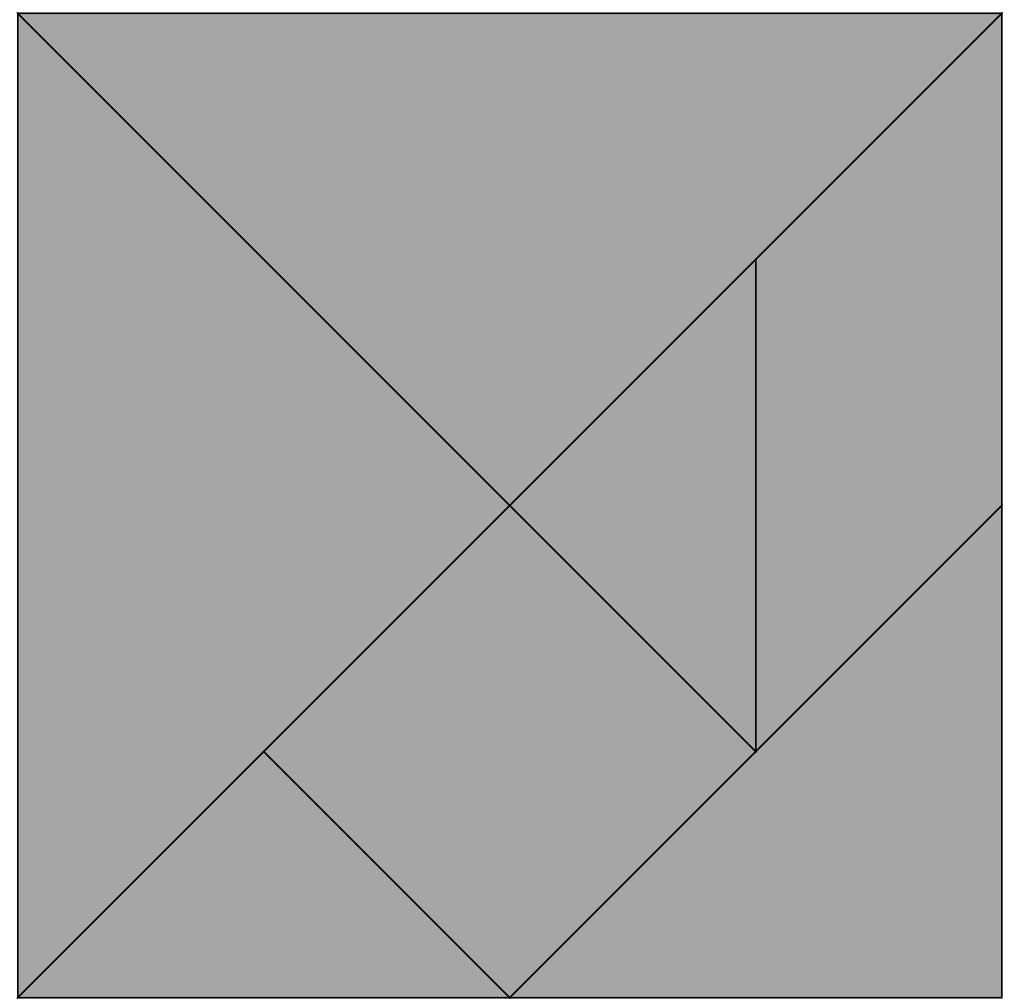

Figura D.15: TANGRAM 


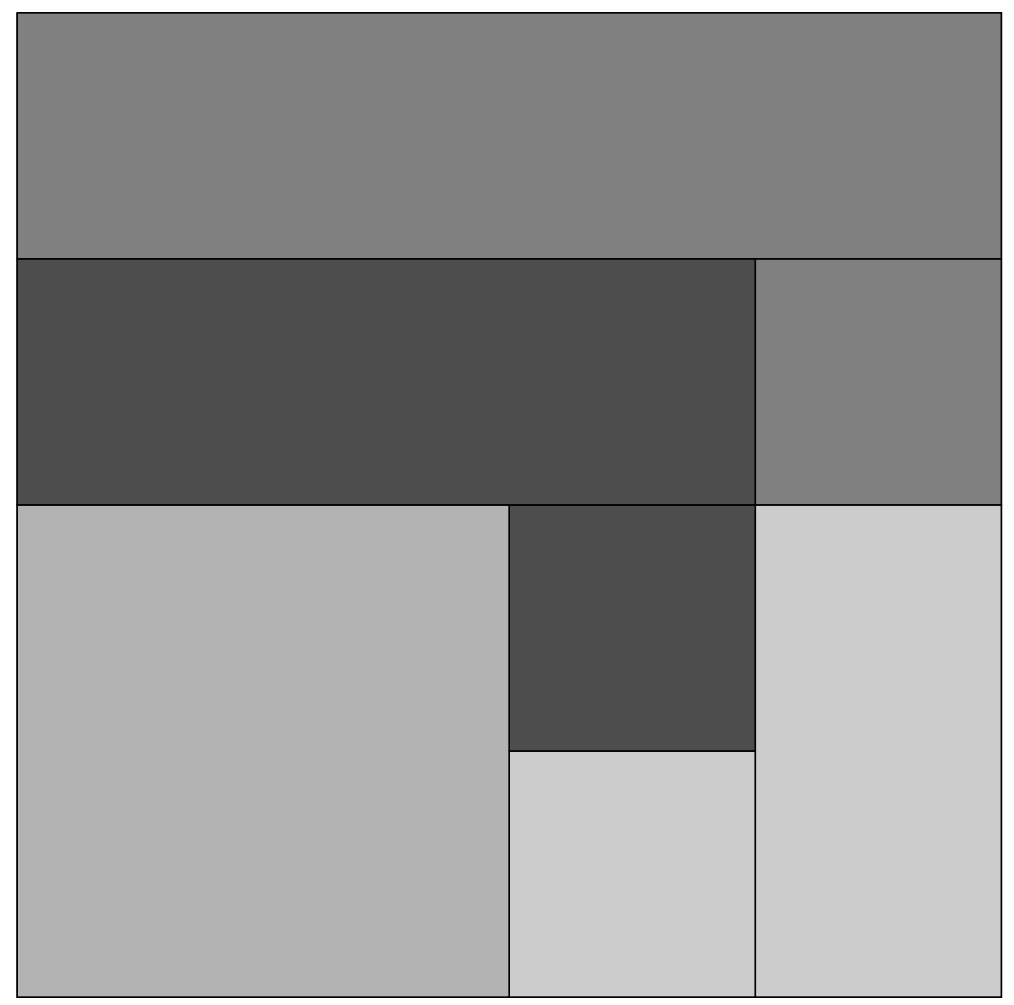

Figura D.16: SMALL PUZZLE

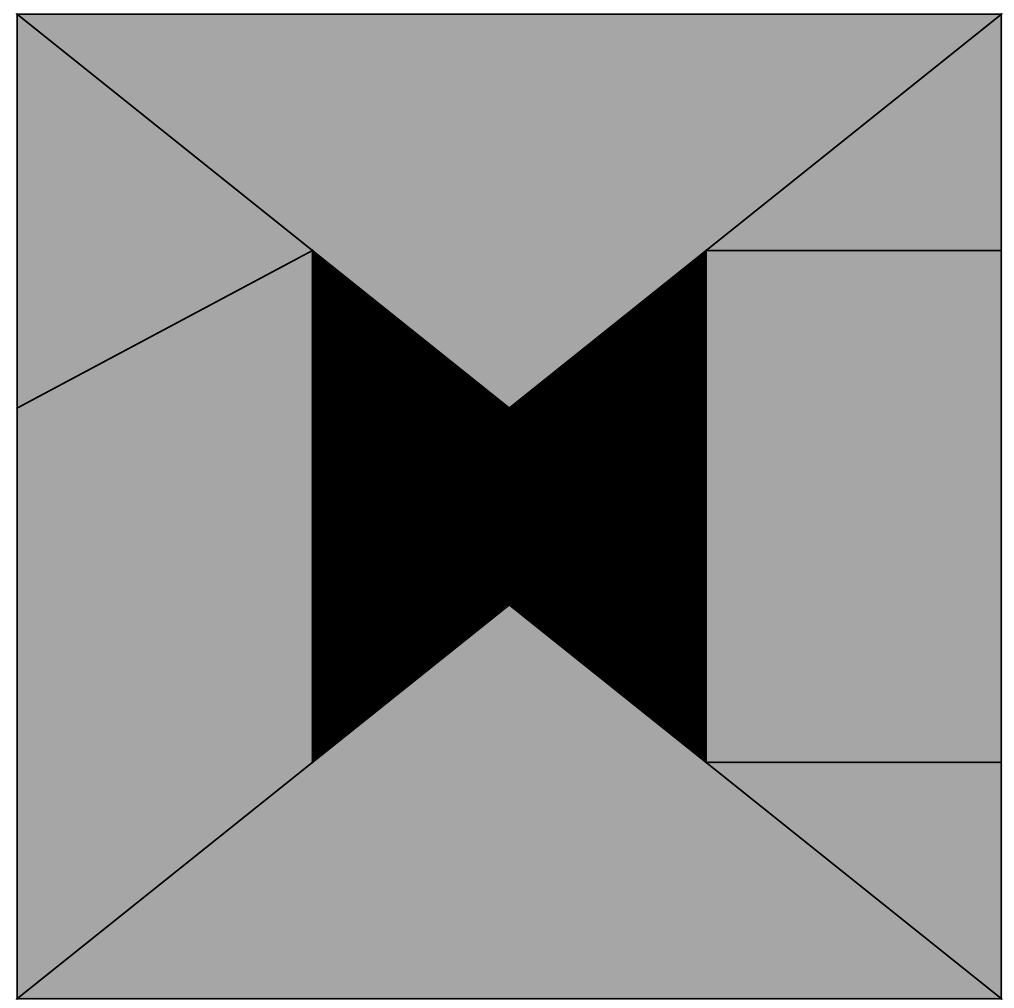

Figura D.17: Container whit hole 


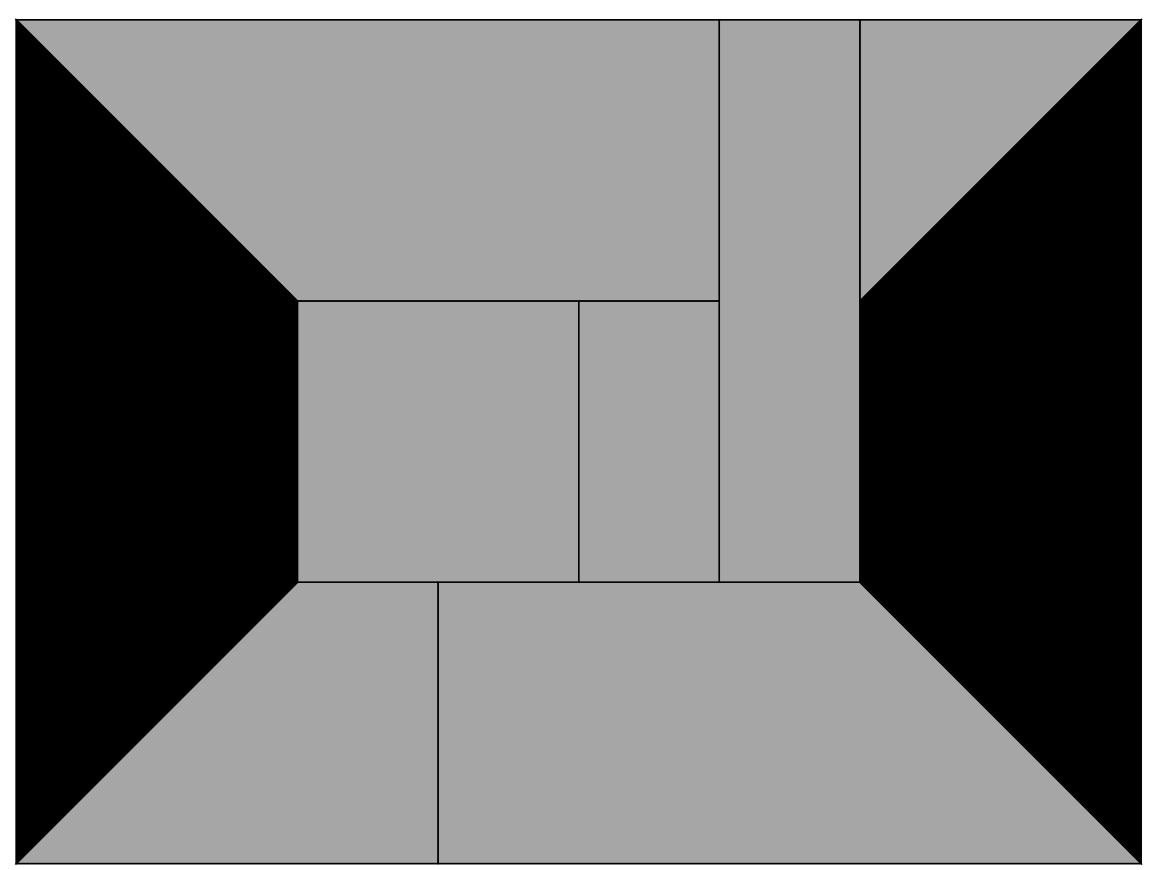

Figura D.18: Irregular Container 